\title{
Tlaturwiffenflchaftliche 悉 Wegweifer
}

Sammlung gemeinverftändlicher Darffellungen $\Omega$

\section{Otto Geucht}

\arfbäume uni Bierfträucher

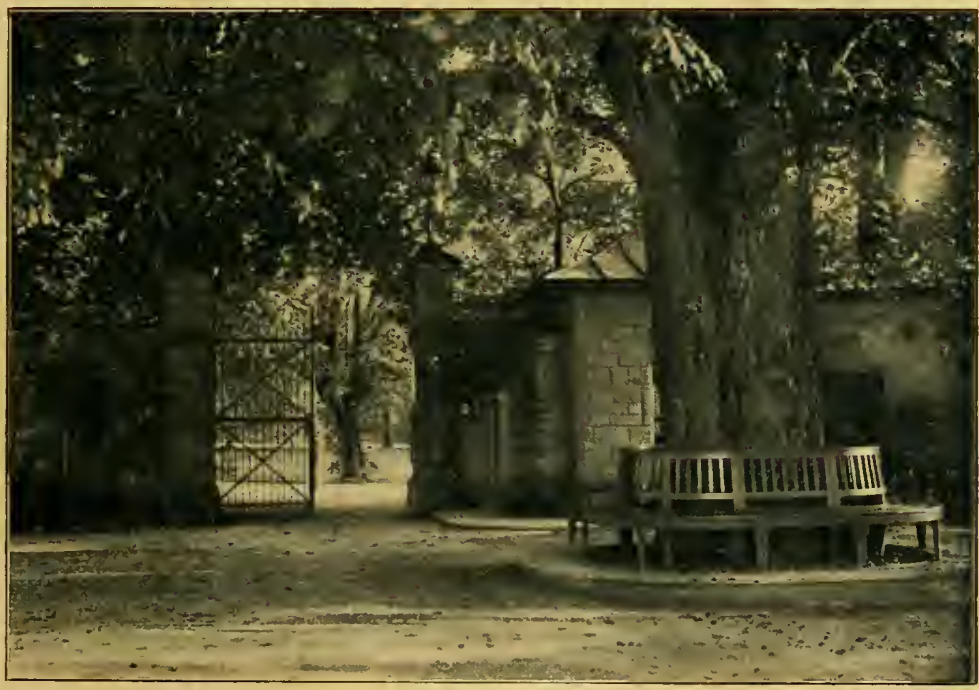

Eerie A

Tand 14

Serausgegeben von Prof. Sr. Rurt Sampert Derlegt bei Etrecker \& Gchröber in Stuttgart 



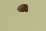



Warfbäume und 3ierfträucher 


\section{Naturwifienidhaftliche Begweifer}

Eerie A: Seder Sand geh. IX 1.-, geb. NX 1.40

1. 3and: Rlein, Die Welt der Gterne

2. Band: Lampert, $3 i l b e r$ au bem Räferleben

3. Band: Eafitein, Sierlebendez deutichengaldes

4. Sand: Feudt), Die Bäume und Gträucber tnierer $\mathfrak{B a ̈ l d o r ~}$

5. Sand: Migula, Deutiche Drooje und Farne

6. Band: (Geyer, Die $\mathfrak{B}$ eichtiere Dentichlands

7. Zand: Dlarzell, Die Wflanzentwelt ber Sllpen

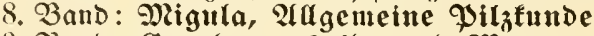

9. 3and: Graebner, seibe und Mloor

10. 3and: $3 \mathfrak{b}$, Die Taturbenfmalpflege

11. Sand: Silzheimer, Die Sattiere in Abitame mung แno Entwicthng

12. Sand: Raufimann, $\mathfrak{D a g}$ Radium

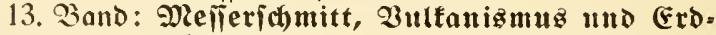
beben

14. 3and: Feucht, \artbäume und 3ieriträucher 15. 3and: $\mathfrak{B}$ ermer, Simblibien und Reptilien I (Sï̈perbat und Qebenżweife)

16. Bano: $\mathfrak{B}$ erner, 2 mphibien und Teptitien II (2Inpafimg Der Organe an bic Lebent= weife)

17. 3and: 3immermann, Die Saturphotographie 18. Sand: Paipbach, Der Pflanzenfammler

Gerie B: Seder 3and geh. NR 2.-, geb. X 7.80

1. 3anD: 2le tïrper

2. Sand: 3uichau, Mienj(t)entunde

36eitere 3ände find it 3orbereitung. Illuftrierte Gpezialproipefte ftehen auf $2 \mathcal{B} u n$ id) foitenloz uno poit $=$ fret zur Berfügung.

"Das Unternebmen bat jid in Denbisbereridie= the

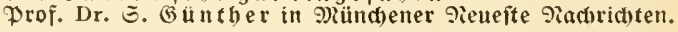

Yertag won Gtreffer \& Garöber in Etuttgart 



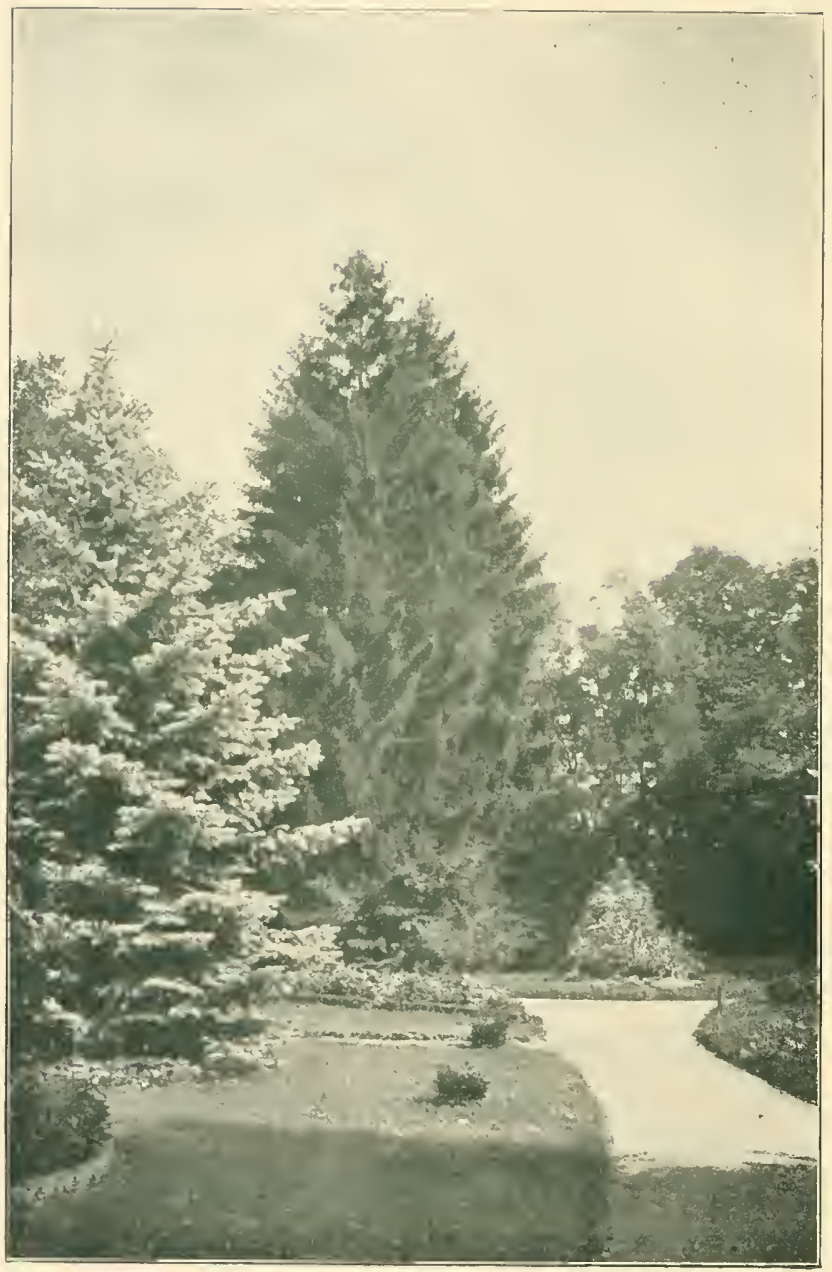

Safel I. Fichtengruppe (liutz̈ Gilberfichte). 


\section{Patumwiffenj(haftliche $\mathfrak{B e g w e i j e r ~}$}

Eammlung gemeinverftändlicher Tarjellungen

Geric A. Şeraużgegeben von \rof. Dr. Rurt Rampert Baub 14.

\section{Partbäume und $3 i e r=$ iträucher}

3ion

\section{Otto Feudbt}

Foritallefior

Mit 6 Safeln und 48 Plbbiloungen im Sext nach Siaturaujnahmen Des Sierfalfers und Driginalzeidumungen von $\mathfrak{S}$ a

1.-6. Saujent

Etuttgart

Serlag vout Etrecter \& Ed)röber 
Sllle Tiedte von Der Berlagibuchhandung vorbehalten

Druf vou Etrefer $\&$ Edhröber in Etuttgart

Solzirei Phtotupie=-Drufpapier von 3ohnenberger \& (iie., Japierjabrit, Siiejern in 3aden 


\section{Berjeituiz oer abbillominen.}

a) Ilmidylagbiro.

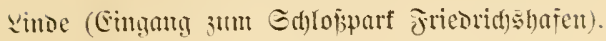

Zafel

b) Tajelu.

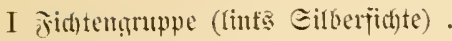

3wisten Seite

II 50jährige Mellutgtonien . . . . . . . . . 24 245

III 110jährige Rebcusbäume . . . . . . . . . 32/333

15 Edwwargtiefer, sogybudenlaube, Edhierlingstmme, Gle= Ditichie, Sitfafidste . . . . . . . . . . 4849

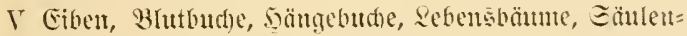
wadholber, \$eiptamten . . . . . . . . 64/65

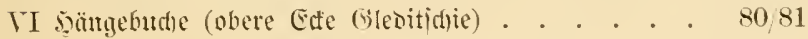

$46 b$.

c) Agbildungen im Tcrt.

Site

1 Wince Wein. Bartbirs mit Ethen . . . . . . . . . 1

2 Blattuartationer Der gemeinen Fothude . . . . . . . . 6

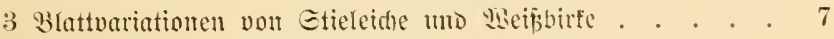

4 3apien Der Eapindusichte . . . . . . . . . . . 11

5 Sdjerlingstame . . . . . . . . . . . . . . 14

6 Douglaszapfen . . . . . . . . . . . . . . 16

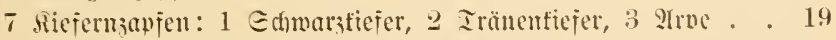

8 Seumoutbsticjer . . . . . . . . . . . . 21

9 3apfen der 2ttlasceder. . . . . . . . . . . 22

10 Engizneig mit 3apien . . . . . . . . . . . . 23

11 SSellingtonienzapien . . . . . . . . . . . . 24

12 Iriebunterieite merit)ienener stalbentefien . . . . . 26

13 Samaracumenje . . . . . . . . . . . . . 27

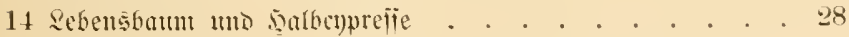

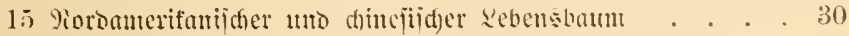

16 5enberie แn jiba . . . . . . . . . . . 31

17 (Sinfgo . . . . . . . . . . . . . 34

18 jorjutrie . . . . . . . . . . . . 36

19 Einfud)blättrige Ejade . . . . . . . . . . 40 


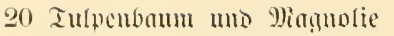

21 Samanija) Esheutquitte

29) 2iandelaprifoje (gefüllt)

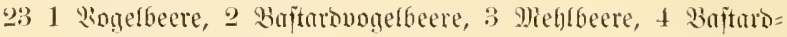
melbeere, 5 Elabere. . . . . . . . . . . 4ti

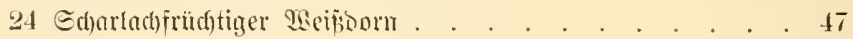

25 Ramabióde Simbere . . . . . . . . . . 51

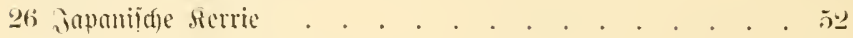

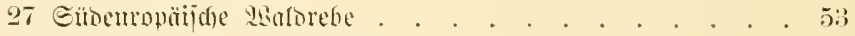

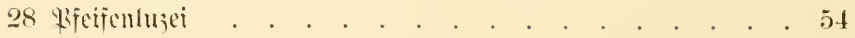

29) Steigclie . . . . . . . . . . . . . . 57

30 Edmencere . . . . . . . . . . . . . . . . 5!

31 Geferbte Dentic . . . . . . . . . . . . . 60

32 Shutrote un gotogelbe jobantisbere . . . . . . . 62

33 Mabonie (mit Beerem) . . . . . . . . . . . ti3

34 Rerüctenjtrated) mo Vederbam . . . . . . . . 6i

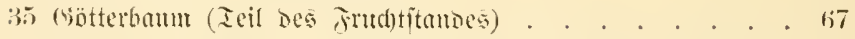

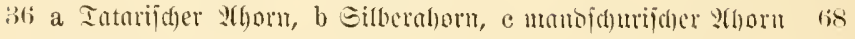

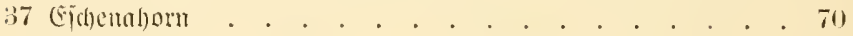

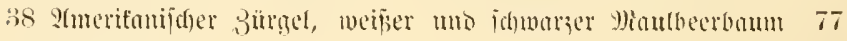

3:) Baumulajel . . . . . . . . . . . . . . . 7!

fl) Eünleneidle . . . . . . . . . . . . . . . 81

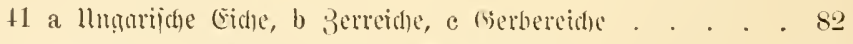

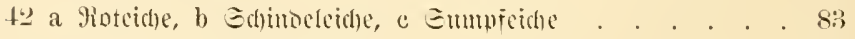

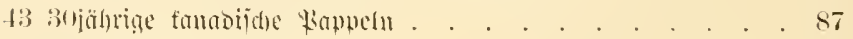

H Immariste mo Eanonorn. . . . . . . . . . . . 8.

4 .) intostam . . . . . . . . . . . . . . 90

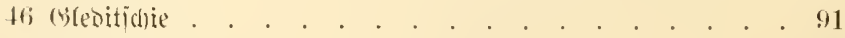

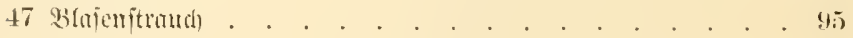

48 (bincinte. . . . . . . . . . . . . . . . . . . . . 


\section{Begleitwort.}

Der freundidyen $\mathfrak{A}$ fiforberung beßె Şerru Şerausgebers uno ber Szerren Berleger, den "Bäumen แno Sträuchern

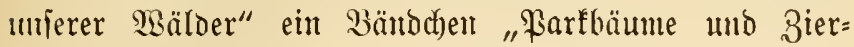
fträucher" folgen z"lafjen, fomme ich gerne nach, ba eine derartige, fïr weitere Rreife beftimmte Arbeit ïber bie

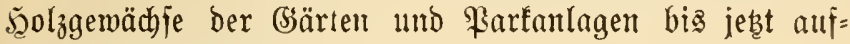
fallenderweife nicht vorbanden ift.

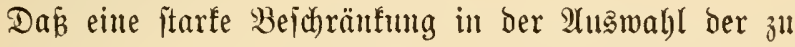
hejprechenden Arten nötig war, ijt bei ber füllle de马 Materials mold jelbitweritändlich, aud muste bie Renntuiz minerer beimifben Solzarten unt ibrer allgemeinen Rebens= verbältniffe vorausgejebst werbelt. Ganz unberürfiichtigt muß̧ten bie Rleinjträucher bleiben.

Die Beidunungen find faft aushnalymblos unmittelbar nach ber Patur gejertigte Drigiuale. Son den photogra= phijhen Bilbern ftanmen Iafel V aus Dem Parf von

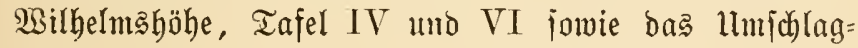
bild aus dem Schlopparf in Friebrichshafen, Iafel III

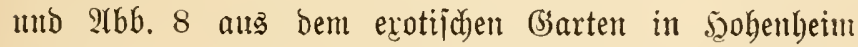
(Wgürttemberg); bie ïbrigen find fleineren 2tnlagen ent= nomment. Das Miotiv zu 2(b). 1 bot bie Rgl. MBilgelnta bei Stuttgart.

Stuttgart, in Februar 1910.

\section{Fendst.}




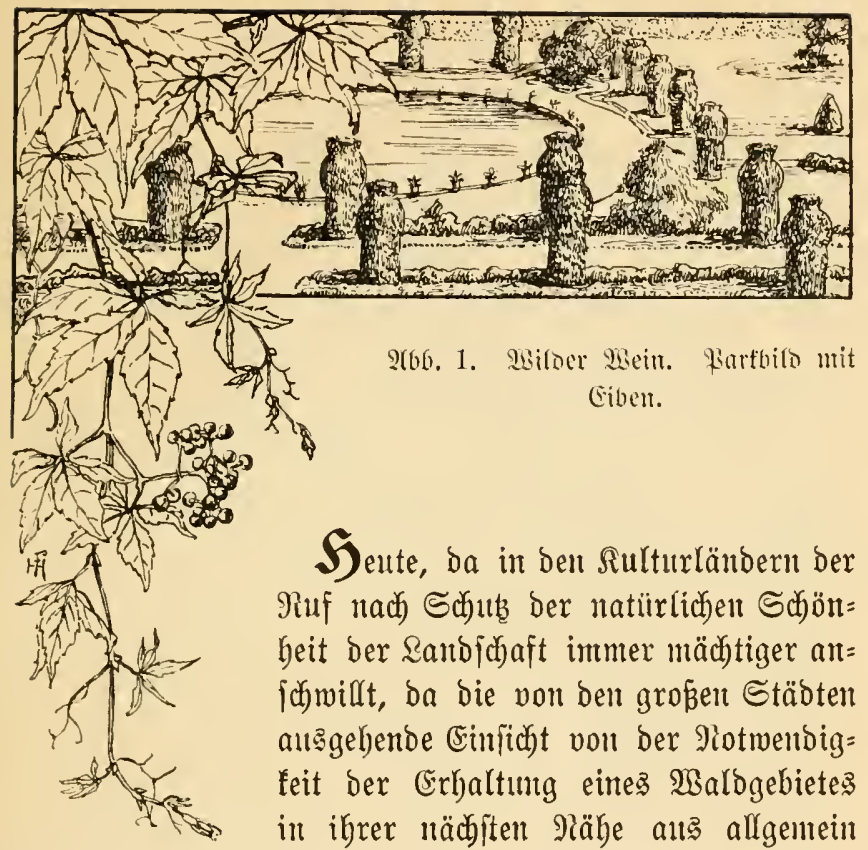

\section{2(66. 1. 9Bifoer 28ein. Rartbils mit} Eiber.

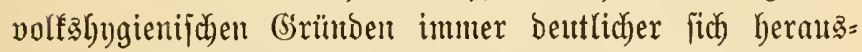
bilbet, ridjtet fidh die 2ufmerfiamfeit meiter fireije melyr bentu je auf die Baumbeftände ınd alten \$arfanlagen, die ums als Erbteil frïberer Jabrbunderte inmitten grof̧er Stäbte jowohl wie meit zerftrent im sano ïberfonmen

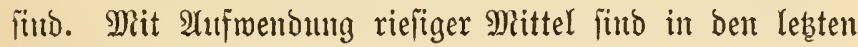
כabrzebnten groß̧z̈̈̈gige Sientanlagen von meitblidfenden Stabtverwaltungen gefdraffen worden, find ausgebebnte Walbteile in ber গähe von Gtäbten mo furorten unter

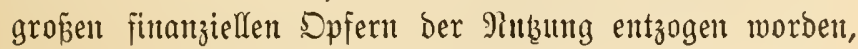

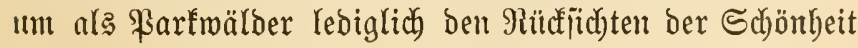

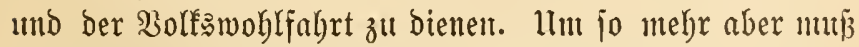
naturgemä́z die Bertjdyäbung bes Borbandenen fteigen, 
bie Schonung und Erbaltung der alten Rarfanlagest und Friebhöfe, ber lyunbertjülyrigen arleest und Baumgruppen ein allgenteines Solfaintereffe werben, wenn auth allzu oft noch heute auffitrebende Sleiuftäbte in übler Rurzfichtig= feit die Entfermung igrer alten Baumbejtände für igre erite $\mathfrak{A}$ ufgabe zu halten icheiner.

Itber noch von anderen Gefichtspunten aus gewiunt der Parf au Bedentung. Se mehr die Forftwirtichaft unter bem Drutce der Serbältnifife das Şauptgewicht auf finanzielle Erwägungen z̆t legen gezmuntgent wirb, eine

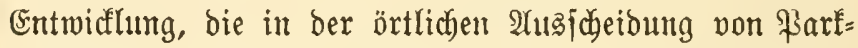
waldungen aus dem Berbande bes Wirtichaftzimaldes beutlichen 2 (nsobruof findet, bejto weniger bietet fich unjeren

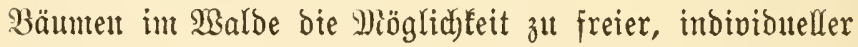
Entfaltung, defto mebr werdent die mäd)tigen, dyarafter= vollen Baumtgeitalten, für bie der Deutiche jo empfänglich ift und bie wir beute als Raturbenfmäler ${ }^{3}$, wo fie vor $=$ hamben füb, zu f(t)üben juchen, in ipäterer Beit nur nod) im Parf und im gejighibten Parfivald eine Stelle finden.

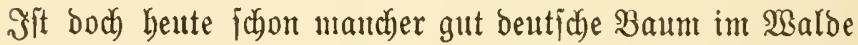
braußen fo fehr zutrïdgebrängt, baß wir ohne umjere alten

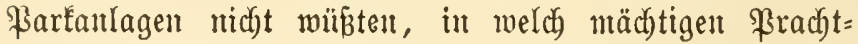
geitalten er aufautreten vermag. Seierfïr füb Eibe uno Feldahoru, aber auch Sinde, Traubentiriche, sipe mo Eläbeere treffende Sheifpiele. Es wäre auts diejem Brumbe minjichenswert, dá̧ aud bei Mieutanlagen ber beimijuchen Bauntmelt etwas mthr Plab eingeräınt würbe, als es

Täheres biernber ¡. 23. 10 biejer Sammung: Yaturbenfmal= pflege, von \$rofefior Borf. 
die Bevorzugutg frember Irrten heute in ber Regel 3uläß̧̄t.

IInjere ältejten Baumbejtänbe reichen zurüd in bie 3eit, ba von Berjailles aus ber "frauzöfifiche Barten" vorbilolich wurbe für die \$arfanlagen zahllojer Füriten= höfe und herrjchaftlicher Sanditbe, ausgedehnte, von ge=

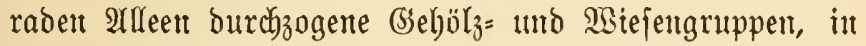
benen allerband 9 Safferfünite, Grotten, SBurgen und andere

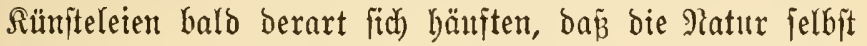
zurüdtrat uno fich zum Teil in ourchaus umnatürlidie

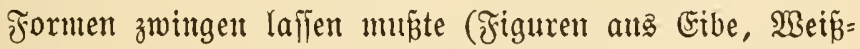

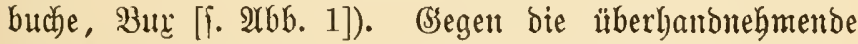
Rünitelei erfolgte von England anz die Rücffebr zu ben Jormen ber natürlichen Randojhaft, ber "englijche (Sarten".

(S)leichzeitig aber machte fich ein meiterer \$unft geltento. Mährend uriprüngliç ber Beftand ber ßarfanlagen faft burchmeg ber heimijchen Pflanzenwelt entnommen war uto erif jpäter burch eintige füoliche, hauptjächlich vom Balfan

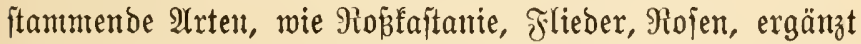

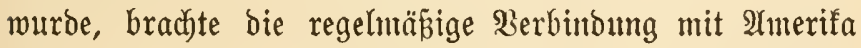

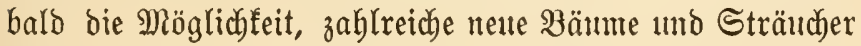
aus eirtem bem deutichen Rlima ähnlichen ausgebebnten Malogebiet eintuführent. Echou 1636 bejā́ ber \$arijer (S)arten gegen 50 fantadijch=virgintiche cinfülyrungen, eine

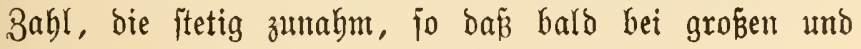
fleiten Parfbefibern ein förmlicber פ̧etteifer im Bujanntent= bringen jrember und intereffanter $\mathfrak{A}$ rten entbrannte, zumal

1 Bgl. Daju: Sultur uı Ratur in Der Gartenfunft, von Freiherr v. Engelhardst - (Band 6 Der Eamulumg "Simuft und Sultur"). 
als Durd) die Rlafiffifation sumés ein neuter 2tuporn zu juitentatiphen Santuteln binzugefonmen war.

Fitr Dentichlanto gemantnen eine führento Stelle bie 2mlagen in Şarble mo Tegel, bie, in ber Furcht vor

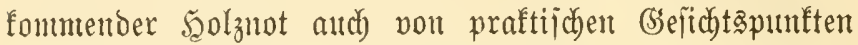

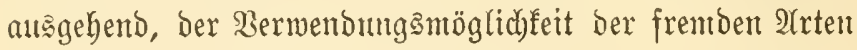

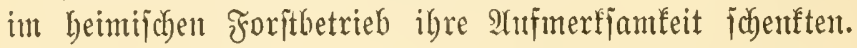
Bon ganz bejonderer Bebeutung wurdent bie Erfahrungent, die Freiferr v. Wantgentheim als Dffizier bes nadj Mord: amerifa vertanften hejifichen Felojägerforps von 1777 bis 1784 an Drt und Stelle jammeln founte. Jnt jenter Beit entiftanden bie Pflanzungen frember Şolzarten, bie heute

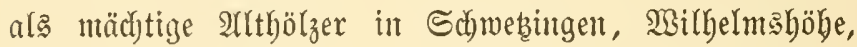
SBörlit uno anderen Drten unjere Bemunberung erregen

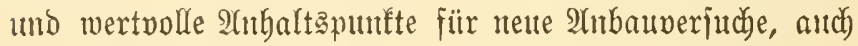
in forftlidjer Scinficht, bietent. Dem 19. Jabrbutioert blieb

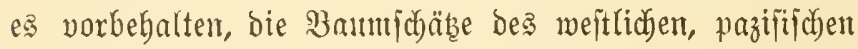

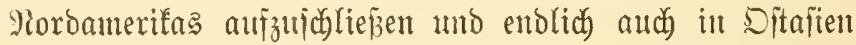
einzudritgen, woher in den leb̧ten Jahrzehuten insbejondere japanijche und matojchurijobe arten in immer fteigentor 3abl bei utts eingefïhrt murbent.

Эinch igrer Scerfunft verteilen fich jomit bie in umieren

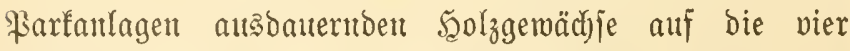

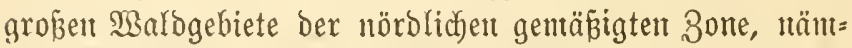
(id) Mittelentropa eimidylieñlich ber (Gebirgäzüge von Epa= nien bis zur Revante und zum Raufajus, bas atlantifche und bas von biejent wejentlich verichiedene pazifijche Tord= amerifa, endich Ditafien. Das find bie Bsebiete, Deren flimatijche \$erbältniffe mit benen Dentichlanos am meiften ९̈(hulfidfeit aufweifen; bie übrigen Ieile ber Erbe, por 
alfem bie ganze fitblidye Erobälfte, haben mur ganz wentige, meijt unbedeutende 2 rten geliejert.

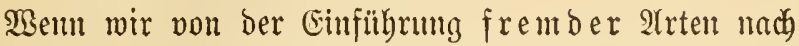

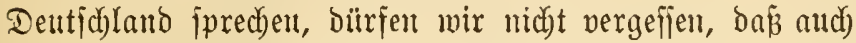
bie "beimifchen" Irten von Matur burchans nicht burch

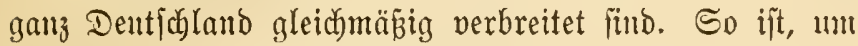
mur einige Beifpiele berangazugreifen, bie särche mur in ben Sllpen zu Samte, aljo überalf in Fladhlamb eine

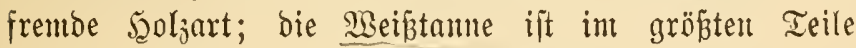

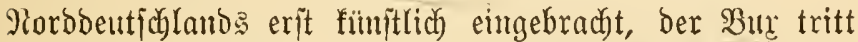
nach feiner natïrlicken Serbreitung mur im füblichen $\mathfrak{B} a=$ bent und an ber oberen Mojel auf bentiches Gsebiet itber, bie Stechpalme gedeiht mur in \$Binfungabereiche be马 at= lantifchen Rlimas, alfo in sigejten mo Poromejten.

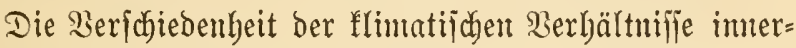
halb Deutichlands mus natïrlich) bei ber Einbïrgerm!g fremolänoifober Irten un fo mehr Berïcffichtigung funden, je verfdchedener bie heimatlidben Berbältuiffe einer ßsflanze an fich f(t)on gegentiber den unjerigen find. arla haupt= jächliche, baz filima bedingento Miontente fommen in $\mathfrak{B} e=$ trackt "bie Ränge ber Froftperiode in Berbindung mit beren Şeftigfeit, bie fribhere oder ipätere Sahreszzeit, in welcher bie zum 2lustreiben ber (jel)ölze nötigen Tempera= turen erreidyt werben, entidich bie Säbe ber fommerlichen Ientperaturen währenb ber Segetationamonate, anch bie Pegenmabrfdheinlidbeit mäbrent diejer Feriode" (Drude). 9)iebr örtriche Interichiede bebingt bie Rage im (Gebirge und bie nilloernde, bie Ientperaturgegenfäbe anggleichende Mä̈be des Meeres oder auch mur groper Seen, wie bies そ. $\mathfrak{B}$. bie auneroroentlid) günjtige sage ber Snjel Miainan 


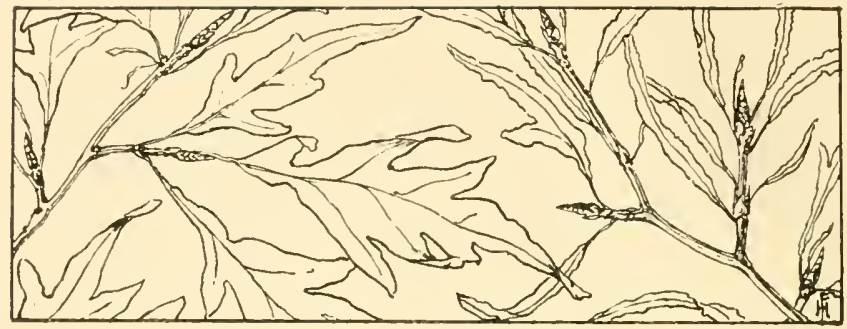

966. 2. B̊attvariationen Der acntinen Rotbud)e.

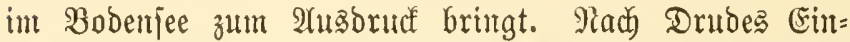

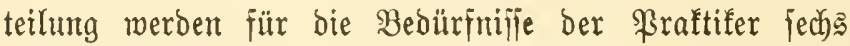
Rlimaprovinzen Dentichlands unteridjieden, von benen bie

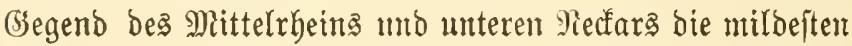
Minter und größten Sommermärmen, bie baltijche Provinz

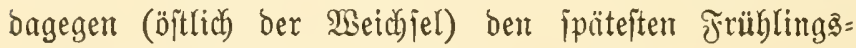
eitzug mit furzen, füllen Sommern aufweift.

Es ift jomit die Babl ber eingefithrten Fुolzgemächje in Deutidaland in ben eiuzelnen Landesteilen jehr ver= johieden, im ganzen find etwa 700-800 Âtrten regelmäpäig im gärtnerijcyen Şandel, ungerechnet bie zahlreichen arten, bie nur als Seltenheiten jporabifich zu finden find. Sim hat aber ferner gärtnerifde Bürbtungäfunit aus vielen Irten, einbeimijchen mo frembsn, im saufe ber Jahre mannigfache neue formen unb Epielarten gejoaffen, gan abgejeben von ben ebenfalls häuf̈gen, aus ber Sreuzutg jweier vermandter Arten berworgegangenen Bajtarben. Shuch bie Samen einer Şolzart liefern burchans nidyt immer völlig ähnliche rflanzen, unter Tamjenden untericheidet fich bas eine ober andere Stïf burch irgendein ganz $a b=$ 


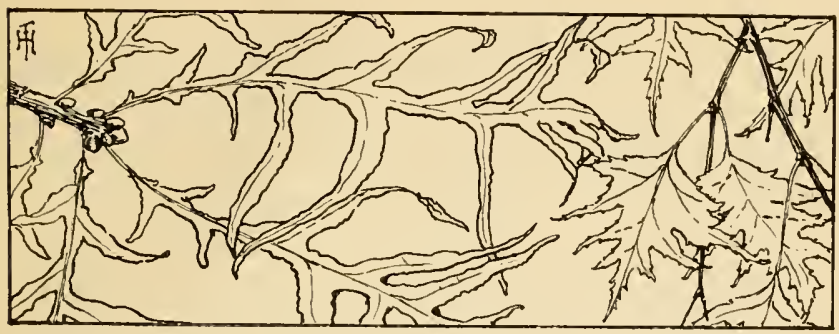

966. 3. Blattwariationem von ङtieleidas แnо Meipbirfe.

weidjendes Merfunal, ber Samen "variiert”. Ebenjo fann aud eimmal eine Rntojpe variieren, io baj am erwadjenen Baume ganz unvermittelt ein 3 weig mit anderş geformten B̧ättern ober fonjtigen Bejonderheiten ("Sportzmeige") auf= tritt (†. 2 bb. 2 u. 3). Soldhe "Spielarten" merben vom Gärtmer auf vegetativent Wege vermehrt, o. h. burd Pifropfung ober Stedfinge, insbejondere wenn fie eine im $\mathfrak{A}$ tūjeben wejentlich neue Baumform zu geben ver= iprechen (buntes \&aub, Şängeäjte, Säulenform u. a.). So fommt $e^{3}$, baj manche heute alfgentein verbreitete Zierform uriprünglich auf ein einzigez Eremplar zurücfłuführen ift.

Dieje Bielheit ber Formen hat aber aud zu einer Bielkeit der Benenmung 2Inlaß̧ gegeben, die oft leoiglich ber Rieblaberei ber Zühter Rechmung tragend obne jebe wifienjobaftlictse Berechtigung eine verwirrende Fillle vou গamen ichuf, in bie exjt neuterbings, hauptjächlich burch die Bemühungen ber Deutichen Denorologijchen (Sejelljichaft, einige Rlarkeit uno (Eintheitlichfeit gebracht wiro.

Ju folgenden find nux joldbe arten und

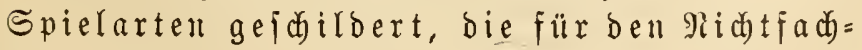
mann jnterejie haben uno von ihm obne ein= 
gebeudere Spezialitudien ertaut werbeutön=

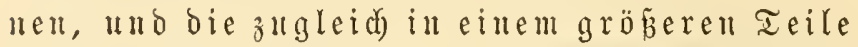
Mitteleuropas jich als wintergart erwiejeu haben, b. h. oluebejouberen Sdub im Freien ïberminteru ud jomit allgemeinerverbreitet fillo.

Mit biejer esmichränfung jheiben fofort ans bie frypto= gamen Bäıme (Bammfarme), die Cycabeen mo bie mono= cotylen Raubbäume ( beren mantbe in mieren wärmeren Ranbesteilen ben ganzen Sommer ïber in Freien aubhalten. Es bleiben ilbrig von ben Siaffiamern bie Siabelfölzer, von ben $\mathfrak{B}_{e}=$ decttiantern die dicotylen saubbäume, o. h. die beiden (Sruppen, denen aud unjere beintifden säunte uno Sträucher angeböreu.

Der Begrifi "giadelyölzer" ift jedent gelänfig, der

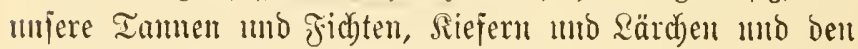
nabelförmigen $\mathfrak{B} a$ ihrer Slätter femt. 2lber vielfeid)t fajon bei Eibe und saatholder wirb er irre, ficher bei Rebenßbäumen und (Eyprejien, bie boch eigentlich gar feine ridgtigen Rabeln lyaben, mo erit ben laubabwerjenden Ginffgo mit jeinen flachen Blättern wiro er fid)er nidyt

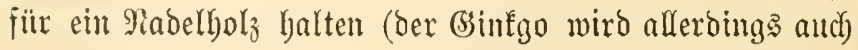
vou ben Syftematifern newerdings nicht mebr zu ben eigentlichen Rabelfölzern gerechnet), zumal er aud bie

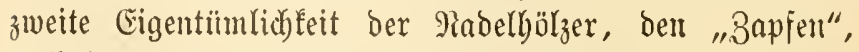
nach) bem fie anch) Bapfenträger (Enniferent) genaunt wer= ben, vergebens juctst. Die gemeinjamen Mierfmale der 
(Sruppe liegen eben tiefer, fie find befonders in ber

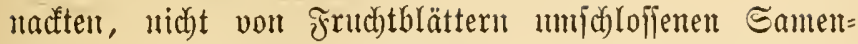
anlage, im einfact)en, gefäßlojen Bau des Şolzes und im

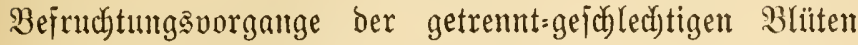
zu finden. Mit wentig 2 hasnalymen fub bie Mabelbölzer

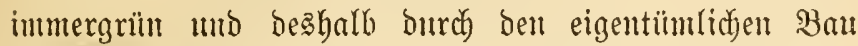
der nabel= ober ichuppenförmigen Blätter gegen :3er= trodumung bejonbers gejobitibt, fajt alle find in ber nörd=

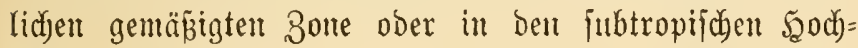
gebirgen зи \$ุaje.

Begimen wir mit ben $\mathfrak{I} a n n e n$ mb Fidyten, bie ja mur allzuoft miteintander verwedjjelt werben. Micht alle Arten füb freilich fo leid)t zu erfenuen wie umjere hei=

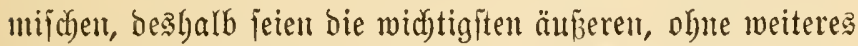
feitiftellbaren Mertmale angefülyrt. Die Sabelu ber Taume

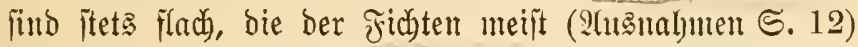
vierfantig, bie sllattuarben, b. h. bie nach dem Abfalle Der Pabeln an 3weige fichtbaren Siarben find bei ben Taumen freišnut und nicht erhöht, bei Delt Fichten ba= gegen rhourbifich und höcferjörmig erhaben, jo ba j fict) ein entuabelter Fichtenjweig ftets raub, reibeijenartig anfühlt, ein Tantenzmeig leiblich glatt. Bntbem fallen bie Rabelu ber Fichten beim Trodfun $a b$, bie Iammennabeln bleibent haften. Die reifen Bapfen ber Tamen itehen anfrecht und zeigen Iange, meijt bentlid zwijhen den Schuppen herausragende Dedfblätter, beim Camenaugfall zerblättern

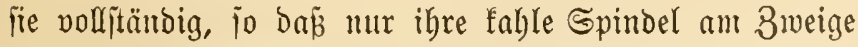
bleibt. Die Fidhtenzapfen bagegen bängen abwärts, zeigen feine Dedfblätter und fallen nad) bem Samentansflug al: Ganzes zu B̧oden. 
Die gemeine Fichte ober "Miottame"1 (Pícea excélsa Lk., i. Tafel I), wegent ihrer iteifen \&angmeiligfeit oft verfdriell, ift in \$Binflidfeit einer unjerer vielge= ftaltigiten Bäıute. Bahlloje 2ubänderungen (Spielarten) treten bei igr in ber freien Matur auf und werden burch bie Runit des Ssärtuers im ßarfe gepflegt mo erbalten, wo fie freilid oft wieder in bie gemöhnliche Form zurüct= ichlagen. Sicht felten find $\mathfrak{S} a ̈ u g e f i d$ ten, bei benen die Seitenzmeige der Şauptäjte (bie $\mathfrak{A}$ (jte zmeiter Dromung) wie

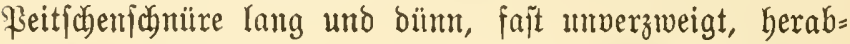
hängen, währento bei den jelteneren $\mathfrak{I r a u e r f i d t e n}$ fämtliche 2lfte mit ibren Berzweigungen foblaff nach unten hängen. Die Schlangenfichte trägt fichlangenäbntich dünn bleibende, infolge von sinojpenverfümmerung fajt unverzmeigte Şauptäjte, bie a ft loje Fich te endich bildet iiberhaupt feine $\mathfrak{2}$ (jte auts, fie ift ein gänzlidy unverzweigter, oben benabelter Epiez. Soldhe abjonderliche Formen findent im Farfe freilich menig Riebhaber, verbreiteter find bort die jäulenförmig rachfende Säulenfichte und bie fug= lige Bülche bildende 3wergfichte. Bablloje andere, eng mit dem Standorte zujammenbängende Formen lafjen fich im Parfe nicht erhalten ober fïnftlich heranzieben, am ebejten trifft man nod) auf jebr trodfenem Fel\$boden bie Rïmmerform ber Fichte, bie fich burch niedrigen, lang= famen

Soldhe 3meige ähneln ber aus Rleinafien ftanmenden Sapindusfichte (P. orientális Lk.-Carr.). Diefe befitit

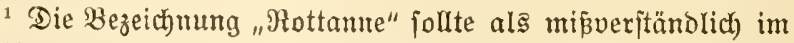
Sinblicf auf verfoniedene amerifamifht)e "rote Iammen" (Red fir) beffer nicht für bie foichte gebraudht veroen. 
von allen Fidytenarten bie fleinften, höchftens $1 \mathrm{~cm}$ lantgen Rabeln, bie fich bicht bem 3meig anjwuttiegen mo jtarf glänzen. Die walzigen $3 a p f e n$ (j. 2rbb. 4, in natürliduer (Grö̈̈e) erreichen $5-8 \mathrm{~cm}$ Sänge unt fint häufig mit Şarztropfen ("Sapinduştränen") bejebut.

Auch einige norbanterifanijuche fichten fint in Parfe gern gejeben, vor allem

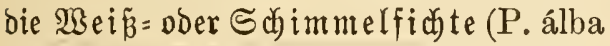
Lk.), bie megen ifrer tiefen, bic)telt $B e=$ aftung eitten ausgezeichneten Wintofhus gibt, weảhalb fie auth an ber bänifabent Siilfte zur Dïmenbefeîtigung gepflanzt miro. Sie trägt ftumpfe, bläulich)=grame Jiadeln uto Gellbraume, 3-6 $\mathrm{cm}$ lange 3apfen mit papieroünnen Schuppen. Die Bapfen fallen bald nach ber Meife ab, während fie bei ber felyr ähnlichen Sch war $\mathfrak{w}=$ fichte (P. nígra Lk.), bei ber fie etroas fleiter fint, meift mebrere Jahre baften bleiben. Ein ficherer Unterichied ber bei= den oft verwechjelten 2 rten befteht barin,

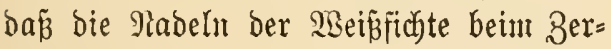

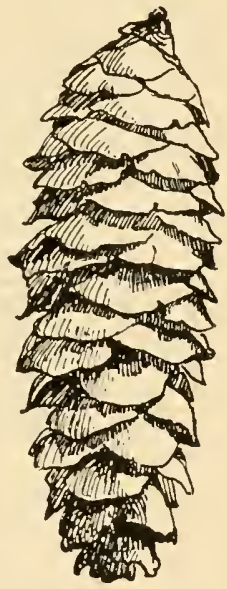

9(6). 4. 3apjen ser Gapirtitis= fitite. reiben aromatijic find, bie etwas bunfleren siabeln ber Schmarzfichte aber nicht. Die Snofpenjdyppen uno die jungen Iriebe ber lebsteren find ferner bebaart, bei ber exfteren finto fie falgl.

seidyter fenntlic) ift die ebenfalls aus Noromanterifa fommende Stedfid te (P. púngens Englm.), und zmar

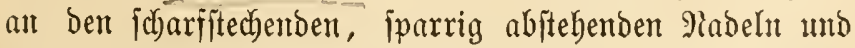

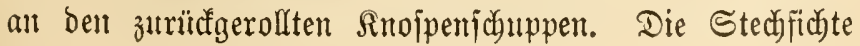


ift erit 1863 nach) Enropa gebradbt worben, ift aher bente bie beliebtejte und jojönite Bierfid)te mierer (säronten, ints=

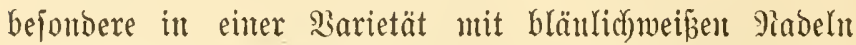

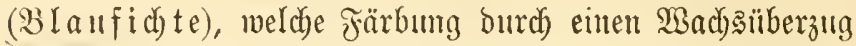
verurjad)t wird, ber als Berbumfturgsidduts aufgefapt werben fant. Derjelben präd)tigen Färbung wegen wirb andh eine Form der Engelut a u is fichte (P. Engelmánni Englm.) gejürät, bie Silberfidte (†. Iafel I). Die wentiger jodarfen, nad) vorn gerid)teten Siabeln uto bie anliegenten Snofpenichuppen unterict)eiden fie vout ber Stedffich)te, mit ber fie jonjt großje Berwandjodjaft jeigt.

Meueroings trifit nan nun aber fomohl int Mald als

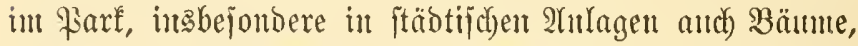

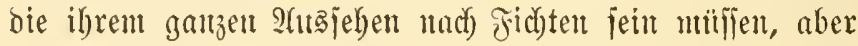
boch in einem \$amft erbeblid) von Fid tentupus abweidyen, uämlich) im Ban ifyrer Siabeln. Dieje find nämlidy tanten= älntlich) zweifläc(b) tragen an ber Dlerfeite, bie aher meift infolge einer Drebung bes Stieles nad) mten fiebt, zwei hellere Streifen

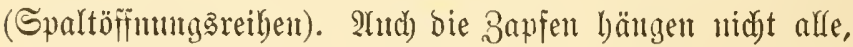
jonberu jteben zum Teil jeitlick ab. SBir Gaben Bertreter ber Dunorifafid) ten vor uns, von benen die Dmorifa= fichte jelbit mebr in Parfe, bie forjtlich jebr mertoolle Sitfafichte mehr in Malde zul treffen ift.

Die Dmorifafiddte (P. omórica Pančič) ift in

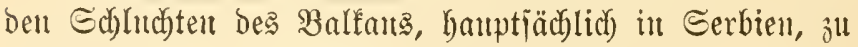
Saltie, aber in ihrer F̧eimat fchon itarf bejimiert (Dmorifa ift ibr dortiger Mame). Bei unts wirb fie fowohl ifres jublanten, fegelförmigen sisuch)es wegen gepflanż, als gantz bejonders ifrer geringen (Empfundict)feit gegen siatd)= mo 
Miußbeidäbigung megen. Dieje Eigenfidjaft ijt für bie

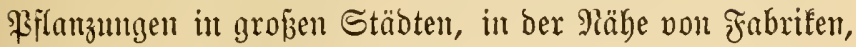
3abugüfert ufw. auberorbentfich) wertwoll, zumtal bei einem immergrünen Sabelgolz, bas ber giandyuergiftung viel

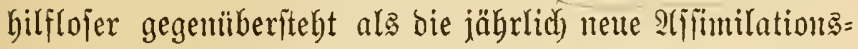
organe treibentent Ranbböl zer. Sift ja bodi) jelbit im freien

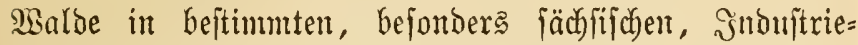
gegentoen bie Errbaltung bes giabelwaldes ummöglidy ge= worber. 2Ym gefäbrlidjftent finto bie Snlfate ober Fluoribe führentoent 2 (bgaje, im übrigen ipielen natürlidy bie ört= licyen Berbältntifife einte wichtige giolle. Befontoers ge= fäbrot finto alle ærflanzen zur Zeit ber Entfaltung ihrer Blätter umb Blüten.

Die Zapfen Der Smorifafidyte find flein und duntels rotbraum, bie Rabelı bäufig, wie bei ber Tamue, fanmm= förmiz angeorbutet. Die iul pajififd)en Porbamerif́a (aud) auf ber Snijel Sitfa) bejtanobildembe Sitfafichte (P. sitchénsis Trautv.-Mey., i. Tafel IV) trägt feime, aber fteife

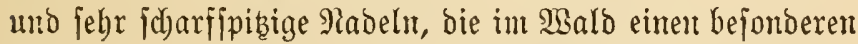

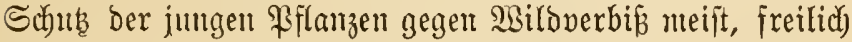
nicht inmer, umütig machen. Şm Park ijt bie Sitfafidyte feltener, ihre Eleinfd)uppigen, hellbramen Bapfen erreiden bis ju $8 \mathrm{~cm}$ Ränge. - 3wei weitere 2trten ber Dmorifa= gruppe finto in Japall z̆ Šauje.

2tud bie Tannen find burde eine ganje Reilge pon Irten im Farf vertreten. Reben der Meiźtanue (Abies pectináta D. C., i. Iafer V), die aud d), aber feltemer als bie Fiddte, in Trauer = แmo Säulenform vorfonmut, ift in erjter Sinte bie ans bem Sianfajus ftammende, nad) ibrem Entoecter benamte Sioromanns tanue (A. Nord- 
manniána Spach.) zu nentuen, bie audf ben \$Beg in ben

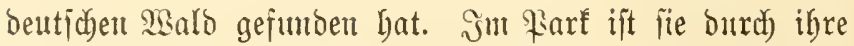
f(d)öne Beaftung beliebt, bie in Freiftande länger aushält

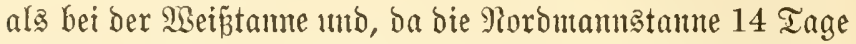
jpöter ausitreibt, aud nidyt jo leidft burd Spätfröfte be= jö)äbigt wirb wie jente. Die Rabeln finto etwas länger und

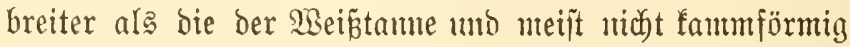
autgeorbmet, jondern biurftenartig an ber Dberjeite ber Trieke.

Pur für froftfreie, gefdübte Iagen eigntet fich bie ähnliche

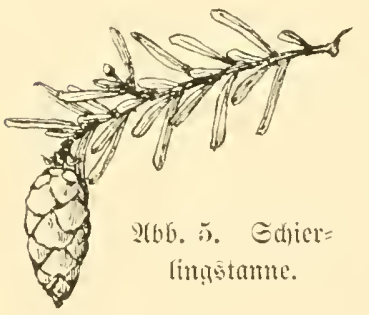
griectifde $\mathfrak{T}$ anne (A. cephalónica Lk.), bie fick burch) itechende, rings vom Trieb $a b=$ ftehente Mabeln unterjobetbet. (sbenfalls froitempfindlich, aber ihrer eigenartigen Ericheinumg wegen trokbdem häufig gepflangt ift bie panifde $\mathfrak{T}$ anne (A. pinsápo Boiss.). Sie ijt leidut

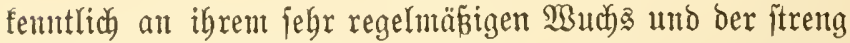

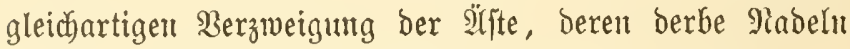
ftarr mo bidyt nach allen Seiten jenfredst abjtebent.

Bon norbamerifanifichen arten ift bie Roloradotanue (A. cóncolor Lindl.-Gord.) eine ber foünjten. Sie ver= bankt ihre Beliebtheit ben jebr langen, jobmieglamen, atrfwärts gebogenen labeln, bie beiberfeits gleich farbig utattgrïn finto. Weitere Borzitge finto ifre Frofitlärte uto

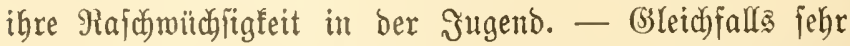
lange Mabeln, aber zweifarbig, trägt bie kaliformifd)e Sïütentanue (A. grándis Lindl.-Gord.). Sie erreicht in ibrer joimat eine Söbe von etwa $90 \mathrm{~m}$ und ift $\delta a=$ 
ntit wohl bie bödfite aller Tamtenarten. Shre 3meige find fammartig geidjeitelt, die Slabeln ber Trieboberjeite mejentlich fürzer als bie anderen.

Eine andere anterifanijhe Gruppe bilden bie niebrigeren, häufig jogar mur ftraudförmig wachjendent $\mathfrak{B a l}$ am tanten, bie zum Ieil ben in Sandel befutolichen $\mathcal{R} a=$

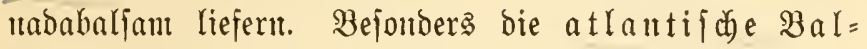
¡ a ut anne (A. balsámea Mill.), fenntlic) an ben gläızen= ben, ftarf verbarzten Fnojpen und ben beim Berreiben aromatifonen Rabeln, ift als Parfbaum nidyt jelten. Die oftajiatijuen Tanten Gaben bis jebt mur wentg Fingang in unjere Bsärten gefunden.

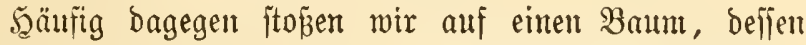
flache, itumpfe Rabeln ibn zu ben Tamten meijen wïrben, wenn uicht ber unregelmä̈ige, quirllofe 2ufbau jeiner meiit an ber Spize etwas lyängenden 2iffe mo noch melyx ber id)laffe, nicfento (sipfeltrieb ilym ein ganz mtgemohntes 2tusjehen veridjaffte. Dit findet man auch winzige 3äpfdhen ohne fichtbare Decfichuppen, bie am Bmeige hängen und

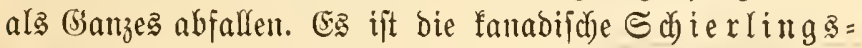
tanne (Tsúga canadénsis Carr., f. 2lob. 5 u. Tafel IV),

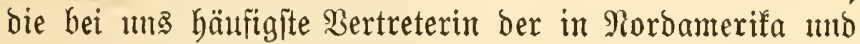
Ditafien heimifden $\mathfrak{S}$ em lod Iroctuen abfallenden, unten weipftreifigen Siabeln ermeijent fich bei näberer Befichtigung als vorne leidbt gezäbut und ¡chmäler als am Grumbe, im Bsegenjał zu ben gröperen (bis $2 \mathrm{~cm}$ ), vorn nid)t verid)mälerten Rabeln ber we it =

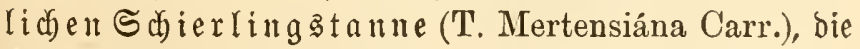
zwar weniger miberitandäfäbig, aber bichter benabelt und rajchroüchiger ift. 
Eine der ichöniten mo zugleich foritlich wertwolliten Errutgenfchaften ift bie Douglastanne (Douglafie),

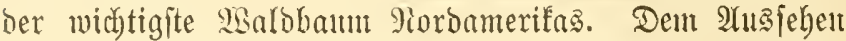

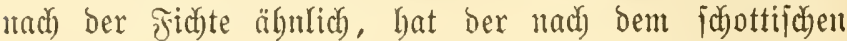

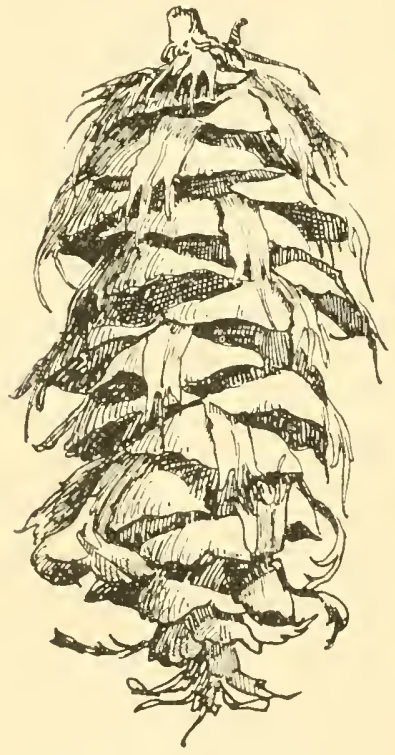

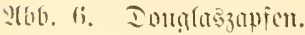

Botanifer Douglas benamute Baum feine, angentebm duf= tende Mabeln und mittelgrofie hängento 3apfent mit breiten rotbraumen Schuppen und weit Gervortretenden Dectblättern (i. 2ubb. 6, nat. (Srr.). Die Siabeln fallen beim Iroditen nicht ab mo gleidjen aljo barin dent Tammen, wogegent der 3apfen fich nidyt entblät= tert, fondern als Ganzes $a b=$ fällt. Die Rinde ber Dou= glafie ift oft von zaldreichen sarabeulen blafig aufgetrie= ben, bie iduarffpibigen Sinufpen find glänzeno bram. Die ges wölntiche "grünte" Douglafie

(Pseudotsúga Douglásii

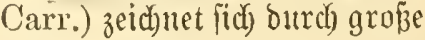

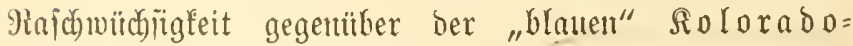
Douglafie (Ps. gláuca Mayr) aus, bie bafür aber froft= bärter ift. Die Sindeln ber lescteren finto fürzer und haben einen gant leidgten bläulidyent Sdyimmer, int Sitben ilgres Berbreitungagebietes funbet fie fich fogar völig bläulich)= meīis, jo daj fie mit ber ebenfalls in Feljengebirge 
Geimificen blauen Form ber Stectfichte (ई. S. 12) als 3ier= baum in \$ูSettbewerb tritt. Sn unferen $\mathfrak{B a ̈ l d o r n ~ b a g e g e n ~}$

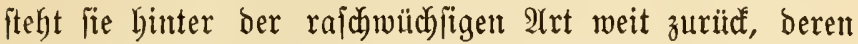
Solz die Büite bes wertwolfiten ä̈rchenbolzes erreichent faum. Die Zapfen ber "blauten" 2lrt find burch geringere Giröß̈e, graubraute Farbe uno eingerollte Dedfachuppen d)arafterifïert.

Mäbrend bei ben biaher bejprochenten Battungen bie Siabeln ftets einzeln ant 3weige itehen, ift bies befauntlich bei ben Riefern mur in ben allereriten Rebenzjabren bez Bauntes ber Fall. Allle ipäteren 3meige, bie meitermachjen= ben Rangtriebe, tragen nur bäutige Schuppen, in beren

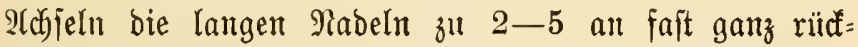

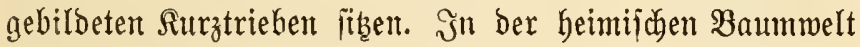
find bie zmeinabligen Riefern burch bie genteine Riefer (Föhre, Forche, Pínus silvéstris L.), die öjterreidyifde Schmarzfiefier (P. larício Poir., ¡. $\mathfrak{A} b \mathfrak{b} .7$ ) unb bie jub= alpine Bergfiefer (Regföhre, P. montána Mill.) vertreten, wogegen bei ber in Şodygebirge heimiij)en $\mathfrak{A}$ r ve (Birbel= fiefer, P. cémbra L.) und ber als eingebiügert geltendent

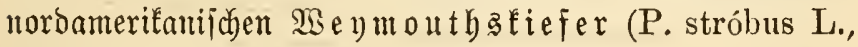

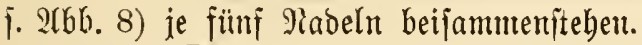

Dieje arten find natürlich auch im $\mathfrak{P a r f e}$ zu treffen, im übrigen ipielen bort aber von ben etwa 80 befannten

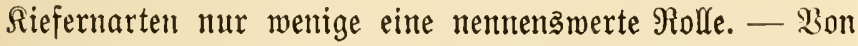
ber vielgeitaltigen $B$ erg fiefer fimb bie niederen 13 ud formen in Felienanlagen und Arpenbeeten verbreitet,

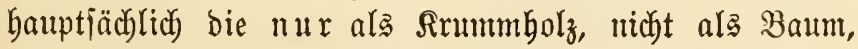
vorfommende Mugofiefer (var. míghus Willk.) ber Ditalpen, aber auch bie beutjue 3 wergfiefer (var. 
pumílio Hk.). - Die nach der jafwarzgrïnen Färbung ber bejonders langen Rabeln benante Sdy wa rzfiejer (j. Iafel IV) ift wentiger lichtbedinfitig als die gemeine Siefer und bringt bies ourch bidate Benablung, tiefe

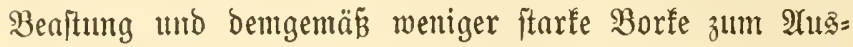
brud. Stuch bie wie bei allen fiejern früheitens im zmeiten

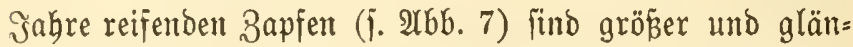
zento gelbbraun. Die im Mittelmeergebiet heimiface for fifche Foru (var. corsicána Poir.) unterficheidet fich ourch fantälere Srone und bellbraume Farbe ber einjäbrigen 3weige von ber Form der p̈fterreichijchen Bebirge (var. austríaca Endl.).

Die Siejern wactjen in der Jugend jo regelmä̈̈ig, baß̧ aus ber 3 ahl ber aftquirle mit Sidferbeit auf bas alter bes Baumes gefdylofien werden fann; mur bei einer fleiten Gruppe ber zweintabligen Siejern bilden fich an ben Jahrestrieben, oit ebenfalls quirlförmig angeoronet,

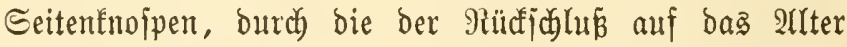
erichwert wird. Şierker gehört die norbanterifanijobe Straudfiefer (P. Banksiána Lamb.), bie iGrer gropen Arnjprud)ălofigfeit an ben Boben wegen eine ber widtigften forittichen Einfüthrungen und aus bem gleichen (srunto auth fitr ben Park, bejonders bei Meuanlagen auf Sdutt und Doblano, wertwoll ifit. Der niebere Baum erwächjt bich)t= beaftet, im $\mathscr{A}$ uffou ber Fichte äbnlich; bie fehr bichtert, berben Jabeln find kräftig grün und meijt wellig ge= bogen.

Dreinadlige Riejern find in Rarke jelten, menn= gleich bie mur in milden Ragen fortfommento (S) elbfiefer (P. ponderósa Dgl., pazif. Noroamerif́a) ihres üppigen 
2Suchjes uno ihrer prächtigen, bis $25 \mathrm{~cm}$ lantgen Benablutg juliebe jelgr gejöäbt ift.

Defto bäufiger treffen wir aber fünfnablige :Trten aus ber Bermandtichajt ber sisenmuthafiefer. Dieje jelbjt (P. stróbus L.) ift ja in unjeren Sä̆lbern Gente allgentein ver= breitet und banf ihrer weichen, jeibegläızen= Den Benablung auch als Bierbaum jebr be= liebt. Die Seimat ber IBeumouthafiefer ift bas atlantijcte Pord $=$ auterifa, int pasififictest wird jie ourdy die jebr ähnliche, aber bei uns feltene (S) ebing $=$ it robe (P. montícola Dgl.) vertreten. Fajt nur burch bie ausein= anderfallenden, mehr bängentoen Rabel=
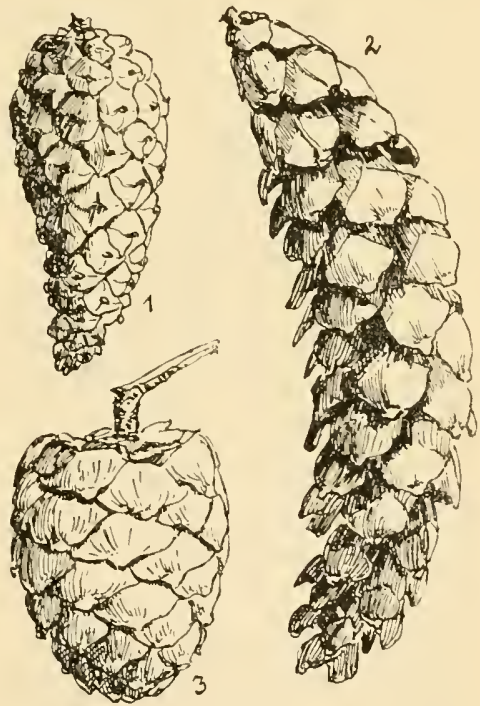

2(66. 7. Siefentapfen: 1 Edhwarztiefer, 2 Iränenfiefer, :3 9true. biijchel untericheidet fich bie im Şimalaja heimifde Iränenkiefer (P. excélsa Wall.), beren grofae, bis $25 \mathrm{~cm}$ lange 3apfen (¡. 2l6b. 7) meift mit tränenartigen Şarğtropfen bejeb̧ füto. Mit ihr trifit man im Parfe weiterbin die rumelifdae Strobe (P. péuce Gris.) mit kürzeren Zapfen uno fürzeren, iteifen Nabeln, bie aber vielfach ıur als örtliche Barietät ber 


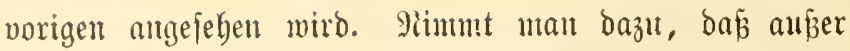

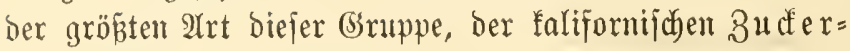
fiefer (P. Lambertiána Dgl., mit $40 \mathrm{~cm}$ langen Bapfen), and nock in Sapan eine mur wenig mterichiedene ârt, die (S)yofiefer (P. pentaphýlla Mayr) aufgefunden wurbe, fo weift bas Beifpiel ber Stroben beutlich barauf bin, dẩ unter gleichen Rebensbedingungen in ben ver= ichiebenten Ieilen ber Erobe aud biologijh gleiche arten entfitebent muifien, die fich wiederum audb äuserlich un jo äbulicker fint, je jünger ibre Abtrennung von einer ge= meintanten Stanmiform ift.

Der frïkere territoriale Bujammentyang ber heutigen großen SBaldogebiete Miorbamerifas, Europas und Dit= afiens aber erflärt jur (Gienïge die noch hente beitebende

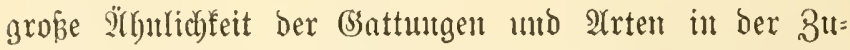

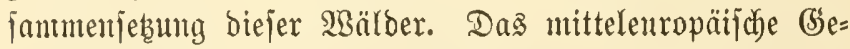
biet ift heute meitaus bas artenärmjte, aber es feblen gerabe joldbe Gattungen vou $\mathfrak{Q} a u \mathfrak{b}=$ und Rabelbäumen, bie nachweislich noch in ber jüngeren Iertiärzeit bet uns jablreich vertreten waren. Die \$ermutung liegt nake, ba

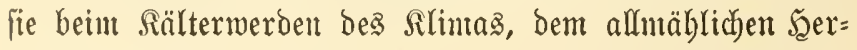
auffommten ber (Eiżzeit, jich) nicht anzupajjen vermod)ten, andererieits aber, gebindert burch ben Duermall ber Altpen, nicht imftante waren, fich in ben wärmeren Süben zu flüchten. In शiorbanterifa und Ditafien aber ermöglichte

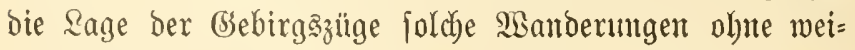
teres, ebenfo (jomeit ber Bujammentyang nicht geftört war) bas jpätere Wiebervororingen Mad) Sorden, und pou bort

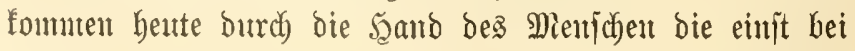
uts erlojdyenen Gattungen, die Stroben, Sumachs, Ma= 
gnofien und viele antore, zurüct in unjere SBälder mo unjere Parfanlagen. Ilno da biefe Gattungen und atrten hier diejelben flima= tijchen Berbältniffe vorfinden wie in igrem natïrlicben Serbrei= tungsgebiete, jo fallen die Stymierigfeiten ber arkflimatijation volfftändig weg, ba ja eine 2Hpaffung an jrembes Slima gar nicht in Frage fteht. Miizerfolge ber $\mathfrak{A} n=$ pflanzung finto aljo nur auf uttgenïgende Sientnis ber beimat= ‘içen \$erbältnifje und unrichtigeßehanolung zurïd

Die Gruppe der Stroben unteridjeidet fich von den meiften anderen Riefern burch böbere Mitprüche an den ß̧oden und burd)

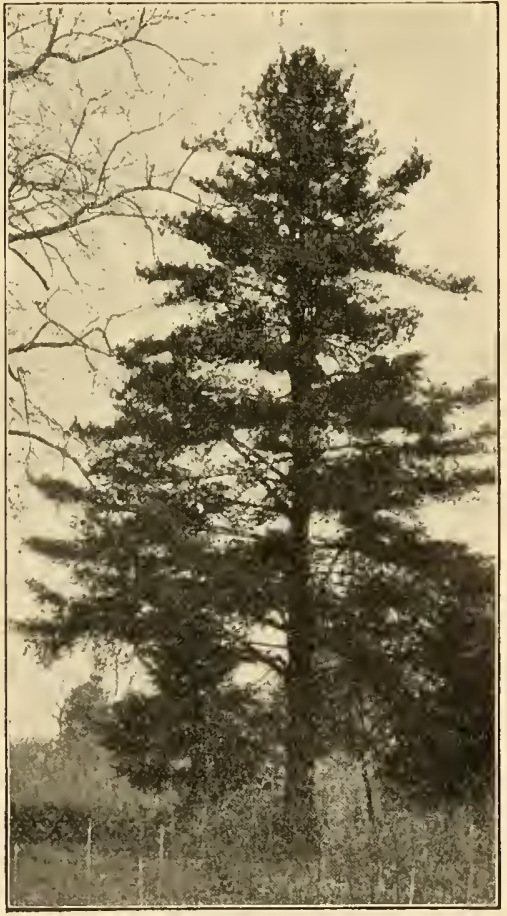

966. 8. meyntouthafiefer. größ̈eres Schattenerträgntis, audd bilden igre Fronen in Arter nie bie befante pinientartige Schirmform, fondern gleichen in ber Form viel eljer benten ber Tamten (j. Albb. 8).

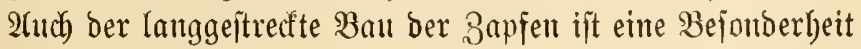


der (Srmppe. - Eine antere (Sruppe ber fünfuabligen Riefern bilden die $\mathfrak{A} \mathfrak{r}$ ent, deren einte (Pinus cémbra L.), anch) Sirme, Birbelfiefer genamnt, ein ftarf int Rïdfgang begriffenter äuberit d)arafteriftifcher Saum ber salogrenze in ben sllpen ift. SBegen ifrer bichten Semablung und ifres

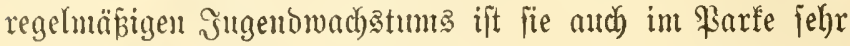

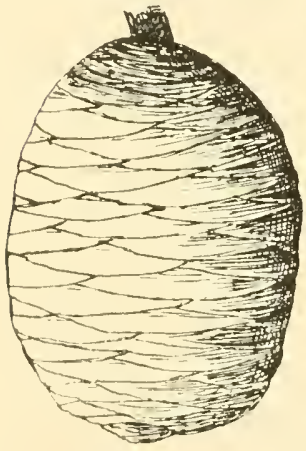

2(b6. 9. 3apten der Ytusceder. beliebt. Die Madeln füb fteifer und bicfer als bie ber Strobenarten, bie jurgen Iriebe find mit roiffarbenem Filz befleibet. Die 2ruen tragen

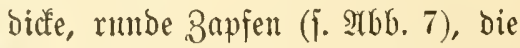
bei ber Reife jerfallen, un bie meift ungeflügelten máartigen Samen („3irhelnimife") freizulafient.

Serbreiteter, weil im şalde ilberall augepflanst, ift bie ebenfalls

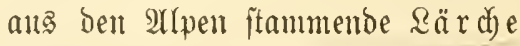
(Lárix europáea D.C.). Mit bell Cedern zujanmen tragen bie Rärdben all ibren Trieben in erften salyre bie Mabeht einzeln (Rangtriebe), bann aber bilben fid feitlich) fnopfige Rutrztriebe, an benen bie Siabeln als bidjte Büichel fich bärfen. Sä̈hrend bie Mabeln aber bei ben Eedern

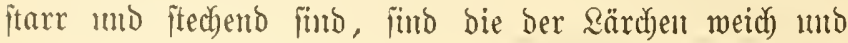
zart. Deun fie branchent ja mur ein einziges Jahr lang

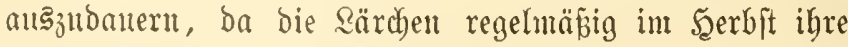

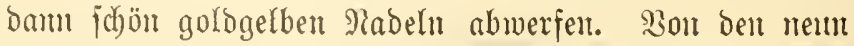
Cärchenarten, bie alle bei $m$ m im Freien aushalten, ift ibrer beforativen Sirfing wegen bie ants Japan fonmtende 5ondolärdye (L. leptólepis Murr.) bejonders beliebt. 
Shre Nabelı zeigen infolge eines zarten $\mathfrak{B a c h b u ̈ b e r z u g e s ~}$ eine blangrüne F̈ärbung, die im Şerbłt inş Biolette ïber= geht, die Iriebe find rotbraum (bei ber europäijchen \&ärdbe

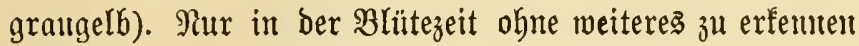
ift bie jibirifde $\mathbb{2} \ddot{a} \mathfrak{r}$ be (L. sibírica Led.), und zmar an ber grünen Farbe ifrer meiblicken Zlïter, bie befanntlich bei ben anderen Arten in prächtigem Rarminrot (eud)ten.

Die orei immergritnen Cebernarten gebeiben in Deutichland mur it milden, luftfeuthten Ragen, ant eljeiten die Htlasceder (Cédrus atlántica Man., f. $\mathfrak{A b b}, 9)$, bie fich an ifrem ftets auf= rechten (sipfel ficher erfenmen läßjt. Die iit ihrer Scimat fajt ausgerottete Ribanonceder (C. Líbani Barr.) trägt in ber Şıgento einen überhängen= ben sipipfel, im arlter billot fie eitre präd)tig aufgebaute jodirmförmige Rrone. - Mit Dem Mamen "Eeder" wiro ïbrigens, wie mit bem ber "Evpreffe", mancher Mip̧brauch getrieben, injofern

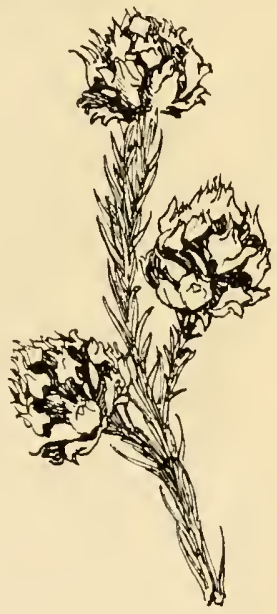

966. 10. Etgijmeity mit 3apien. vielfach aud ganz anderşartige Rabelhölzer fo bezeichnet werben.

(Fin Beifpiel lierfür ift die in ifrer Sceimat Sugi genannte $\Re$ ryptomerie (Cryptoméria japónica Don.), bie auch als "japanifjye Ceder" im Szandel ijt. SSie $\mathfrak{A b b} .10$ zeigt, hat fie mit ben echten Eebern feinerlei פ̈lhnlichteit, ihre Benablung erimtert viel eher an bie im

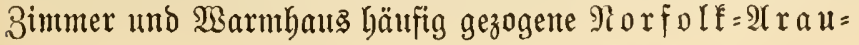


farie (Araucária excélsa R. Bro). Die pfrientlict)=fantigen Rabeln oronen fith in fünf Beilen um den Trieb, bie kugligen Zapjen bleiben nad) bem Samtenausfall nod) längere

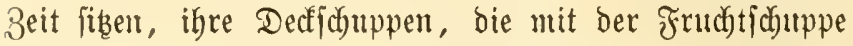
unten verwad) jen find, frimmen fich hafenartig rücfwärts. Die Sugi iif bas widbtigite, in vielen Formen gezogene

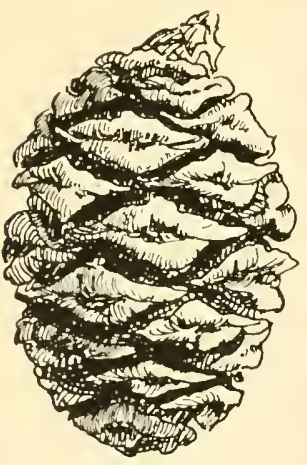

966. 11. Wellingtonien= zapjen. Siublyol Japants; ihre Bermelyrumg geforbiebt, mie auch in umjeren (şärten, in ber Piegel burdh Stectinge.

arcs Begentitïcf zu biejem japa= nijoden Saume finden fidd) in Rali= fornient die Sequoieu, jwei 2 rrten als Reite einer im Tertiär weit= verbreiteten (Siattung, beren eime aud) in Dentjoland vielfact) gepflanzt wirb. Ese ift bies bie Riejen= fequoie ober aberlingtoute (Sequóia gigantéa D.C., โ.Tafel II), ber burch) feine riefigen (şrößenver= bältnifije แno jeine altertïmlidbe (Ex: icheimung berïhnte Miammutbaum. Sn unjeren \&arfan= lagen begegnen wir ilym als jtrentg fegelförmig gemachjentent

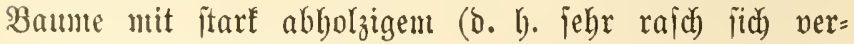
jobmälernoem) Stanme, befien piriemliche Mabeln ganz an bie Iryptomerie erimmern, aber alljeitig um ben Trieb ftehent.

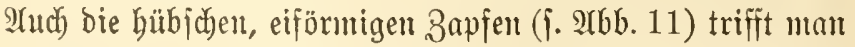
nicht jelten, mur entbalten fie faft mie feimfähigen Samen. Die Bellingtonie erreicht in falifornifiben (S)ebirge, wo fie in fleinen, als Siationaleigentun erflärten Seftänden nod) ber Bernichtung entgantgen ijt, eine Şöhe von nicht weniger 


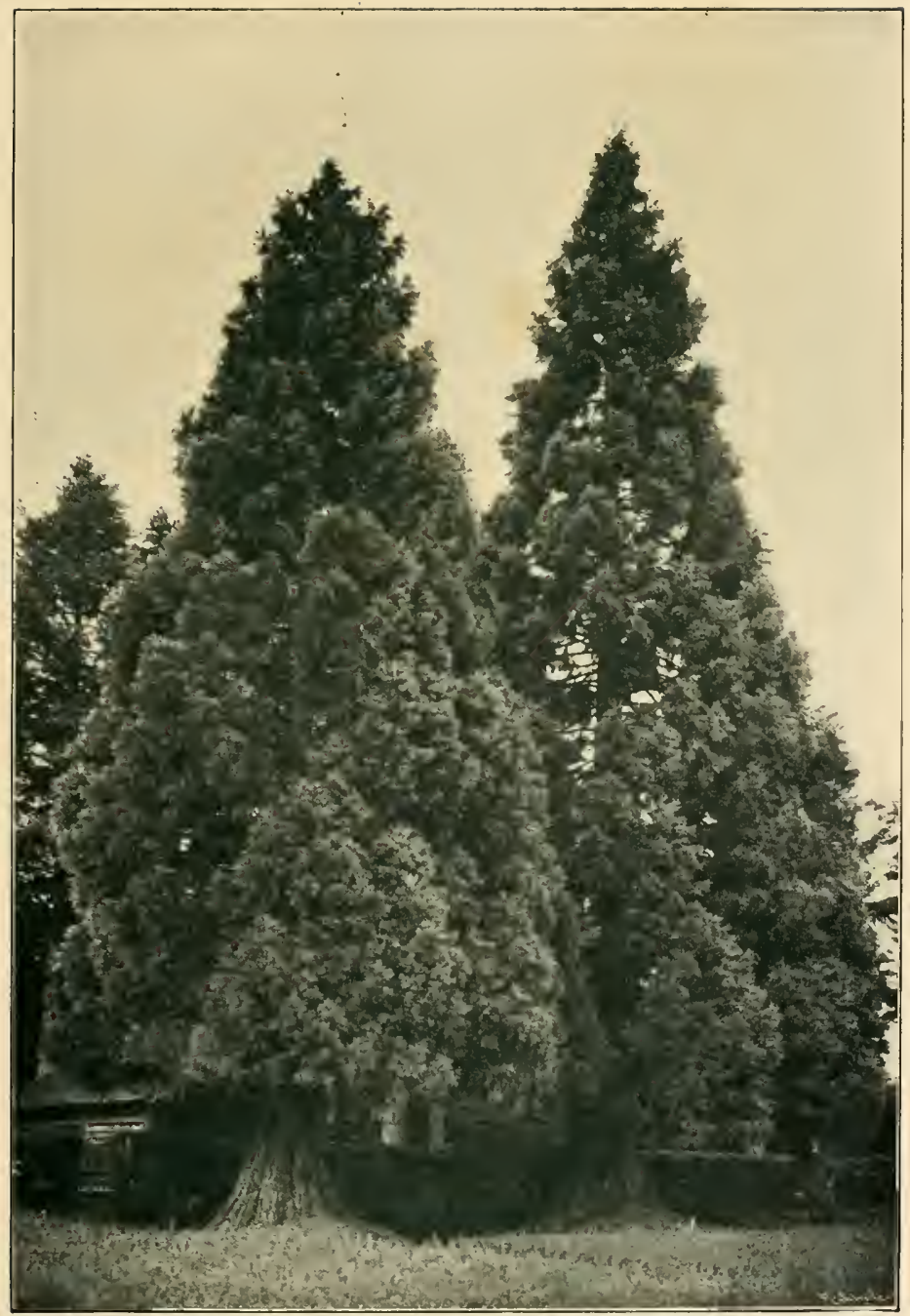

Eajel II.

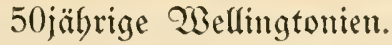



als $120 \mathrm{~m}$, ïe ijt aljo nädjit ber mijtralijd)en Enfalupte ber böchite Saum ber Erde. Dả aller foldher Miejen wirb auf etwa 4000 Jahre gejdäbt, ber Durdfmefier be= trägt (am $\mathfrak{f} u \tilde{\beta}$ ) bis zu $10 \mathrm{~m}$, bie weiche, fajrige Borfe allein fann einen balben Wieter Stärfe erreichen.

Ebenfalls altertünliche, im 2Uätterben begriffente Formen

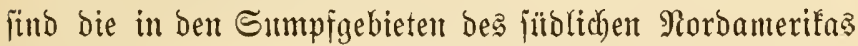
heimijuen Iaxobien ober Sumpicuprefien. Die bei uts verbreitete virginifche $\mathfrak{\text { Irt }}$ (Taxódium dístichum Rich.) trägt zarte, eibenähnliche Nabeln, bie an ben sangtrieben einzeln, an belt Rurztrieben fammartig in zwei bichte Feiben georonet fteken. Das auffalfenojte aber ift, baj mit ben Siadeln jugleidh audch bie Surztriebe jelbit im Serbft abgeworfen werben. Die Sumpfcypreffe, die in ihrer Seimat mitten im Sumpfwafier jtebt und baraus bejon= bere, eigentiumlich) fuicfige Stemmurzeln (Rueumatophoren) an bie Rujt jentet, verlangt bei unz, im fälteren Rlima, einen troceneren Standort, InI ber Froftgefahr zll ent= gehen, und unterläfst natürlich bie Sildoung bejonderer Ittmungsorgane, werm bie Bodenbejchaffentheit dies nicht erforbert.

Waa mm die Eyprejien jelbjt betrifft, deren Bild je=

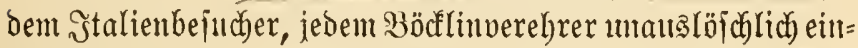

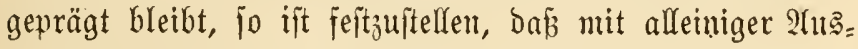
nalyme der Bobenjeeiniel Mainan und ifrer Itmgebumg wohl nirgentos in Dentichland Eupreffen im Freien jabre=

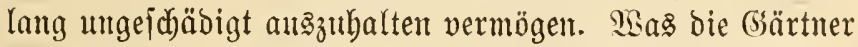
als Eupreffen bezeidjen, fins vielmehr Ingebörige ver= ichiedener anderer (Ssattungen, vor allem ber $\mathfrak{5} a(\mathfrak{b}=$ ober Lebenzbaumcyprejien (Chamaecýparis), bie aller= 
bings ähnlidbe Bentablung tragen, aber in ber Schönkeit

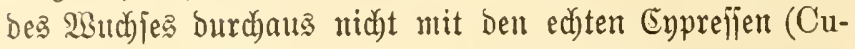
préssus) metteifern fömen. Im Interichied von biejen Find bie 3meige ber Salbcuprefjen nicht gleichjeitig vier= fantig, jondern flach), mit bentlid) verjofiebener, meift auch anders gefärbter Dber= unb Innterjeite, uno ver=

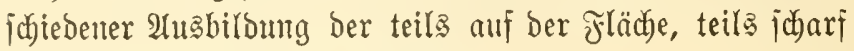
auf Der Sante fikentiden Nabeln.

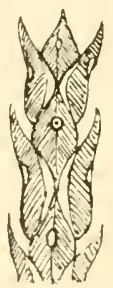

1

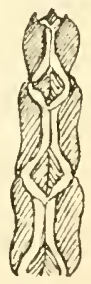

2
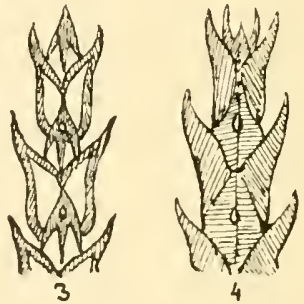

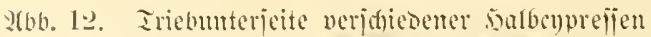

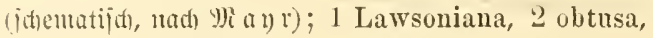
3 pisifera, 4 nutkaëusis.

Die verbreitetite, and im beutichen Saalde idjon eime

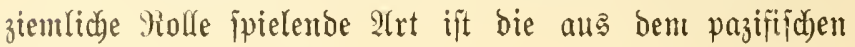
Biorbanterifa fommtende, nad) bem idjottificen Gärtmer Rawjon benannte Rawjongcuprejie (Ch. Lawsoniána

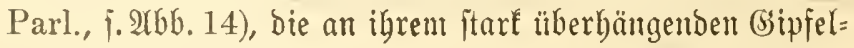
triebe jofort von ben anberen 2 rten zu unterjobeioen ijt. 2Uuf Der Dberjeite Der Sprojie tragen bie Flächenblätter eine Rängarinne mit einer D̈broüfe, wie dies bei ben meiften $\mathfrak{2}$ rten ber Fall ijt, bie Unterjeite zeigt eine burd) bie 2tnordmung ber Spaltöfinungen bebingte ganz d)araf= terifitifue meife Beichnumg in $X=$ form (i. 21bb. 12), ein 


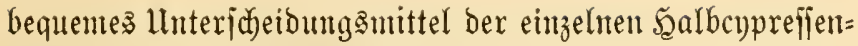
arten. Fur bei ber an ber Siutfabudt in Moromeitamerifa heimijoben $\mathfrak{R}$ ut $\mathrm{t}$ acıp r ejje (Ch. nutkaénsis Spach.) feblt

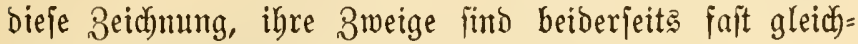

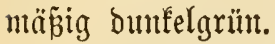

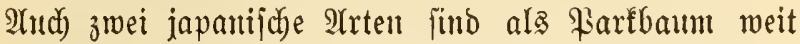
verbreitet. Die burch ichräg abitebentoe, icharfipibige

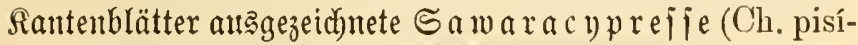
fera S.-Z., F. 9l6b. 12 น. 13) wirs itt mebreren Forment ge= züchtet; im Biegenjak bazu trägt Die ft ump fblättrige $\mathfrak{S} a \mathfrak{l b}=$ ( v) prefie (Ch. obtúsa S.-Z.) fitumple, einwärts gebogente Siantenblätter (โ. $\mathfrak{A b G}, 12)$.

Bei erwachferten \$albcy)= preifen ift nad) ber idyppen= artigen Belaubung freilich bie
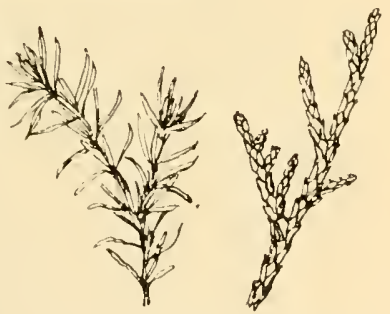

266. 13. Eamaracmprefie (linf jug justorm). 3ugeljörigfeit zu ben Tiabel= lyölzern nidat obne weiteres einleudytent, elyer nody madyt dies der Ban ifrer fleinen, bei der Samaracuprefie nur Erbjengröpe erreidbenten Zäpfdien verftändlich. Sobald man aber junge 和lanzen zu Geficht befommt, wirs ber 3ujanmentang flar, Denn all bieje und äbuliche arten tragen in ber Jugento weiche, piriemliche Mabeln. (S'ärt= nerijher Bühtung gelingt es mun, joldhe Jugentozueigdhen als Stectlinge zu verwerten uno barauts \$fflanzen heran= zuzielyen, bie aud) im stler mur nabelförmige Primär= blätter tragen. Solche Jugendoformen, die frülyer als be= jonbere Gattung Retiníspora angejeben wntoen, fimo beute 
- vielfach nod) unter diejent irrigen Ramen - vou allen Şalbcrprefienarten, aber aud vou anderen cypreflentäbn=

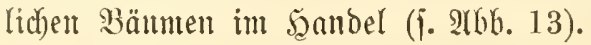

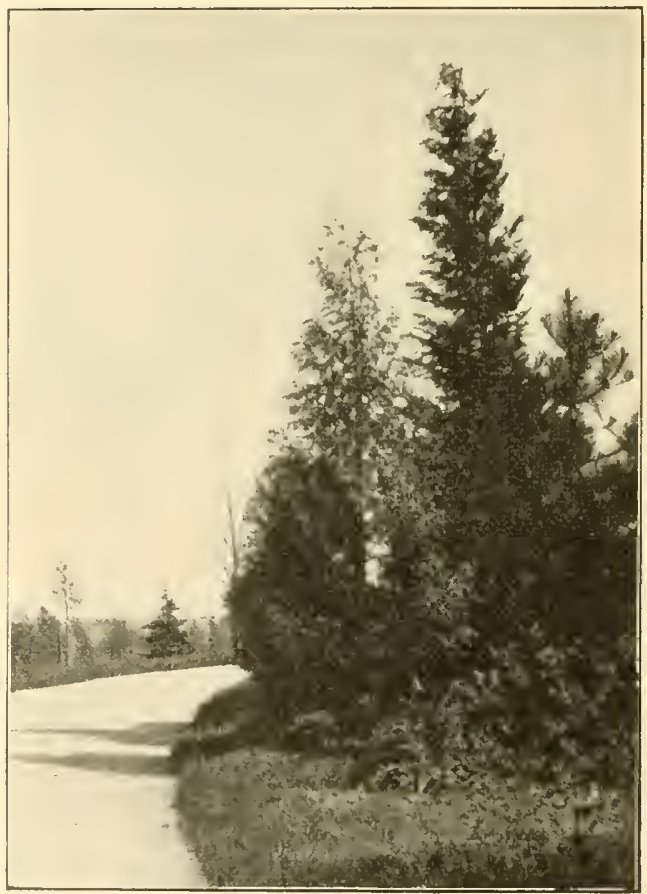

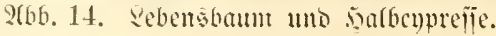

So bejonders von dem allbefanten dinefifdien Lebensbaume (Bióta orientális Endl., f. 2(6b. 15), ber

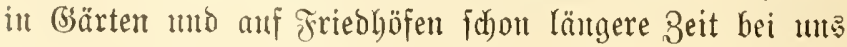
eime Seimat gefmben hat. Seine Bueige tragen unterfeits 
feine hellen Flectent und find überhaupt weniger beutlich in Dber= und Unterieite geidieden. Es bängt bies bamit zu=

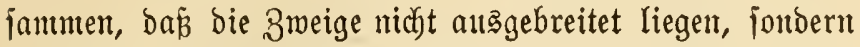
burchweg iteil aufgeridytet getragen werben, woburch ber Baum fofort mit Sicherheit zu erfenmen ift. $\mathfrak{A}$ utch bie blaubereiften, aus jed)s bicfen Frudtichuppen gebildeten Zapfen find bejonbers darafteriftifd, bie oberen Flächent= blätter tragent eime rimnenartig eingejenfte D̈lorïje, währento bieje bei ber folgenden art fitglig erhöht ift.

Es ift bies der norboftamerifanijo Rebensbaum (Thúja occidentális L., i. 2イ⿱⺊b . 14, 15 uno Tafel III), ber jobon 1566 nach (Europa gebracht murde und beute als Zierbaum allgemein verbreitet ijt. Seine flachen Zweige find unterfeits hellgrïn, int $\mathfrak{B i n t e r}$ aber nebmen fie infolge einer teilmeijen Ummandlung des Çblorophylla eine braun=

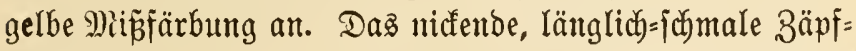

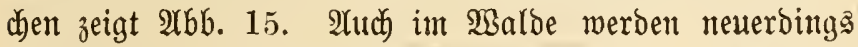
Rebenabäume verjuchsmeife gepflanzt. Dod ift bies mehr

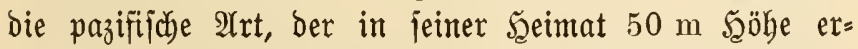
reichende $\Re$ iejenlebenzbaım ( $\mathrm{Th}$. gigantéa Nutt.). Seine aromatijatien, interjeits bellgrau geflecften 3meige zeichnen jïch burch ben regelmäß̈igen $\mathfrak{B a u}$ ber Iriebentoen und bie ftreng parallele \&agerung ber äuperiten $\mathfrak{B e r}=$ zweigungen aus; im Winter verfärben fie fich nur wentig. Pock) regelmäpiger, babei aber zmeigabelig geteilt, find

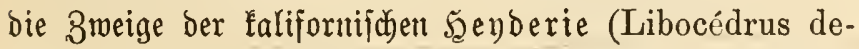
cúrrens Torr., f. $2(b \mathfrak{b} .16)$, Derent gemöhnlicher siame "F̂flüceder" als irreführend beffer nicht gebraucbt wiro. Bei ifrr itehen die Flächenblätter auf ber gleichen ફ̧öbe

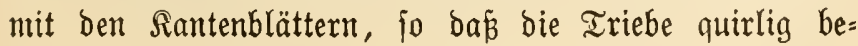




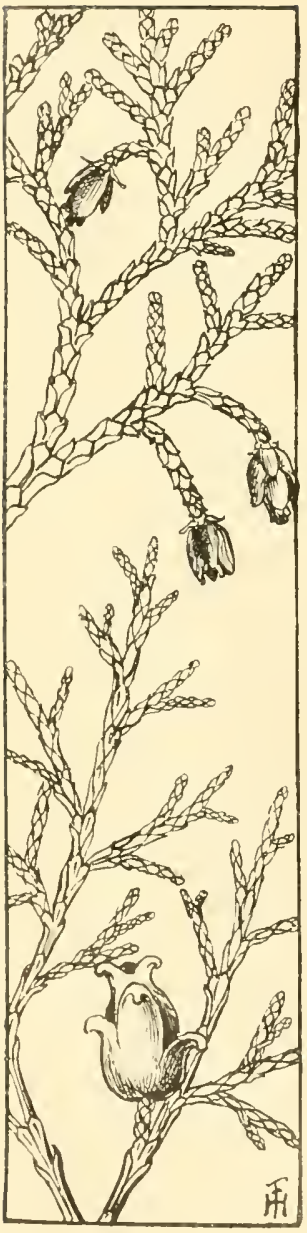

26b. 15. Morbanterifan. แ. chinej. 2ebensbaum. blättert und bie $\mathfrak{A}$ d) jenglieder zmi= joden ben Blättern bejonders lang ericheinen. Şhr SBuchs ijt joblanfer, cypreflenartiger als ber der Rebens= bäume.

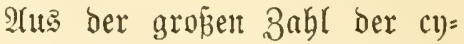
prefienartigen, oft ichner zu unter= jobeibenden Rabelbölzer ift nody ente jehr leidjt erfembare $\mathfrak{2}$ rt zu nemmen, die in Sapan grob̧e \$älber bil= dende $\mathfrak{g}$ iba (Thujópsis dolabráta S.-Z., j. \$(b6. 16). Die Siba trägt jebr breite, oberjeits glänzenogrïme Iriebe, Derent $\mathfrak{A}$ j) je ganz unter ben breiten fduppigen Blättern ver= jobuindet. Die Unterieite Dagegen ift faft ganz von ber bläulicbneiß̄en Spaltöf̆mmgszeidumng eingenom= men. Da die Siba volfomment winterhart iit, ein jebr bauerbaftes 5olz liefert und gegen Bejdyattumg wertig empfindrich ift, wird fie $10=$ gar von mandocer Seite aud fïr den bettichen TSald empfoblen.

Bon allen bisher genannten Jabelfölzern trennt bie $93 \mathrm{ad}$ ol berarten ber fleifodige Bau ber 3apfen, beren Sdyuppen bei ber Reife völlig verwachjen, und die beşgalb ganz ben sindruaf einer 
Beere madjen. \$on ben etwa

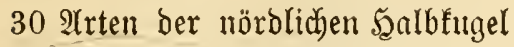
find in unjeren Parfanlagen mur wenige zul finden, da bie meiptent bei un' nur in gaur milden Bagen zu gebeihen permögen. arber auth unjere beimijache $\mathfrak{A}$ rt, ber ïber ganz Europa verbreitete gemeine $\mathfrak{B a} a$ c) old e r (Juníperus commúnis L., 1. Tafel V), ift jelten in Rultur zu treffen. $\mathfrak{A}$ m häufigiten uoch bie im Scochgebirge und Polargebiete wad)= jente Forn bespelben, ber 3 werg= wo a d) older (J. nána Willd.), ber mit jeinen nieberliegenden ïriten Inlo ben bicht georängten, weicheren Imb fürzeren giadeln gern als Gartenjadnutud vermendet wirb.

Bon alters ber im Sarten gezogen wirb bagegen jeitrer offizi= nellen (5igenjwaften wegen ber in ben Ulpen und $\mathfrak{P y r e n a ̈ e n ~ h e i n t i j c h e ~}$ Sabeit $r a u d$ ) (Sevenbaunt, J. sabina L.). Ilnter ben mancherlei 3uchtformen find foldse mit nad= ligen, ägnlich wie beim gemteinen Wactyolder in oreigliedrigen Duirlen ftehenden Blättern, jonit finto bieje aber ¡duppenförmig und idjmiegen fich freuzftänoig angeoronet bicjt

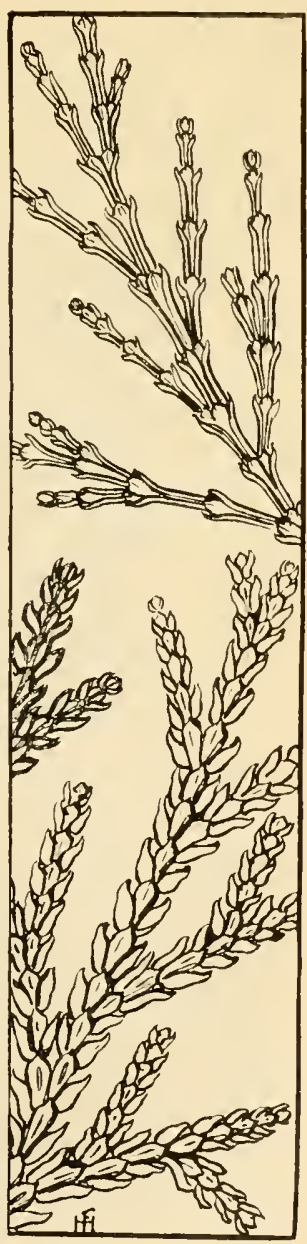

2(66, 16. Şendectie แtto ๖̧ía. 
ben rumben Irieben an, bie unangenebm harzig buften. Die jebr ähnlictent Bueige des virginijoen $S_{a b e}=$ baumes (J. virginiána L.) find geructolos, ibre $\mathfrak{b} e=$ naolung ijt aber auperorbentlich wechjelnd, bald nablig, bald jchuppenförntig, jo dañ bie 2 (rt nicht immer leidgt erfentbar bleibt, memt nid)t gerade bie bramnioletten, int Begenjak jum Sabeftraud nidjt nidenden Beerenjapjen jur Berfïgung iteben. Dod) bilbet bie Art ftattliche Bäume, wälrento bie europäifde ftets ein meift nieber=

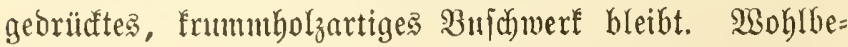

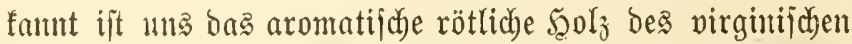
Sabebaumes, es wiro mämfict) allgemein zu Bleiftiften verarbettet uno beghalb aud) ber 3 aum von ber Faber=

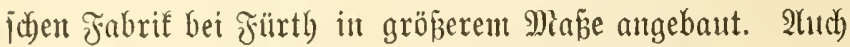
bie Ramen "Bleiftiftceder" uno "virginijche Ceder" werben für ifn gebraucht.

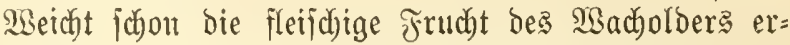
heblich vour gewohnten Sillo bes Mabefholzzapfents ab, jo ift bies in viel böberem Miá̃e ber Fall bei ber präd)tig roten, feltener gelben Scheinbeere ber Eibe, bie in michts mehr an bie Bapfenform erimtert. Dafür fint aber bie

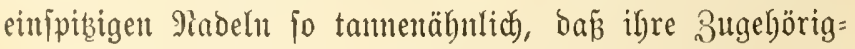
feit zu ben Siabelhölzern jelbituerjtänolich erjecint. Bon ben Ianmennabeln tremnt fie aber ibre weiche Bejhaffen= heit und die gleidhmäñig grüme Mnterjeite. Die gemeine Eibe (Táxus baccáta L.), die im bentichen Maldoe nahe= zu ausgeftorben ift, wo fie nicht unter bejonberem Schutbe fteht, ift in Parf und Siarten eine ber befaunteiten Er= jcheinungen. Denn fie mächjt jelyr langjam, leibet nidyt

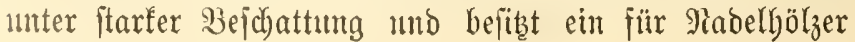




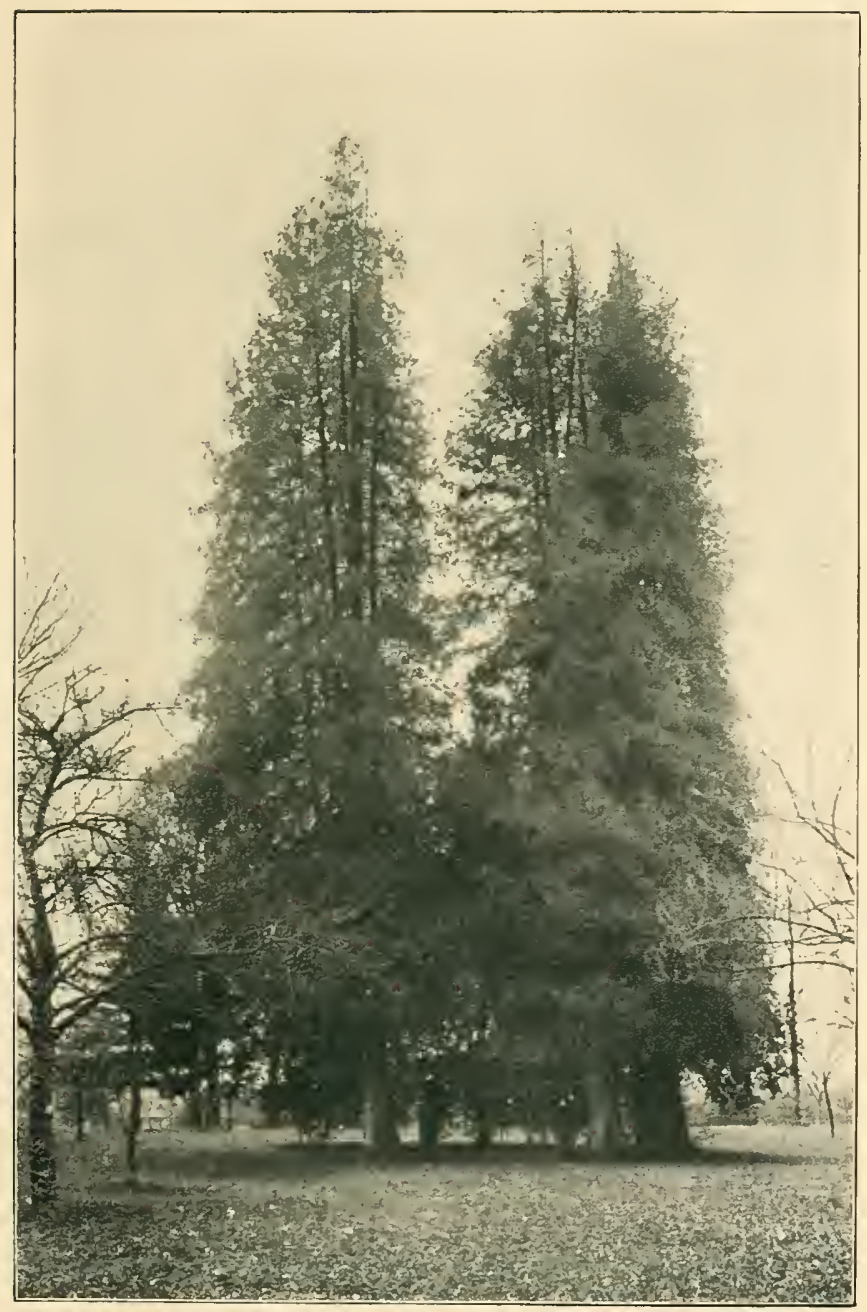

Safel, III.

110 jährige Qebenตีbäume. 



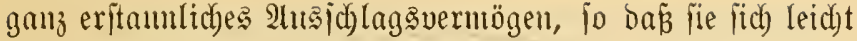
burch Stectlinge vermebren umb zu Seectell und Figuren in

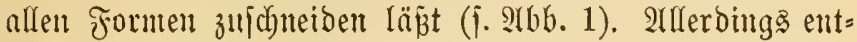
balten bie Sindeln, wie aud bie Santen, ein giftiges $\mathfrak{H}_{\mathrm{f}} \mathrm{n}=$ loio, bas Tarin, bas bejonders fïr Fferbe, aber anch für Schaje mo Biegen gefäbrlich ift. Der Sumenmantel da= gegen wirb von ben Amjeln gerne verzehrt, die babei bie SBeiterverbreitung bes Samens bejorgen. Die Eibe ift

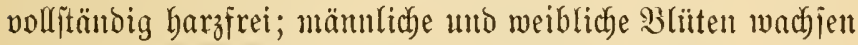
meijt getremnt auf verichiebenen : Fffamzen, doch bat man gerabe bei ber (Eibe bie Beobactung gemacht, oñ ein Stodf, ber jabrelang mur einerlei 3̧lüten trägt, plöblich beiderlei 3̧üten herworbringen faum.

Alte Stänme ber Eibe find meift im Dueriduntt felgr vielgeftaltig, nicht rumb, und lafien baburch ibre Entitelung aus mehreren zufanmengemadbfenen Einzel=

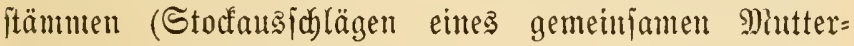
baume: erfenten, ein Beijpiel dafür, baj niddst immer

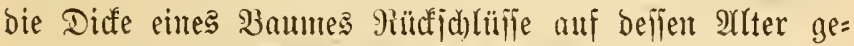
itattet. \$on verichiedenen Spielarten ber Eibe ford jäulen= artig wadbjenbe und gefledtnablige formen befonders beliebt.

Die nad) ben föpfdyentartig zujanmenftehenden Blüten benamter Ropjeiben (Cephalotáxus) Ditafiens ges Deiben mur in milden \&agen; bie bäufigite 2 rtt ift ber $6-8 \mathrm{~cm}$ lange eibenähnliche Mabelu tragende C. Fortúnei Hook.

2lts Ditafien endlich fonmt aud eimer ber interefian= teften $\mathfrak{B a ̈ u m e ~ u n j e r e r ~ ( S a ̈ r t e n , ~ b e r ~ l ̈ b e r r e j t ~ e i m e r ~ i n ~ f r u ̈ b e r e n ~}$ Eroperioben meit verbreiteten Pflanzentruppe, ber Ginfgo= 
bau (Gínkgo ${ }^{1}$ bíloba L. =- Salisbúria adiantifólia Sm., ๆ. 21b6. 17). Sact) Belaubutg, Berzmeigung und 2us=

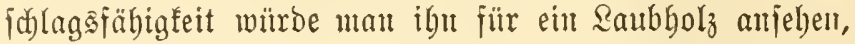
Der Bau bes harzfreien Şolzes und ber Błhuten meift ihn zu ben eibenartigen Sabelbölzern, ber eigenartige Befruch)= tungsporgang erimtert an bie Farne. Ilno an einen Farn, bas Frautnhaar (Adiantum), flingt aud ber fächerförmige

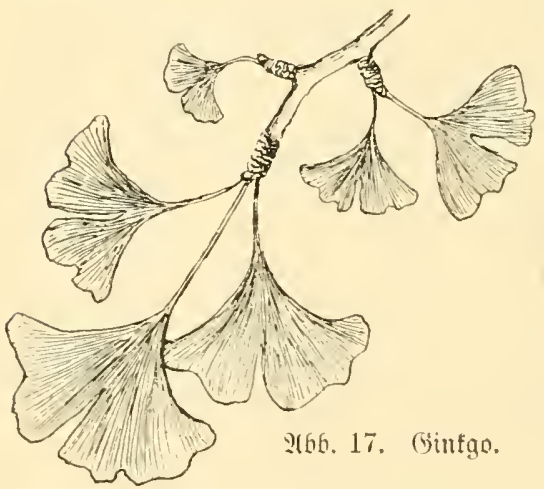
Sall Ind bie Mier= vatur ber Blätter an, bie an ben nicht= blïhenton 3̧weigen jweilappig find unto im Şerbjite fäntlict) abgeworfen weroent, uno zmar alt bent weiblichen $\mathfrak{B a ̈ u m e n t ~}$ (ber Ginffgo ijt zmei= häuïig) ipäter als an bell mämulidbent.

Die Blätter ber blübenten 3weige find ungeteilt, bie ber Stocfausid)läge bagegen mehripaltig=viellappig; Der Baum entipridyt aljo ber bei den Ranbhölzen in weitem lumfang geltenton Regel, wonach bie Blätter ber Blïtenzweige ein=

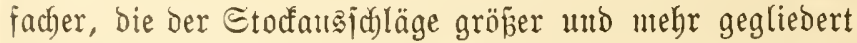
finto als bie ïbrigen Blätter. Die iteinfrudutähnlicben, von einem gelben Mantel umij)loijenen Samen bienten geröitet in China als giabrungentittel. Der Gsinffgo ift bort uno in Sapan als beiliger Baum ein iteter Begleiter ber Tempel,

1 Mincf) Mianr minpte cigentliç Günfyo gejdrieben werben. 
aber feine eigentliche seimat ift heute nod) unbefannt, wild ijt er nod) nirgendo gefunden worben. Sn Enropa

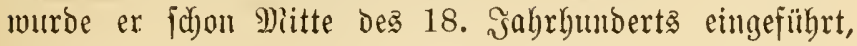
er gebeigt hier meift obute Edywierigfeit, hat jich burch leine Itrempfindlichleit jogar als geeignet jum Strafen= baum erwiejen. Die Form ber Blätter hat ihm anch) ben bitbichen Siamen Elefantenohrbaum eingetragen.

* * *

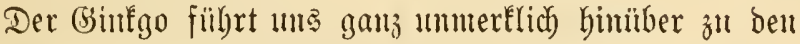

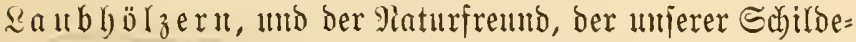
rutg bis lyierber gefolgt ift, wiro nach den jodeinbar gleich= artigen, oft idjwer zu untericheidenden $\mathfrak{T}$ rten ber Madel= hölzer erleidftert aufatmen, wenn er an bie vielgeitaltigen Strauch = und Baumformen der Raublölzer bentt, bie burch bunte Blïtenpracht ober eigenartigen Blätterjämutcf ilnm viel leichter einzuprägento Merfmale barzubieten ver= iprect)en. Bei näherer Siactaprüfung freilich wird er fict)

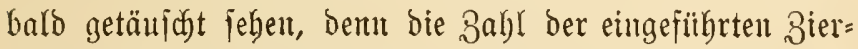

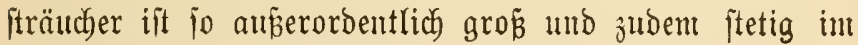
Steigen hegriffen, bie Interjchiede der einzelnen Irten find jebre ojt jo geringiügig und idner jejtüutellen, babei burd) Bajtarobiloungen und Bublformen nod weiter ver= wifcht, baf eine zuverläjïge Feitftellung ber Arten ober gar ber Spielarten in vielen (5iruppen mur ourd) grïnd= liche Spezialfemer möglid ijt. Damit bängt es zujammen,

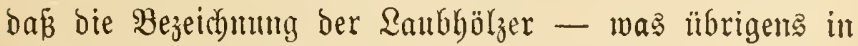
geringerem Brabe aud für bie Pabelgölzer gilt - in öffentlichen (3̈ärten uno Snlagen, joweit bieje nicht unter 


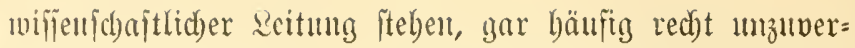
läjitig und feblerbait ift. Bum Gilüd für ben giaturfremto aber, ber in allgemeinen keinen sgert barauf legen woirs, alle Geltentheiten jelbyt zulemten, ift bie Bahl berjenigen Irten, bie in unferen Rartanlagen in größzerem Maß̧e

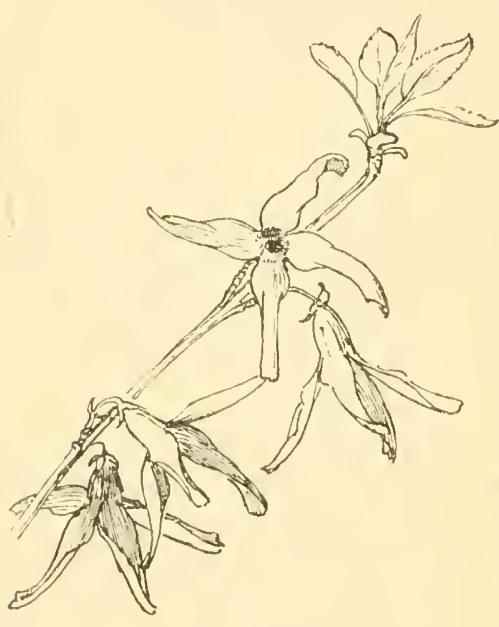

9(b6. 18, jorjuthic. vertreter und allge mein verbreitet finto, bod) verbältuismäß乃ig io flein, baj ex fie wohl zul ïberblictent und fich einzuprägen verntag.

Sm exften Frübjabr, oft ichon im slärz, weun

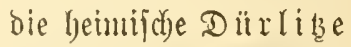
(Sionmelfiriche, Córnus mas L.) ibre zierlichen Stermbiijder antegt, grifint uns lendytendes (Gielb and in sinarten mo Fark. Die For = ¡utbien f(d)micfen fich uit ihren vierjipfligen, glodfigen Blüten, die bei Siegen= metter fdylaff aboürts bängen und fo das Jnnere vor ber

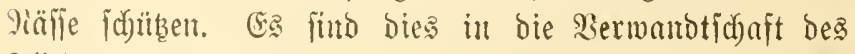
Fliebers zählende, nach dem englifd)en Botanifer Forinth benaunte Sträucher, bie lange nur aแs Japan uto Ebina befomit roren, bis oor faum zehn jabren auth in ben

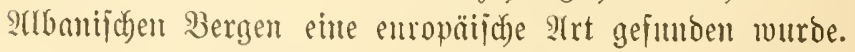

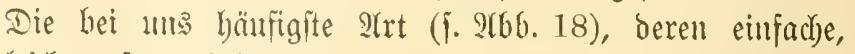
leidy) gejägte Blätter erĭt nach) ber Blüte ericheinen, trägt 
braune, aufantgs anfifrebenbe, ipäter ïberbäıgende Zweige umo gilt als Forsýthia suspémsa Vahl. Etwas ipäter blüht bie empfintichere grïme Forintbie (F. viridissima Lindl.), Derent grütte 3weige ifre 3lätter fajt gleichzeitig mit ben B̧üten hervorbringen. Sie ftantmt aus China, wie aud ein meiterer Früblibher, der mit den Forjutbien verwantote gelbe $\Im a \xi m$ in (Jasmínum nudiflórum Lindl.), ben man in gejdübten Ragen bäufig zujammen mit diejent antrifft. Seine grïnet, vierfantigen 3meige jomiegen fich gern an Mautern ut Bäute an; bie breiteiligen Blättchen brechent erit heraus, wesm bie an Schliifielbhmen eximtern= ben Röhrenbrüten zu Enbe gehen.

Itno mit biejer Blütenform fulipfen wir an befauntere Strüucher an: unr fleiner, bafür aber viel zahlreicjer in Miipen vereinigt, fint bie vierzipfligen Bliiten bes Fliebers. (S) (eic) beliebt in modernen \$arf wie in altmobijdyen Bautertgarten ift ber eltropäijhe gemeine Fllieber (Syrínga vulgáris L.) mit jeinen Greitherzłörmigen $\mathfrak{B}$ lättern 1umo jeinent gebrungentu, derben Błütenjträufen, wie ber zartere perjifde flieber (S. pérsica L.), an befien mit

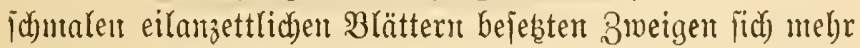

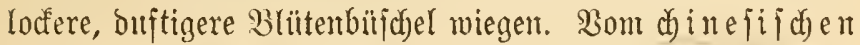
Frlieber (S. chinénsis Willd.), Dejien reidbłühende Zweige fich unter ber \&ajt ber bichten, fibwach duftenden Blüten zur Eroe neigen, iteht nidyt fejt, ob er uicht mur einte Sartenform, eit Srenzungagprobuft baritellt. Ierm jo lange ift ber Flieder

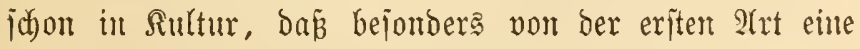
Mentge Form = unto Farbenabweichungen gezüchtet werbent.

3u jeiner Beliebtheit is ntenerer Beit trägt wejest=

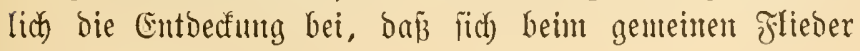




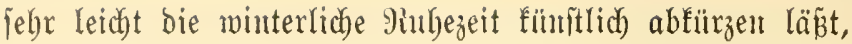

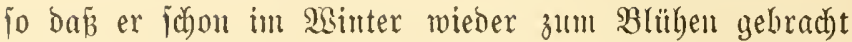
werben fann. Şierzu ift befunntlich eine längere Betäubung der Prflanze nötig, die entweder burch 2̈therifieren oder butrch genall abgeftimmte Scibemirfung (3as im warmen פBafier) erreicht wiro. And in Freien hat man mehr=

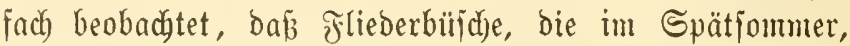
etwa bei einer Fellersbrumt, großer Şize ausgejebt waren, joweit fie baburch nicht zerftört wutroen, bald barauf wieder zut treiben und zu brïben begamter. 2huch fonjt formut

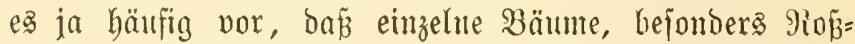

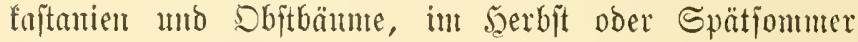
noch) eiumal treiben und blïben.

Bei anhaltender Ditrre und Trocfenheit tritt jïr frei und jomig fitebende Bäume, bejonders in itäbtijchen \&flan=

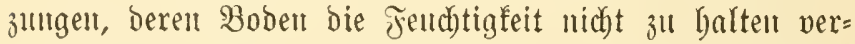

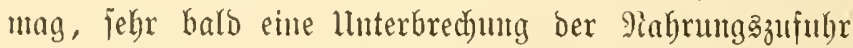
ein, fo baj bie norntale Entwicflung gehemmt und ber Saum zu unfreimilliger Sinke gezmungen wiro, was fich

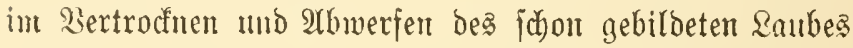
befumbet. Folgt num im Spätionmer eine längere 3eit marmer, erfrifbender liegen, jo treibt ber Bam fröhlich rvieder aus, uno da es zur silloung ber nädfitjöbrigen 3lütentuojpen vor ber Irndenbeit meift nod) gereicht hat, fo fömen aud bieje fid jebt jodyon vorzeitig entfalten.

Die genanten früblublyenden Flieberarten find alle burch glatte, utbehaarte slätter ausgejeid)net; mentiger be=

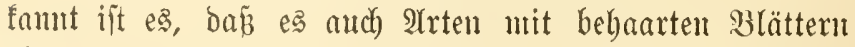

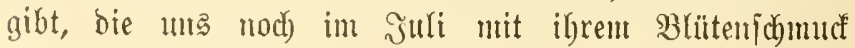
erfrenten. Der wohlriechende En obi= Flieder (S. emódi 


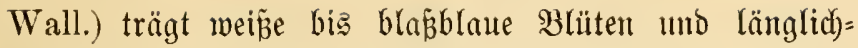

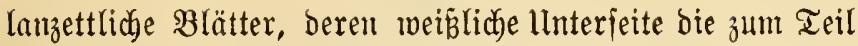
raubbehaarten Blattnerven bentlich hervortreten lä̈̈t. Er

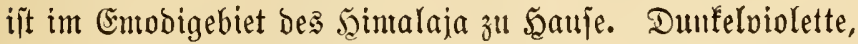
jelgr lange Brïtenrijpen und gemimperte Blätter fenn= zeichnen ben in Siebenbïrgen vorfonmenden, nad) feiner Entoederim benamten sofifa= Flieber (S. Josikiea Jacq. f.).

Snll ber Geimifchen Pflanzenmelt ijt ben Flieder an

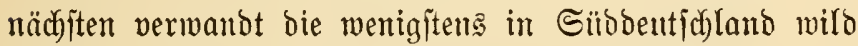
machjende Rainweibe (Ligústrum vulgáre L.). Jm

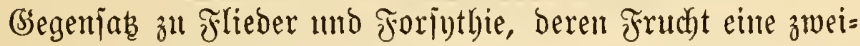
teilig alfjpringende Rapjel ijt, trägt fie aber jochmarze beerenälntidbe Steinfrildhte, die befamiten "Iintenbeeren". Somohl bieje als veridhiedene frembe $\mathfrak{A r t e n}$ (bejonders bie jebr reichblübende japanijd) gainweide, L. ibóta S.Z.) werden gerne zu Szecten bemubt, ba fie fich leid)t jăneiben laffen, ihr grïnes \&anb zum Teil im Sinter

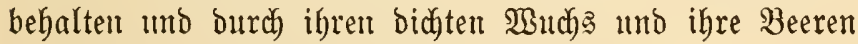
and fiür bie Sogelwelt pon $\mathfrak{B}$ ert finto.

Alle bieje Sträucher merden ben S̈rbaumgemädjen (Dleaceen) zugezäl)lt, beren auffäligites Merfinal bie 3weizahl ber Staubgefäße ijt. 2ht gröperen Bäumen fün

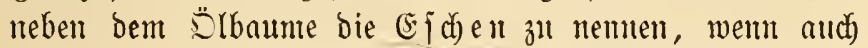
bei unjerer heimifchen (sjche unto ben ihr naheitebenden Arten ourd) bas Fehlen ber Bhumenhülle die Bujammengehörig= feit nidyt fo ofne weiteres flar ijt.

Die gemeine (E) fbe (Fráxinus excélsior L.), der

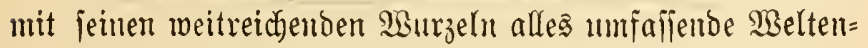
baum 2)gorafit, ift natïrlich aud) in Sarke zu furben, jo= 
wohl in ber gemölntichen form als mächtig aufitrebentoer Sanm, wie in melyeren Bierformen. Bon bejontorent Meiz fïr dent Botanifer ift bie emfad)blätterige Epielart (i. 2(b6. 19), Deren Blätter meift nid)t mur bie ungeteilte Eiform, fondern zugleid) alle ithergänge von biejer ein= fachen Stufe, bie wohl bie Irform baritellt, zum gewölhn=

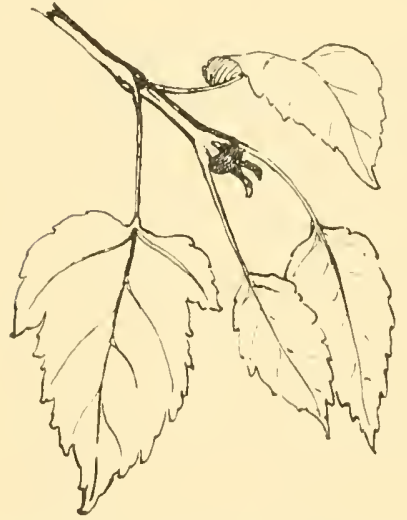

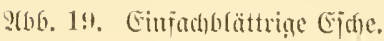

lichen fieberteiligen esjothen= blatt anjmeijen. Eine Iraner= form ber Ejobe, beren Seiten= äje fich im Bogen abmärts frümmen, wiro häuïig oaburch) verwertet, on $\tilde{\beta}$ joldde Şäıge= zweige burd) Bifropintg allf eine 2-3 m hohe Stamm= interlage gebradjt werben, jo bá̉ mit ber 3eit einte bid)te, madi) allen Seiten gleid)mäpig abwärts gewölbte Sdyirm= laube entitelt, für die ein meiteres รૃöhenmadystum ıa= türlich ausgejchlofien ift.

3on fremben Efichen treffen wir am eljeften bie and im

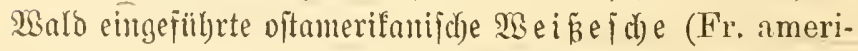
cína $T_{4}$ ), die burd) rojtbrante Sinoipen mo getbliche Iriebe fenntlich iit. Dod) finto bie Ejoben, von Denen zal)lreidge 2 rten bei uns eingefülyrt fint, im ganzen im Farfe nidgt fo bäufig, zumal igr weitiftreichendes 9̧urzel= werk immerlyin läitig falfeu fam.

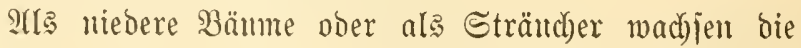

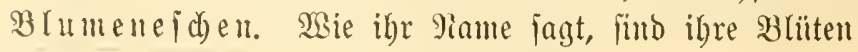


micht verfïmmert, fonderu als Selch) แแ⿰ $\mathfrak{B}$ ไumentrome vieripaltig ausge= bildet. So trïgt bie 3 lumteneidhe Südeuropas (Fr. órnus L.) meifje Blïten uno oreipaarig gefiederte Blätter. 2Ats ilgrer अinde fliep̈t beim 2 midutt ein jüfjer Saft, ber ast ber \&uft erljärtet, in Silditalien heute noch in bejonderen Anpflan= zungen gewoutuen und in ben $\mathfrak{A p o}=$ thefen als "Mllama" gefülyrt wirb.

Siebren wir wieber in ben auf= blïhenden Frïhlingagarten zuritdf, it ben uns bie goldene 33 lïtenprad)t ber Forfuthien gelocft laat! Da ftelyen auf ber jebt noch misfarbenen Bajenfläche gerabe, iteifwerzweigte Sträucher mit mächtig ichwellentbent Sirojpen. Into nicht lange mährt's, bis an alfen 3weigenden groß̈e, im

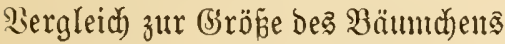
ganz ungeheuer großje Blïten her= vorbrechen. 9lit ihrer fteifen, etmas froptigen Iracht bieten bie meift meíben, auzen rot ïberbaudbten mehrteiligen Brïten einen ganz eigenartigen $\mathfrak{A} n b l i d$, um jo mehr, als von ben Blättern zunǚd fit nock) nichts zu jehent ift. Diefer 2 huf= fülligfeit wegen werben won ben

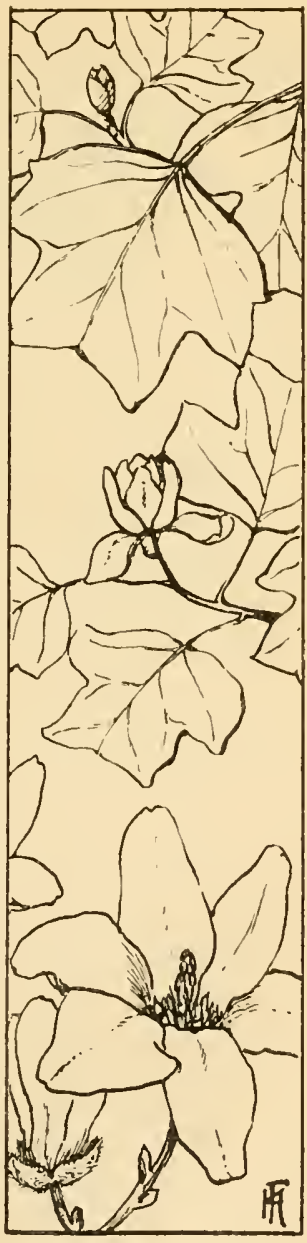

2(66. 20. Tntpenbaum mo Miannotic. 
Miaguolien (†. 2(bb. 20), dem nady dem franzöfifichen Foridber Magnol fint biefe \$flanzen benamt, zalltreiche Spielarten gezüld)tet, als beren Stammiorm hauptiäc)= (ich) zrei oftafiatifiche Irten, bie reimweipe, angenehm drftende Rilienuaguolie (Magnólia yulan Desf.) uto bie geruduloje rote Miagnolie (M. obováta Thbg.) gelten. - Die norbamerifanifchen Magnolien futo weniger beliebt, obgleich fie frofthärter fino, oa näı=

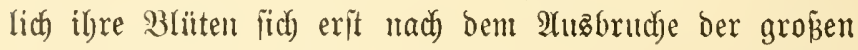
ovalen Blätter entfalten. Dagegen iit ibr vorzügliches 5̃olz fïr bie Miöbelinouftrie von einiger Bebentung. So=

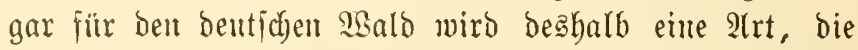
japatijuge jomagnolie (M. hypoléuca S.-Z.), netrer= bings empfolderl.

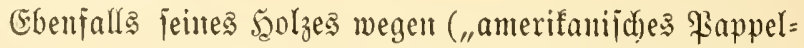
lol $z^{\prime \prime}$ ) von Bedeutung ift der ben Miagnolien nabe verwante

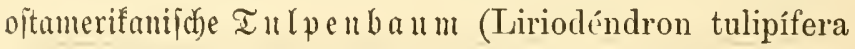
L., Ғ. 2(66. 20), der, wie bie mäc)tigen Stämmte mnjerer Farfanlagen beneifen, icton frith zu 1 mb gefoumen ift. Die tulpentälnlichen, grünlichrotgelben (silodenblüten treten

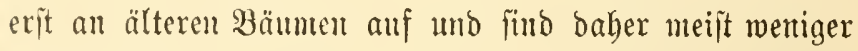
befaunt als die auffallento geformten Blätter. Dieje Blätter verdienen nach zwei Miditutgen bejondere Beachtutg, eimmal weil fid) bei innen bie Entwidflung ans ber überans zmedf=

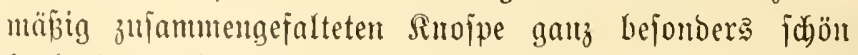
beobachten läß̈t uno zmeitens weil fich in den Iroerwinfeln ihrer Ilnterjeite fleime 5̧ohlräume in ber $\mathfrak{A}$ rt ber von

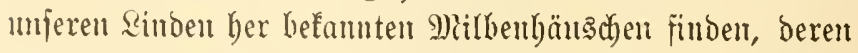

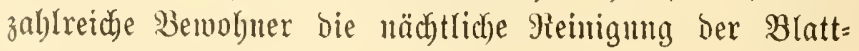
fläche bejorgen. 


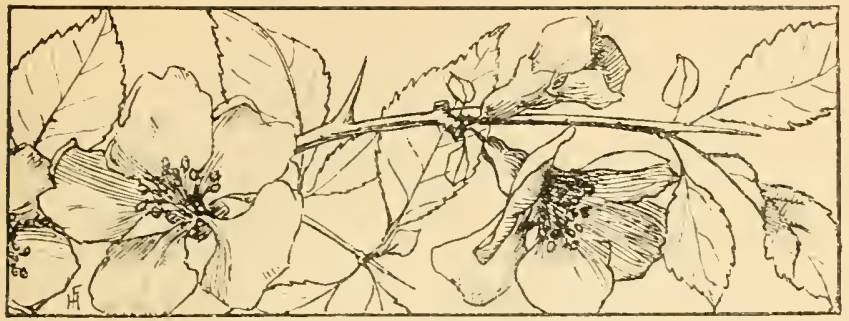

2(t6. 21. Japanifat) Edheinautte.

Dod) wir finto nod im eriten frübjalyr. 2trs nieorigen

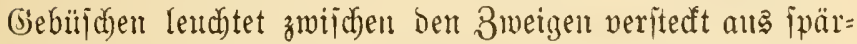
lichen Grïn brementes Sadyrot. Der Särtner bezeichnet

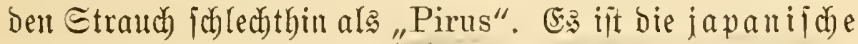
S (h) e in u u i t te (Chaenoméles japónica Ldl., ¡. 2th6. 21), bie, wie ja ber Rame jagt, in bie Bermanotidaft ber Dntte unto bamit audd) ber Birne (Pirus) gehört. Die Blüten jtehen, 3u id)wachen Dolden vereint, an ben häufig bebornten Zmeigen. (Grop̉e Piebenblätter begleiten bie länglichen, feingejägten Blätter. Andere Ifrten blülen blärrot oder memtigfarbeur.

Uno bantit fund wir mitten in ber groß̧en famtile ber apfelbrütigen Dbjtbäume (Rernobit) unb igrer Sermanden, ber Rirjdblütler (Stemobjt). l̈berall in ben wärmeren Teilen Dentidylanos gebören Pifirifid) (Prúnus pérsica S.-Z.) und Atprifoje (Pr. armeníaca L.) ju ben

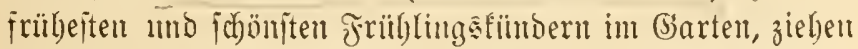

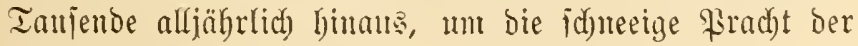

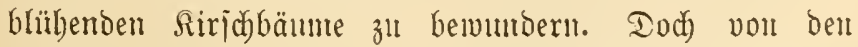

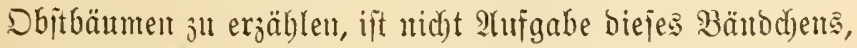
nur joldue 2rten, bie lebiglidi) als Bierbanm in Betrad)t foumten, haben wir zut jodjlbem. 


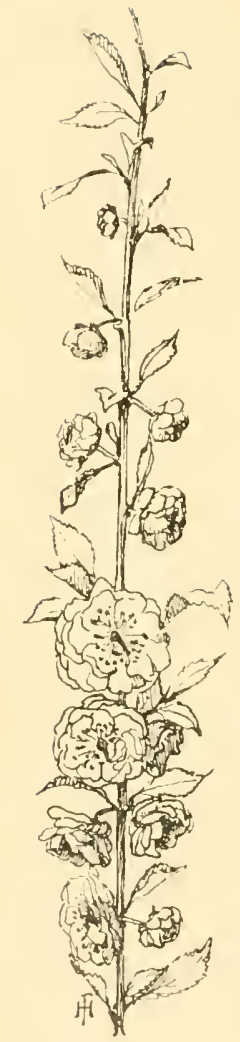

2669.22.

Mimostaprifnje

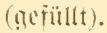

Da if eine ber entzücfentiten ber breilappige fifirfid) (Pr. tríloba Ldl., j. 2hk6. 22) ans Eljuta, ber aud als Mandelaprifoje ober Möżchemmand befanut ift. In id lanfen, faft muer= zmeigten Mnten iteljen bidhtgereilgt bie zartrofafarbenten Blïten, meift gefïllt mo baljer flemen Möschen vergleichbar. Giegen Entoe Der Blütezeit erit fonmmen an den janmethaarigen 3weigen bie längliçen, gejägten Blätter zum Borichein, beren Spibe bäufig breiteilig gelappt ift. $2(\mathfrak{b}$

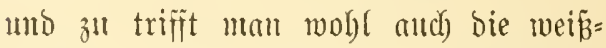
bliibende echte Mandel (Amýgdalus commúnis L.) an, beren Früdte aber un in bejonders gejdurtbten sayen reifen. Şäntriger ijt bie von llngarn bis હibirien

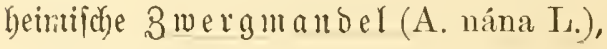
ein fleinter Stranch) mit (antzettlid)en, fein= gejügten $\mathfrak{B}$ lättern umb bicht an ben vor= jährigen Bmeigen gebrängten Eleinen Moja= blïten, benten zuliebe fie vielfach gepflanzt wirb.

Son ben Ririchen geben unfere beiden gemöhulichen strten, Sitbliridge mo Sanerfirid)e (Prúmus ávium L. Imb cérasus L.), ïber mo ïber mit meíben,

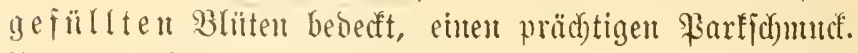
llnter "Jïllung" der Blüte, vou ber fichon mebrfach bie Hebe war, veritebt man befumutlidy eime fiunjtich berm= 


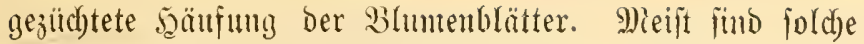
Blïten zur Unfrudbtbarfeit verurteilt, da jowohl Stanb= fäben als Stempel bein hörditen Brabe ber "Tüllung" vollftündig bie Form von Blumenblättern amnebnen. SBie aber biefe leb̧teren nicht jelten "vergrïnen", ๖. h. bas Tusjeben eines sanbblattes vieber amebuten, auts bem

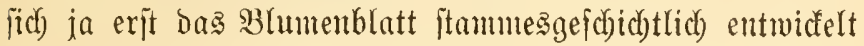
hat, jo trifft man ebenjo nicht jelten, baj jümtliche Teile einer Slitte fich zu Raubblättern ausmacbjen, ober baß̧ bies mur bie imeren 3 lïtenteile, Stempel und Stanbfäden, tur, jo baj inmitten der slïte ein oder melyrere $2 a u b=$ blättchen fich anbbilden. Gerabe biejer lebste Fall ift bei

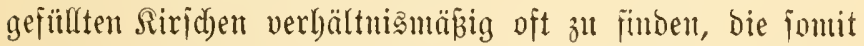
ein bequemes, leid)t zu erlangenbes $2(n j$ d)anungsmaterial fïr bie Entwicklungareile (Mietamorphoje) des Rflanzen= blattes darbieten.

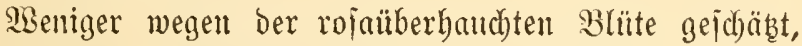
als ibres saubwerfes halber bänfig gepflauzt wiro eine rotblättrige Form der Sirfdypflanme (Pr. cerasífera Ehrh. f. Pissárdi), Derent \&aub burd) reichliche (Ein= lagerung won Anthocyan älnlich ben befannten 3 lutbuddent (i. S. 80) prïchtig braunrot gefürht ift. Es ift bies bie= jelbe (srid)einung, die im frübjabre bei vielen \$iflanzen bie jungen Slättçen und Iriebe rötet ıno bantit ibnen

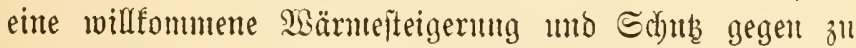

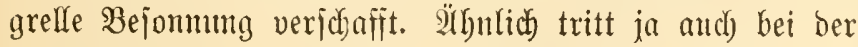
Zaubverfärbung im Scerbite vielfach) eine ßötıng ber Blätter ober menigitens ber Blattĩtiele ein. 2Bo un bieje Jriibjahrşötumtg bei einjeltun Bäumen bejonbers intenfio anftritt und melyr ober weniger ben ganzen Sommer ïber 


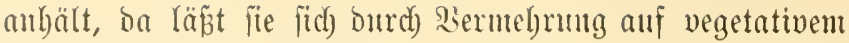
Nege (Firopfen, atblaftieren) erbalten, es ift fogar in

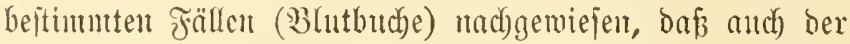
Samen eintes rotblättrigen Baumes zu eintem grop̉en Teile

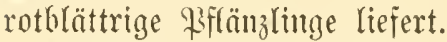

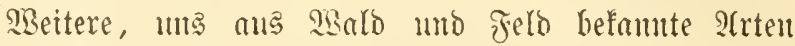
treffen wir in Steinucichjel (Pr. máhaleb L.) unto
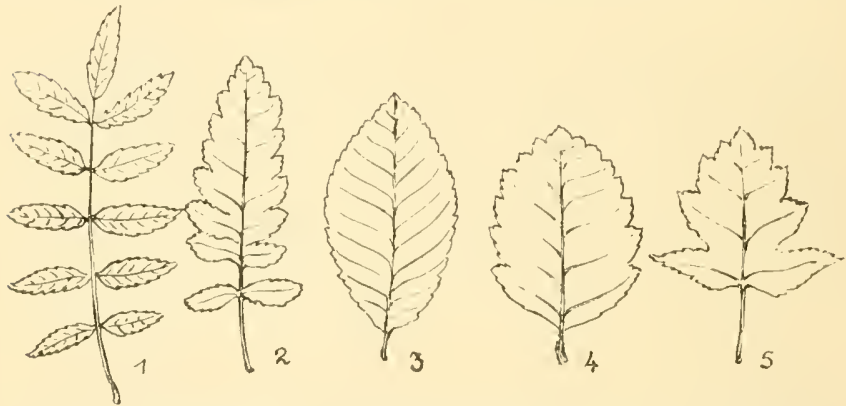

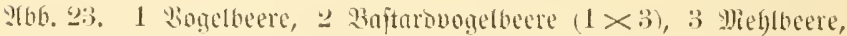

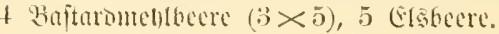

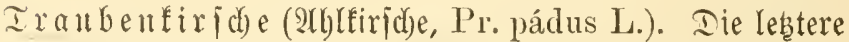
wird neuerbings vielfach burd) ibre virginijche Edjweiter, die ipätblïbende Traubenfiride (Pr. serótina Ehrh.), exjebt, bie fich Durch anfrechte Blütentranben und lorbeerälutliche glänzento Belaubung mtericheidet.

Selyren wir un wieber zum Rernobjt zuriace, fo bietet auch biejes uns anker ber jodjon erwäbnten Sdjein= quitte noch mandien Schnudbaum. SBieder ift es Dit= afien, bent wir in feinemt $\mathfrak{B}$ lütenapfel (Málus floribúnda Sieb.) unto befifen Berwantoten einige ber ichöntent 


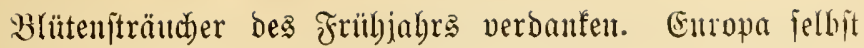

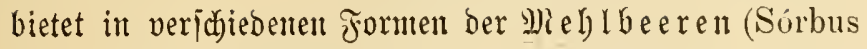
ária Crantz uno suécica Dippel), vor allent aber in beren Baftarobiloungen mit Sogel= und Ersbeere mand)

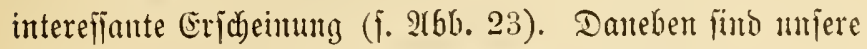

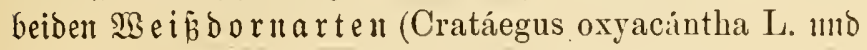
monógyna Jacq.) iun $\mathfrak{P a r f}$ uto Giartent gern gejehen, fowohl in ber milben Form, zแ Seecten 1110 Einfrieoigungen zugejduttten, als bejonbers mit gefüllten roten 3lïten als ,̧ochftamut gezogen. Diejer rotblübende TBei $\bar{B}=$ born wirb luäufig als "giot= born" bezeichnet. Reider haben

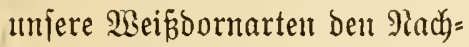

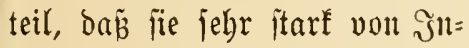
jeftenjwäblingen befallen weroen, jo baś fie, wenn Shitbäume iu ber liähe finto, leicht biejen ge= fägrlich werdent, zuntal ment es

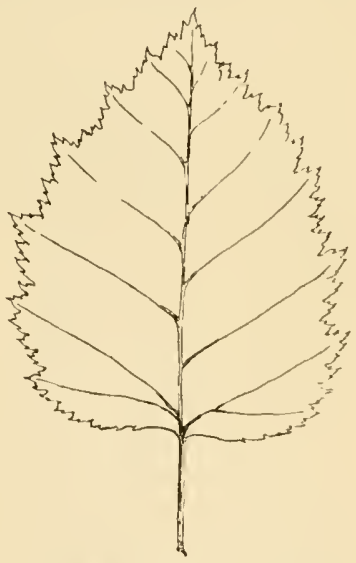

2(66. 24. Escharlad)pruidftiger Iseifion.m. an injeftenfrefienden $20 ̈ g e l n$ fehlt.

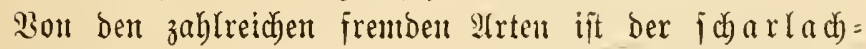
früdytige Meíboorn (Cr. coccínea L.) mit grofen, runolich) gejägten $\mathfrak{B l a ̈ t t e r n ~ ( j . ~ 2 ( b 6 . ~ 2 4 ) ~ j u ~ n e m u e n . ~}$

Mit biefem ftammen ans Porbanterifa einige Mrten ber Feljenbirne (Arónia), bie mit afiatijuden Steiu= mijpelı (Cotoneáster) zแjammen im nieberen Bujchmerf ober zur Befleidung von Felagruppen viel verwentoet wer= ben. Die lebteren find im Serbfite mit igren forallenroten 
Früchten, die mit ben B̧ättern an Dichte แnd Farhe wett= eifern, ein präbtiger 2 Anblick.

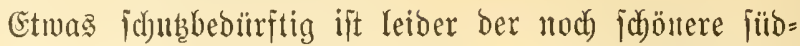
eutropäifde Feuerdorı (Pyracántha coccínea Roem.), befien Frudbtbitichel bis tief in den sBinter hinein wie bremendes Fenter ans immergrünem Ranthe lent)ten. Diejes

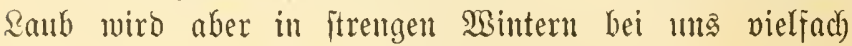
abgeworfen, eit Beifpiel dafïr, baß̄ aud inmmergrïne Ströudber unter bem 3rwange der \$erbältniffe zum \&aub= abivurf liberzatgelyen vermögen!

Bon ben Birnblütlem ijt mur ein Eleiner Schritt zu ben Mojenblittleru. Da find vor allem bie Rojen jelbit, bie als Bierpflanzen trots allem Wechjel in Befchmat und Miobe and hente noch ben eriten giang einnebmen.

Bsegen 6000 Sorten der "Jormurojen" find beute im 5zandel, entitanden aus Sireuzungen ber verichiebeniten Arten unD gärtnerijcher Büd)tutg. Die Bermebrung biejer Sorten ift ferbftueritänolich unr auf vegetativem siege möglich, ourch 2tbtremen eines Teiles der "edeln" Sitlanze und l̈bertragung beșjelben auf eine lebensafräftige lunter= lage. Sigie befaunt, geiobieht bies fajt burchweg burd)

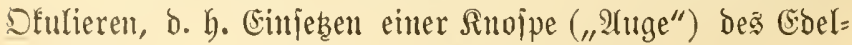

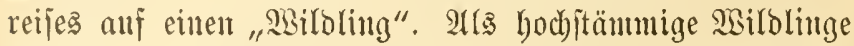
bienen in erfter Rinie die ein= ober zweijäl)rigen Stämmdhen

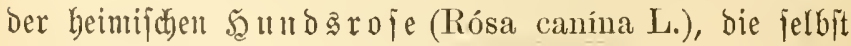
aber zur Büd)tung vou (Edelforten nicht perwendet wird. Snniemeit babei ïberhanpt in ben älteren Sorten heimijche Irten mitgenirfft Gaben, läß̈t fich in ben wenigiten Fällen einmanofrei feftitellen. Sicher ift, baj bie woblriechenbe (5jiigroje (R. gállica L.), bie mit ber jitboftenropäijchen 


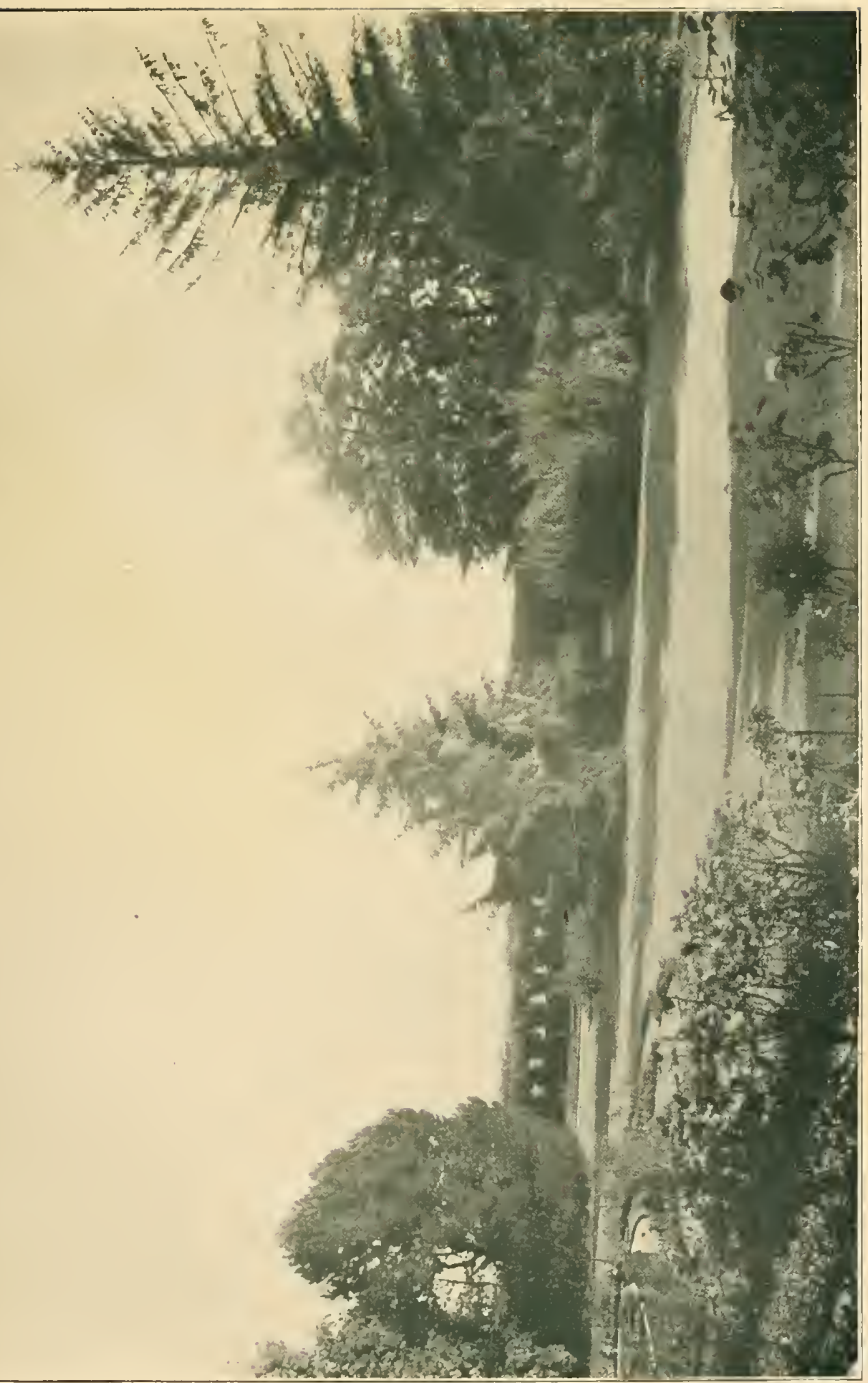

:

苍

苍

苍

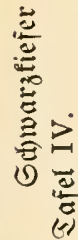


Eentifolie (R. centifólia L.) jegr nabe verwantot ift,

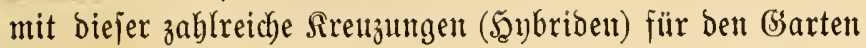
geliefert hat, alz beren befaumtefte bie vielen Centifolien= forten uno bie Moosirojen zu nemten fimb.

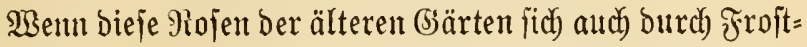

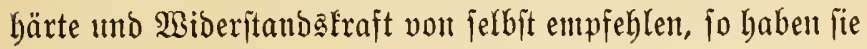
boch ben Mact)teil, in bet meiften Sorten utur einmal im Jahre zu blüben. Dem wurbe abgeloolfen, als bie "Remtontant"= Mojen in Mode famen, bie auf verifbiebene oitafiatifoche

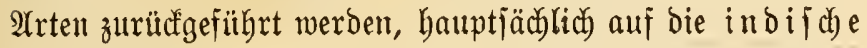
gioje (R. índica L.), zu ber u. a. bie beliebten Teerojen geyören. Şanto in F̧ant bamit ging aber eine ergöhte Empfindlidjeit biejer Sorten, bie beshalb ande) ohne forg=

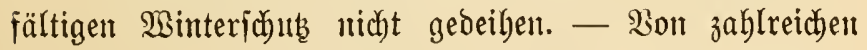
anberen Bruppen ber Gartenrojen ift Entitegung unt $2(b=$ ftamunung völlig it Dumfel gebüllt. Reuerbing wa wiro ifrer Frofthärte megen bie dhinefifide $\Re$ unzelrofe (R. rugósa Thbg.) zur Büchtung empfohlen, ber wir auch) iffout mannigfache fortblïhende Sorten nerbanfent.

Bum Unterfichiede von ben "Formrojen" bezeiduntet ber

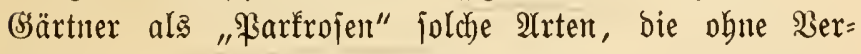

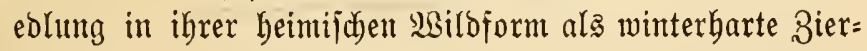
iträucther für $\mathfrak{P a r f a n l a g e n ~ g e e i g n t e t ~ f i n t o . ~ D a ~ f i n t e n ~ b e n t u ~}$ mehrere unjerer beutichen $\mathfrak{A r t e n}$, bie aus bem Biergarten verbannt finto, ibren \$ilaţ. Bon Fremolingen ift bie ebent=

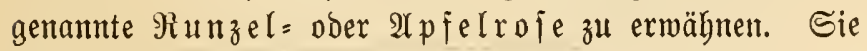

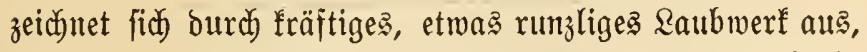
von bem fïh) bie grosen, dunfelpurpurnen Blüten ebenjo prächtig abkeben wie bie hodbroten, rumblidy=platten Früudte

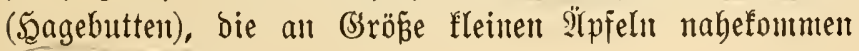




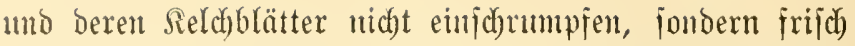
unto grün fteben bleiben. Die aus bem Drient foumente gelbe 9 o o e (R. lútea Mill.), deren bottergelhe 3 litten

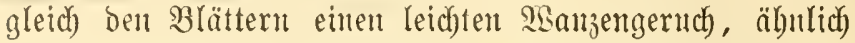
wie bie ichwarze Johanmisbeere, verbreiten, befibt in igrer Blittenfülle hervorragende Fernwirkmg. Banz älulich,

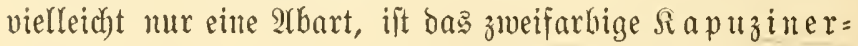
rös d)en (R. bícolor Jacq.), deflen Sronblätter außen gelb, inten aber fdyarlachrot glühen. Shud an fletternoen

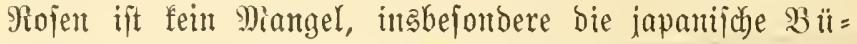
id) elrofe (R. multiflóra Thbg.) f(c)mitct mit ibren py)= ramibeñ̈b̈migen, reichblittigen Rijpen in vielen Farben

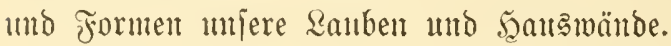

(s)leid) den Rojen jün in unjerer heimifothen Prflanzen= welt bie ifuen nake verwanden Srombeeren eime weit= verzweigte, bas Rrenj der Botanifer bildente Sippe. Bon fremben Arten fieht man aber mur menige hei uns ver= breitet, ant ehejten noch die fanabijac Stimbeere (Rúbus odorátus L., f. 24b6. 25). Shre groß̉en roten, in Dolbentranben gebäuften Blitten mit leichten $\mathfrak{B o b l =}$ geruch) uto ihre mit klebrigen Borị̂tent uno grofenen, mehr= lappigen Blättern hejebten 3weige machent fie bem Sienling nicht ohne weiteres als Simbeere erfembar, wohl aber bie flachen, rötrichen Früchte, bie aber keinen befontoren (s)mús gewähren.

Ilm jo reicher ift mun eine weitere (Ssutppe im Bier= garten verbreitet, bie mierer Sgeimat in Stranchform fait ganj fremb ift, die Spierjträudber (Spiräen). (Segen 50 Arten uto zahlreiche Sreuzungen biejer anjprnd)slojen Sträuther finden bei 1 m Serbreitung, obgleich fie fidc 


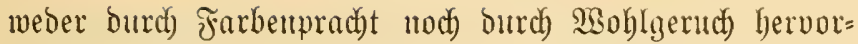

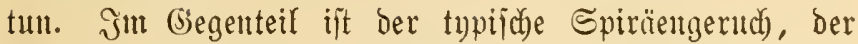
bei eiuzeluen $\mathfrak{A}$ rteu bejoubers ftarf lervortritt, burchaus

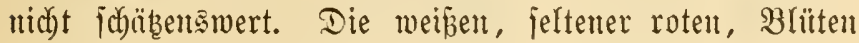

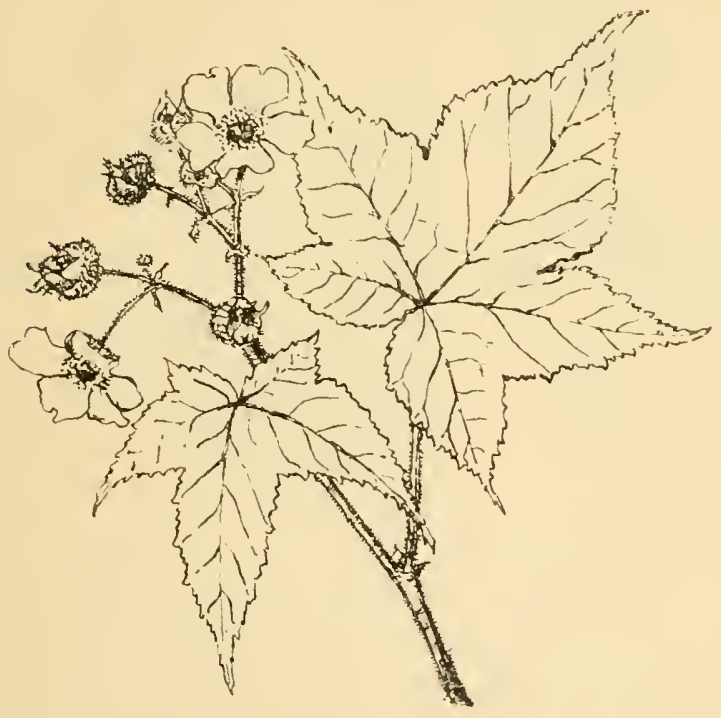

2(66. 25. Simabijd) nimbere.

Gäufen fidt) zu Dolden, Siifpent oder Tramben, bie oft jebr anjelynliche B̧ätenitünde bilden. Die 3 lätter fint hei Den eigentlichen Spiräen (ber (Şattung Spiráea) einfach), meift

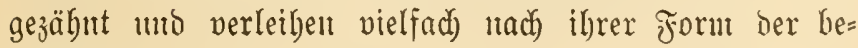
treffenden art den Miamen. So dem weidentälte= rigen Spieritraud) (Spiráea salicifólia L.), ber in

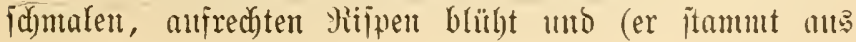




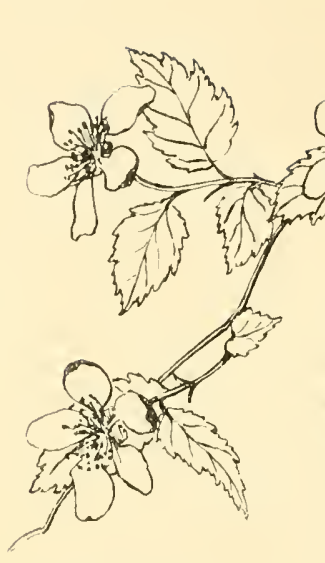

บ(b). 26. janamijac siemie.

Sítermopa) viel= fad) bei uns ver= uilbert ift. Einte ber zierlichjten Arten foummt aud biesumal aus Sapan, näulićd) ber pfla a men= blätrige Spieritraud) (Sp. promifólia S.-Z.), defien meiijt ge= füllte weiß̧e 3 liüten gleich wiızigest Miniaturröschen jofon in $\mathfrak{A p r i l}$ in ichwanten, locteren Dolden an ben faum Gelaubten 3meigen pendeln. Fojenrote şlïtchen in anfrectenter, flachen Dolden und lanzettliche 3 lätter trägt Der \&rad)tipieritraud) ( $\mathrm{Sp}$. callósa Thbg. = japónica L. fil.), beffen Şeimat eben= Falls Ditaîien ift. Mns Morbanterifa fommt ber hain= budenblättrige, ans Sibiren ber gamanderblät= trige Spieritrauch) (Sp. carpinifólia Willd. und chamaedryfólia L.); beibe triffit man uidbt felten audb) verwildert außzerbalb der Gärten an.

Durch gefiederte Slätter unterict)eiden fich die Fieber ipieren, deren bälfigite, bie vogelbeerblättrige Fieberipiere (Sorbária sorbifólia A. Br.) aıs Dit= afien, mit ibren bis $30 \mathrm{~cm}$ langen $\mathfrak{B l i t t e n r i f p e n ~ b e j o n b e r s ~}$ furz vor dem 2luf́litlyen ein herworragender (Sarten= ichnuted ift.

Dod) bamit ift bie Babl ber rojenblütigen Sträudber nod) lange nidjt erjö̈pft, erwälynen fömen wir aber nur 
nod) einen, bie viel verbreitete japanifd)e Rerrie (Kérria japónica D.C., f. 2(bb. 26). Diejer Durch grüne, ruten= förmige 3meige gefermzeichnete Strauch trägt eilanjettliche, ge= jägte Blätter unto ifit jeitter gold= gelben, häurig gefüllten Blüten wegen, bie vour Früljiahre bis Serbit fortblïben, felyr gejchäbt. Da die Blïte nach Form und Farbe jebr an den befaunten Ђahnenjü (Ranunculus) erimert, wird bie Serrie aud gianut fel= fitraud genamut; baneben ijt fite wohl aud als ,japanifde Sconig= rofe" iu 5̧andel; vor 100 Эalyrell etwa hat fie ber englijche (Särtmer Serr nach Europa gebracht.

Die ebengenannten \$abnenfus= genäcbje (अanunfulaceen) jelbit itellen mur eine Straudbattumg für unjere Bärten, uno zwar einen Echlingitraudf), die 23 ald rebe (Clématis). Einfact) unb bejcheiden futb bie gritngelben Slïten ber heimijchen $\mathfrak{A r t}$ (Cl. vitálba L.), bunt und farbenpräch)tig aber blüht bas 5eer ber meift afiatijchent un

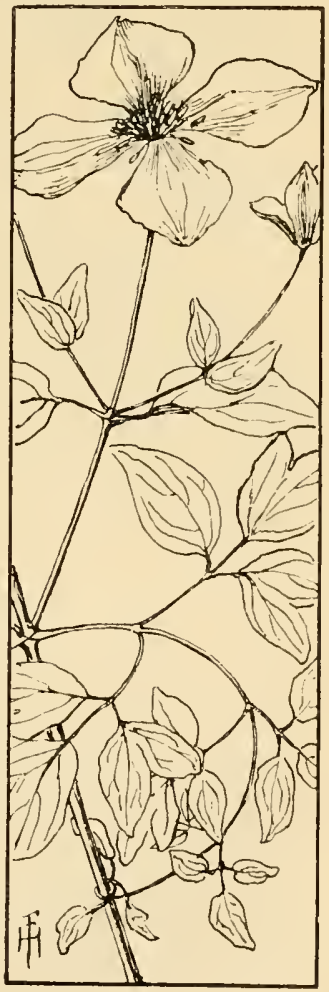

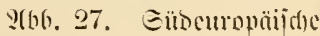
stativere. amerifanifben $\mathfrak{A}$ rten, bie als sianen Miauern uno sauben ïberipinten und bis in bie Rrone ber Bäunte emporflimmen, feitgehalten von den rantenten 

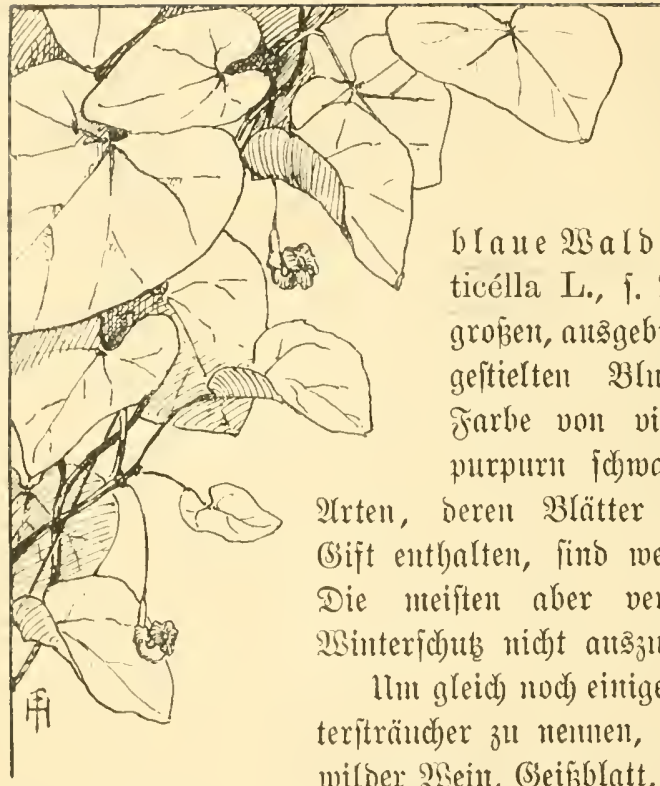

Slattitielen.

Eine ber häufigften

ift bie jüb= eltropäijche blaue 9 ald rebe (Cl. viticélla L., j. 2(b6. 27) mit groß̉en, ausgebreiteten, lang= gefitielten Bhmen, deren Farbe von violettblat bis purpurn fdrwante. Indere Irten, beren Blätter eiu icharfes (sift entlgalten, finto weniger luäufig. Die meiften aber vermögen olyte

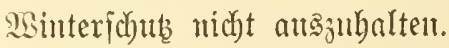

llm gleid) noch eintige weitere filet= teriträncher zu nemmen, jo finto Efell, wilber sein, Gseifblatt, Rfeifenwinde

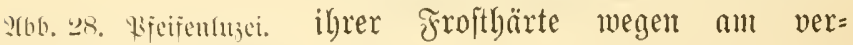
breitetiten. Sejonbers aufällig ift die noromerifanifue sifeifenwinde (Prfeifentuzei, Ari-

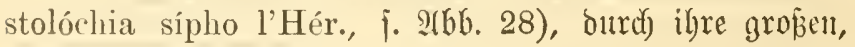
runben, jchattenfipendenden Slätter jowohl wie ourd) igre

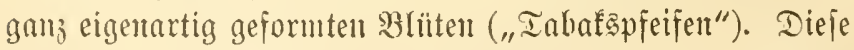
Blüte ift bei alf ibrer lluidbeinbarfeit eine ber intereffan= tejten Formen, bie mir ïberbant femen, mb zwar burd) ibre eigenartige 3eftäubung. Der oft gefdilloerte Sorgang iptelt fidch int folgenter SGeije ab: Angezogen von bem Ifasgerud) ber 3lüte, Dringen Eleine Fliegen burd) den

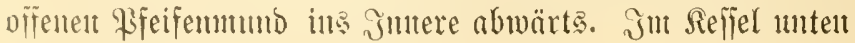


angefoumen, werden fie burdh belle, burd)lendy tende Stellen

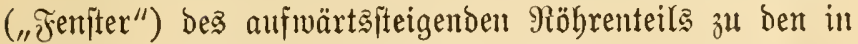

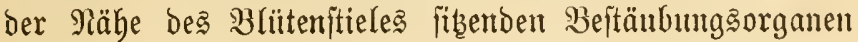
getodt. SWenn fie mun hier einfach fich unfreiwillig mit ŞCütenftaub bepubern und biefen bein Befuche ber nächjten Błüte an beren Stempel abftreifen mitrben, jo wïrbe bieje Befruddung fich ja von ber allgemein geïbten $\mathfrak{A}$ rt uridjt weiter unteridbeiben. Sm vorliegenden fall aber blüben bie Staubfäben, un Selbjtbeftäuburg zu verbindern, erit anf, went bie bicht neben ihnen ftehenden meiblichen $\mathfrak{B}$ (üten= teife befruddet und verwelft fund. \$at nut aber eine Fliege mit bem von einer älteren, bereits int männlichen Stabium ftehenden 3 lüte nitgebrad)ten $\mathfrak{P}_{0}$ llen bie $\mathfrak{B} e=$

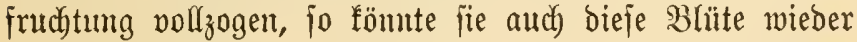
verlafien, wenn ifr nicht ber Bau ber engen cingangs: röhre bies jollechterdings ummïglich machte. Da bieje während ber \$ollblüte fenfrecht in bie Şähe ftebt und glatte, papillöje şändo befitht, fo fam die Fliege veber fliegend noch fletterno die Falle verlaffen, fie mur warten, bis anch die Staubfüben "reif" werben; erft bann finbet fie, vollbelaben wieber mit nettem Blütenftaub, ben şeg

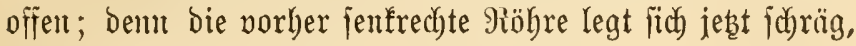
jo dấ fie bequem paffiert werden kann.

Die \$feifenminde ift eine richtige Sinbe, infofern fie fich mit Dem ganzen Sproj um ihre Stüke aufwärtz rninbet, an glatten SBänden verntag fie aljo nidbt zu baften. Der Ef fu (Hédera hélix I.) bagegen veriteht bies fraft feiner bejonderen Saftwurzelu ganz anggezeichnet. Da bieje aber fich nur oherflächlich) ber Interlage anpreffen, nidgt in fie einbringen, fo ift bie vielgelyegte Mieimming, 
burch Den Efen fömnten gejunde Mauern pber Mände zer= ftört werben, burchaus unridgtig, eine Efendede vermag jogar gerabezu bie unter igr liegenden Mauterteile vor

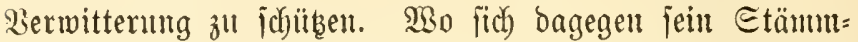
chen jelbjt burdh eime Fuge brängt, ba vermag er, wie alle Şolzpflanzen, im saufe ber Beit burd) fein umwiberiteh)= rideses Didenwad)stum simnder ber Sebefraft zu voll= bringen.

Bu nod böherer Fäbigfeit in Rlettern hat es ber all= befamte "wilde Mein" gebracht, bie norbamerifanifdce Эung ferurebe (Ampelópsis quinquefólia Mchx., fiełe

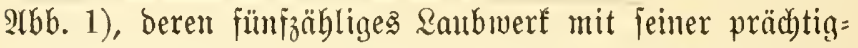
roten Serbitfärbung in unferer heinifiden \$flamjenwelt nidht feitresgleidyen hat. Der wilbe Bein hat zu feiner Befejti= gung bejondere Seitenzweige zu vollfommenen, verholzenden Ranfen auggebildet, beren $\mathfrak{H}$ ifgabe barin bejteht, geeignete

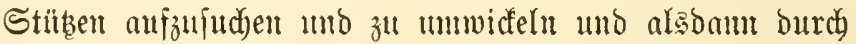
forfzieherartige Einrollung ben Şauptzweig nadyzuzieben. Berntag aber mun eine junge sfflanze, etwa an eintem glatten Baumitamme, feine Stïbsumute zu finden, jo fanm eine ganz bejondere 2 (npajing baourch eintreten, dá̧ bie Taftipiben der Gianfen fid) zu Saugidjeiben verbreitern, bie an ber glatteiten Ilnterlage fich auzuprefjen uno zu haften vermögen. Soldze Scafticheiben werbent an mandhent

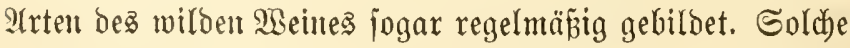

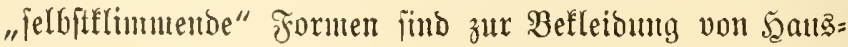
wänden und Multern ganz bejoubers geeigutet, beælyalb findet bie ans Ditafien fommento oreifpitige šmug= ferurebe (A. tricuspidáta $S .-Z$. = Vítis incónstans Miq., eine 2lbart ift A. Veitchi Voss.) mit herzförmig= 


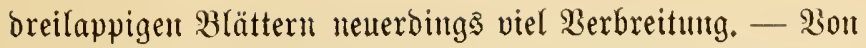
ben Meinreben jelbit wird, ba bieje nteift guten Winter=

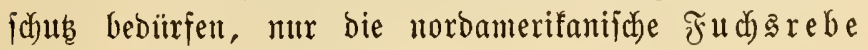

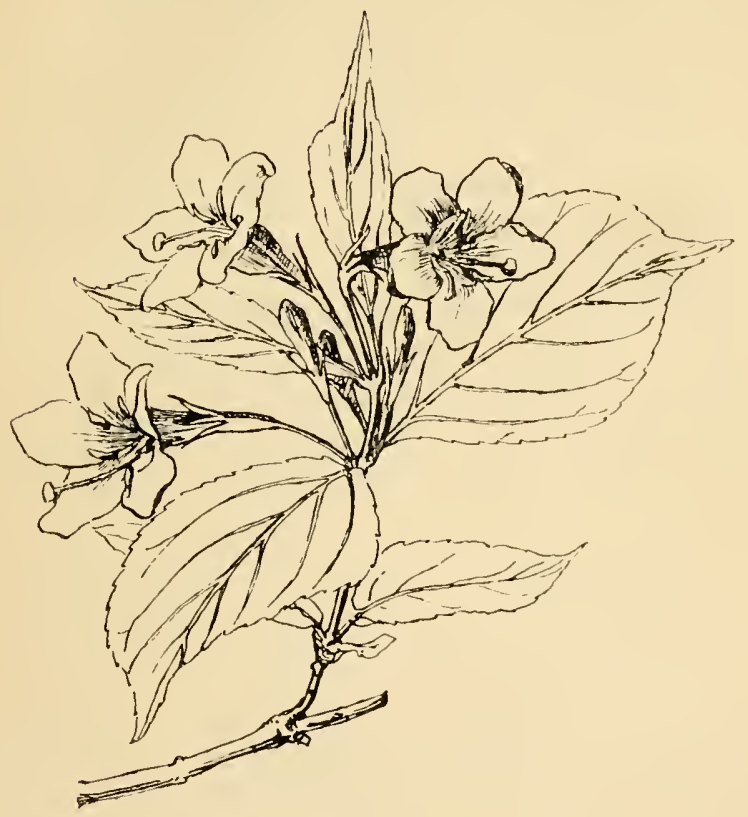

266. 29. Mietuelie.

(Vítis labrúsca L.) häufiger gezogen, bie fid vom ed)ten 2Beinitocte hejonders burd) bie grau= ober roftfilzige Blatt= unterjeite und bie in größ̈erer $3 \mathfrak{a b l}$ ïbereinanderitehenden Ranfen unterjobeiben läbt.

Siddt weniger verbreitet find bie (sieifblattarten, vor alfem bas in ber 2rbendoünmerung herrlich buftenbe 


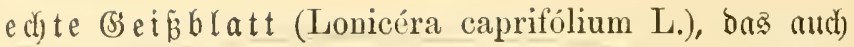
Jelängerjelieber uno Jerict)oroje genannt wiro. Seine langröbrigen, Iippigen $\mathfrak{B}$ lüten ftehen quirlartig zu je fechjent vereinigt jwijoben ben parag verwachjenen Blättern; bie Irt fomut aus Sitbeuropa und äguelt ftarf unjerem beimijchen wilben (beifblatt (L. periclýmenum L.), deffen $\mathfrak{B l a ̈ t t e r p a a r e ~ a b e r ~ i t e t ̧ ~ g e t r e n u t ~ b l e i b e n . ~ F r a ̈ d ) t i g ~}$ nimmt fick aud) bas norbamerifanifoce immergrüne (5) eibblatt (L. sempervírens L.) mit feinen langen, j(d)arfad)roten 3 lüten ans.

Befanutlid) werben bie nid)t windentoen Geipblattarten

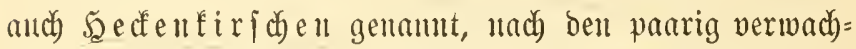

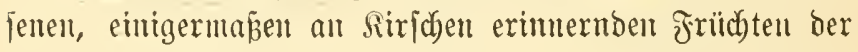
Geimijchen 2 trten. Jieben biefen ipielt in unjeren $\mathfrak{A}$ ulagen Jur eite frembe $\mathfrak{A r t}$ eitte gröpere Folle, bie allerbiutg

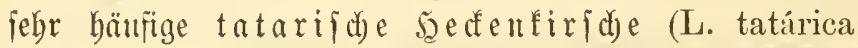
L.). Sie ähnelt in ber Irad)t am meijten unjerer ge=

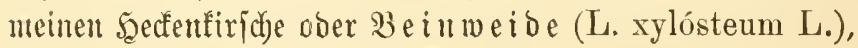
trägt aber rojenrote Slitten.

Den Seectentirfachen vermanot find bie von Mai bis 2hugujt herrfich brübention siseigefien, deren rotblïbentoe Formen meift anf bie nurbdjinefifde şeigelie (Diervíllea flórida S.-Z., ․ 9(bb. 29) zurüt(fuführen jün. Die nach) bem beutid)en Botantifer SBeigel benaunten Strüudber rhiiben in Seldyform und jenden einen zarten, jebr an= genebuen Duft aแs; eine gelbblühende $\mathfrak{A}$ th (D. lonicéra

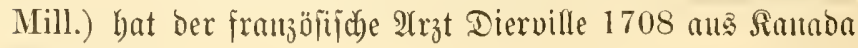
mitgebrad)t.

(sbentort ift anth) bie jebent Rinto befannte $S_{\text {d) }}$ nee = beere (Symphoricárpus racemósus Mchx, f. 9thb. 30) 


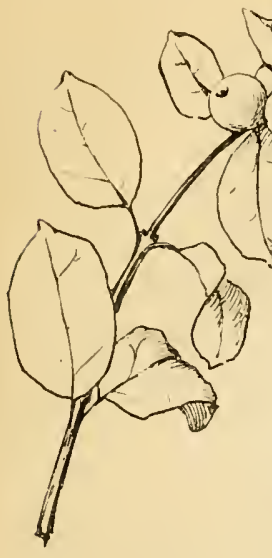

?(66. 30, Ed) Enee= beere.

Thap J Sanje, bie aber nicht um ibrer unjoheinbaren rötlidjen Blïten, fondern ber gropen, weiñen Beeren willen im Garten gevflanzt wiro. Dieje rumben Beeren bleiben in bichten finäıtrn ben gauzen S3inter über an 3meige; ba bie eiförnignen, an ben Raubtrieben häuftg fiederlappigen Blätter viel Schatten ertragen, ift ber Petersiftrauch), wie er anch beifist, zur

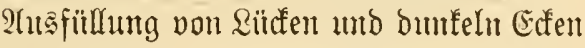
felyr geeigntet; zudem gebeigt er fo leid)t,

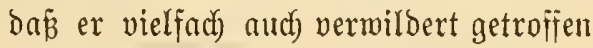
wiro.

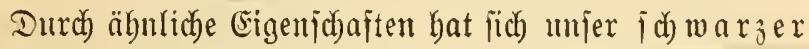
Saolunder (Sambúcus nígra L.) ein anredyt anf dent (sarten ermorben, bejonders futo jeine reid)lichen Beeren eime felgr mertwolle Siahrumg der ßöget. Seine Blätter neigen jehr zur Billoung von Spielarten, o. h. zur jelb= ftäutigen ï(nberung vou Form ober Farbe; Sträudtyer mit jerjoblibtem (boppeltgefiedertem) ober bellflecfigem saube

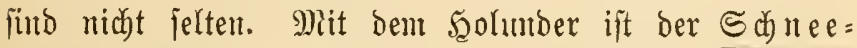
ball (Vibúrnum ópulus L.) in ben Barten gewandert. Dort fübrt er blab̧blittige, fdneeballübuliche Dolden, beren

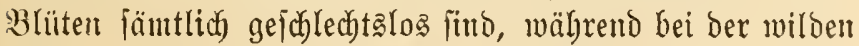
Form mur ber äuberite Sirauz der Dolde aus foldhen Schanbliiten bejteht, die ben imeren fleinten 3 witterblïten als Sodfapparat bienten. Itm Etiele ber mehrlappigen Slätter fỉzen, wie beim Rirjdbbanme, braume, meftar= 
abjondernoe Driffen, die vou Imeijen aufgejucht werben, Deren Bebentung für bie Pfflanze aber noch nicht einmanto= frei feitgejtellt meroen fonnte.

Diejelbe Seryrößerung ber Blüten auf Siojten ber Fruththarket, wie beim Ednneeball, zeigen bie vielent als

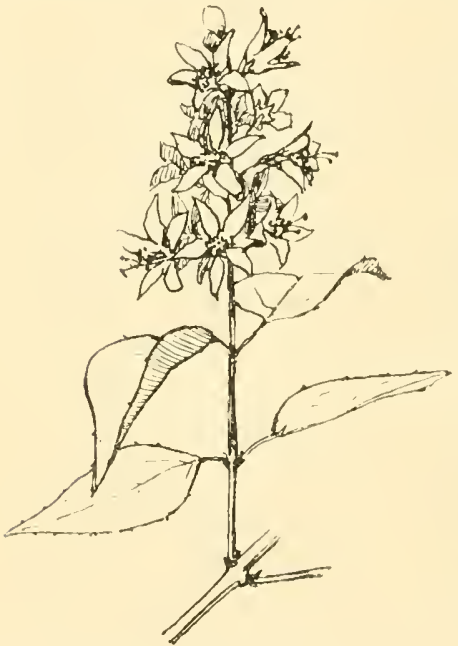

966. 31. Geferbte Denticic. "Wortenjien" gezogenen Gartenformen bez japa= nijchen sigajeritraudes (Hydrangéa horténsis W.), bie aber als nicht witterbart bier nicht int Betrad)t fommen. SBinter= bart ift aber eine gröbere, ebenfalls oftafiatijche $\mathfrak{A}$ rt, ber in weifien, pyrantiden= förmigen Büjd)eln blühende rifpige \$sajferitraud) (H. paniculáta Sieb.), ber metuerdings in Miode ju fommen jocheint.

3ur gleid)en Sermant= j(d)aft züblen die \$reifent= ftrüucher, beren häufigite 2rat, ber woldriechende Preifen= it $r a u d$ ) (Philadélphus coronárius L.) anß affien, in

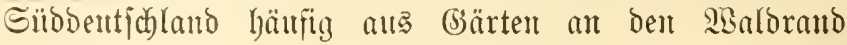

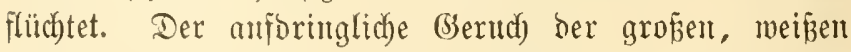
Blütenbiijchel äbnelt in ieiner Stärle eimer früher alb Iopfpflanze vielverbreiteten oftimbiichen sasmmart, die

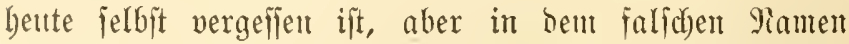

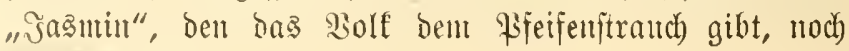


weiterlebt. Die Bezeichnung "Bifeifenftrauch" jelbjt bezielyt fich) auf bie joblanfen, gerabes Schöp̈linge, bie burch ent= fermung des breiten Marts leidat in PFeifenröhren ver=

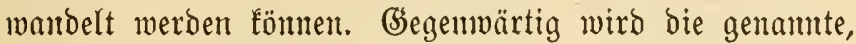
jeit bem 16. Jahrhmoert bei un eingefübrte 2 rt von

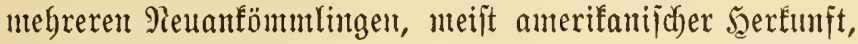
jo fehr verorängt, da $\mathfrak{\beta}$ fie iut (Sarten bald zu ben Selten= heiten gehören miro.

(Santz ähnliche Blüten, nur etwas fleimer und gerud = Ios, find der Schmulf der Deutien. Bon biejen oft= afiatifchen Sträuchern, die bell Siamen bes Anfterdamer Ratsherrn Deub tragen, eine fdhutgareijen, zählen mebrere, butrd Rrenzung miteinander verbundene 2rrten und bartenformen, meijt mit gefülltent Błlüten, zแ ben dantharjten Sonmerblïhern unjerer Gärten. (bejonders die ge ferbte Deubie, Déutzia crenáta S.-Z, 1. 216b. 31). Sthon im Mai offut bie zier riche Denbie (D. grácilis S.-Z.) igre aufrechten, weipen $\mathfrak{B l i t t e n t r a u b e n , ~}$ eit fleiner blumenreicher Straud) ntit eilanzettlicken, ge= jägten Blättern, ber auch alß Topfpflanze Berwendung finbet.

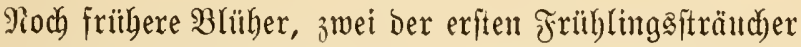
überhaupt, finden wir bei Den ber Deubie nabejtebenden Johannisbeeren. Injere heimijuen Arten jpielen, jo ge= ichäbst fie in Dbjtgarten futb, als Zierfträucher feine Rolle. Aber Siorbamerifa hat bie blutrote Johaunisbeere (Ríbes sanguíneum Pursh, f. 2lbb. 32) gejandt, deren tiefrote, furzgloctige slüten in bängenden vielblütigen Trauben jocton in April hervorbrecten, ebe fid bie ejeu= artig gelappten, weid)haarigen Blätter nody recht entfaltet 


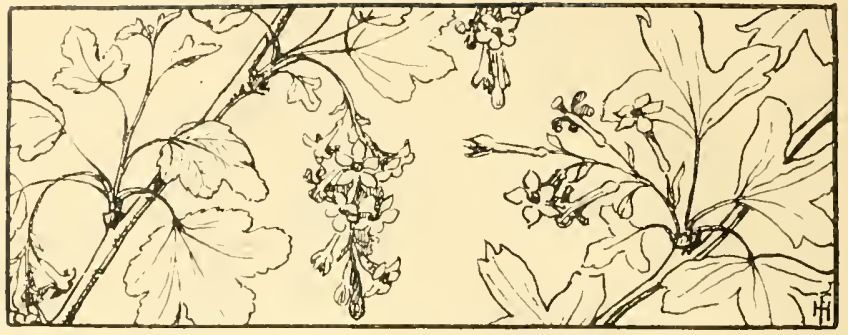

966, 32. Bhtrote un golinglbe jobmutishere.

baben. Sicht ganz jo reizooll bliibt bie andere gioro= anterifautertu, die goldgelbe Gohantizbeere (R. áureum Pursh, f. I(G6. 32), nänlich mit locferen, aufred)ten Büldhelu laugrölyriger gelber Blïten. SGre tiefgeteilten Blätter find glümzento und fabl, fie hat aber auch mate= rielles Snterefie für mIs, bent ihre Sträncher Yiefern bie Pfropfunterlage für bie bochftämmig gezogenten Stachel= uno Johantisbeeriträutcher in Mutganten. Die beiden ge= naunten $\mathfrak{2}$ rten, die unter fich einen intereffanten $\mathfrak{B}$ ajtard billont, fund itbrigents nicht bie einzigen Bieritründber ber (3)attung.

Durct) äbulidfen tranbigen Frudstiftand wie die $\Im_{0}=$

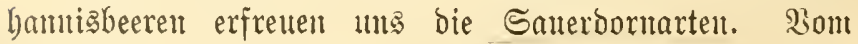
gemeinen Sauerboru (Bérberis vulgáris L.) gibt ę melyrere (sartenformen, bie fich teilmeife burdh weibbuntes oder butfelrotes Raubwerf auszeichnen. Da aber unjer Saueroorm bie Bwifhenform eines gefürchteten Bsetreide= roitpilzes beberbergt, ift es gewagt, bieje 2 (rt in ber Jiad)= barichaft von ssetreibefeldern auzupflanzen, man trifft ba= Ger vielfach ansländijche, z. 23. immtergrüne 2(rtent an jeiner Stelle. Sine Eleme (Grmppe, die Miabonten, deren Pame 
au ben amerifanijaden Botantifer Mac Mabon erimert, trägt gefiederte immergrüme Blätter, barunter bie all= gemein verbreitete glanzblättrige Ma bonie (B. aquifólium Is., 1. 2(b5. 33), bie ihre Beliebtheit jowohl ibrem id)önen Dunfelgrünen, zu-Bintoreien geeigneten হanbe als ifren für bie Sogelmelt jebr wertwollen blanbereiften Beeren verbantft.

Die Bejtäubuntg ber Blïten bietet bei affen Sauer= bornarten Belegentyeit ju einer bübichen Beobachtuntg.

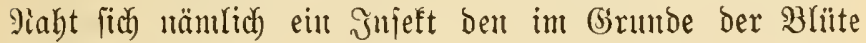

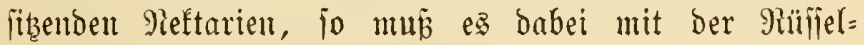
ipibe totwentig bas Bselent an Brunto eines ber jechs

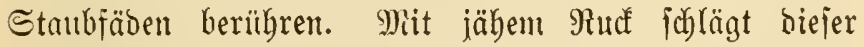
gegen bie Ditte, und bie Summel ober Fliege zielnt mit

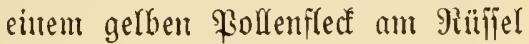

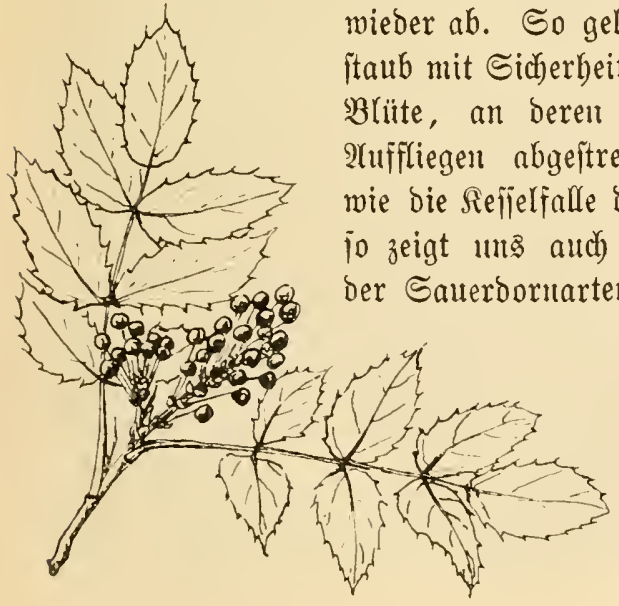

9(66. 33. Mial)onie (mit 3ecren). jigell ber jablyl= lojen siege, anf detten bie Matur bie Fremto = bejtäubung ber PFflantzen Durch)= jekt. Unto bieje ift notwertoig, 
Dem nach allen bisherigen Interjudthungen icheint es ein

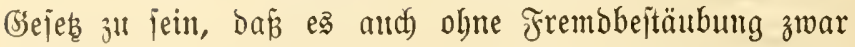
Fortpflaujung unto Bermebrung gibt (bei zablreidgen Pflanzen ijt bie Selbitbeftäubung bie Fiegel), nidjt aber Meiterent= midflung und 2 uffteigen zu แeuen Formen.

Das einzelne Fiederblättchen Der Mabonie gleidst

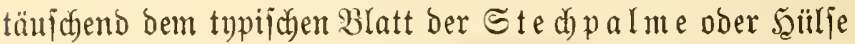
(Ilex aquifólium L.), bie gleid) ben ebenfalla immer=

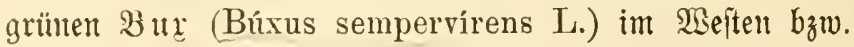
Sïdweiten Mitteleuropas zu Saauje ift. Der lebetere ift

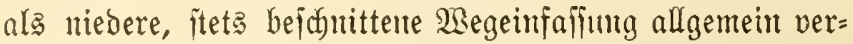
breitet, jeltenter trifft man ihn als jtärferen, $6-8 \mathrm{~m}$ bohen Baum. 2utch die Stedypalme erreicht in Deutichland feltent

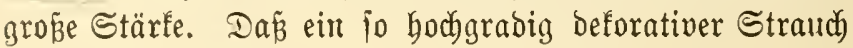
(bejonders im Siginter, wern bie roten Beeren reif find) altd) in verjobiebenen Epielarten gezogen wirb, ift mur natürlicb.

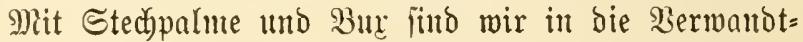
jáaft von Spindelbaum (Rfaffenthïtchen, Evónymus

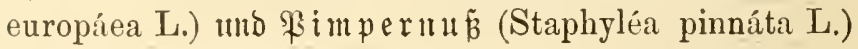
geraten, bie beibe ifrer auffälligen Fritchte wegen entfochieben einen Slab in Parfgebüliche verbienen. Son beiden Gsat=

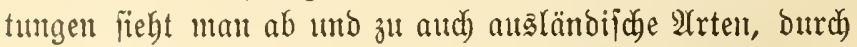
jeine immergrïnten, elliptijchen ß̧ätter fällt bejombers der japanifde Epindelbaum (E. japónica Thbg.) ing Aługe.

In prächtigen Rot, wetteifermo mit bem wilden Wein,

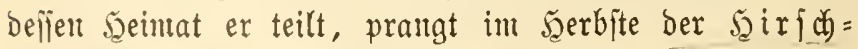
folben=Sumad) (Rhus týphina L.), ein bei uts bei= nake eingebürgerter Strand), Deffen weitreidjende, mit ifrem braumen Fily an ein in Baft ftehentos Sirichgemeily er=

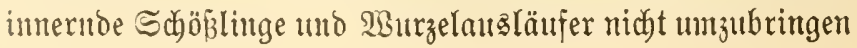




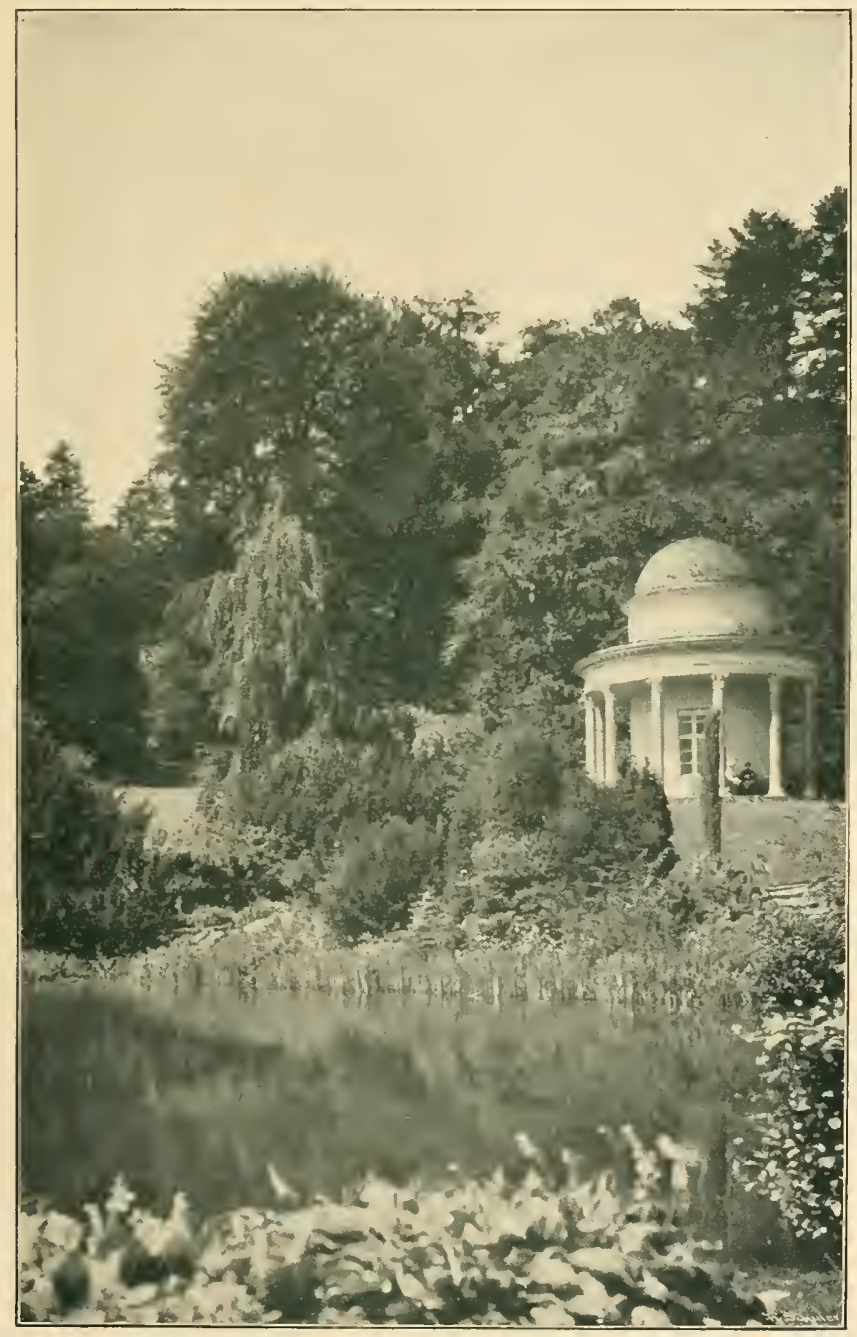

Safel, V. Slutbuctee (Eiben Sängebuct)e உebenzbäume

QGeip̄tanneแ Gäulen=:Badyolder 



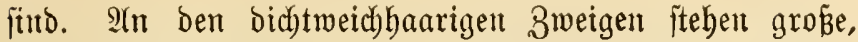
paarig gepiederte Blätter, beren Fiebern unterjetts ebenfalls fein behaart find, im (Segenfab zu bem ähnlichen, gleid)falls bäufigen $g \mathfrak{l}$ at ten $\mathfrak{S}_{\mathfrak{m}} \mathfrak{a} \mathfrak{c}(\mathrm{Rh}$. glábra I.). Die gelb=

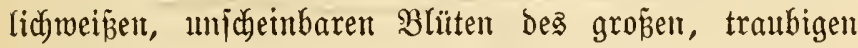
3lütenjtandes reifen zu braunroten frürdtct)en aus. Da bieje zur Berjtärfung bes Ejfigg benïbt merben, wiro ber Strauch auch Ejïigbaum genamnt.

Seiner eigentümtidien Siftwirkung wegen gefürchtet und bock nicht felten zur Befleioung von Raubent benitbt wiro der (s) $i$ ft $j u m a$ d) (siftefeu, Rh. toxicodéndron L.), ein Rletterftrauch aus Siorbamterifa mit breizähligen Slättern und fleiten, grünlicben Blïtenrippen. Âlle Teile des Strauches enthalten eiten gelblichmeipen, an ber $2 u f t$ jobmarz werbenten Milchjaft, ber bei ber Beritbrung einen roten Aluşd lag anf ber Şant hervorruft. Bei emmfint= lichen Perjonen ftellen fich zudem Sdyuindel= unto Srampf= anfälle ein, ja oft genïgt, bejonders an heiben Iagen,

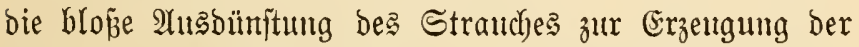

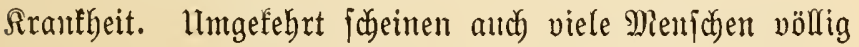
unempfindido gegen bieje Bjiftwirkung ju jein.

Şarmlojer ift eine weitere vielgepflanjte $\mathfrak{A}(\mathrm{rt}$, ber jïlo=

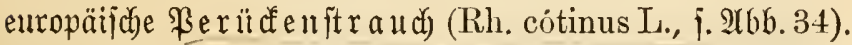
Die einfachen, gantzrantoig=eiförntigen Slätter lajien ihn jo menig aufiallen wie bie lodłeren Blütenrifpen, bis zur

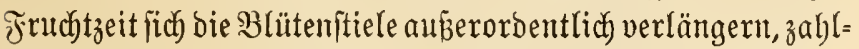

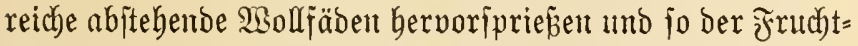
itand wie eine willo zerzaujte Ferücfe auf bem Straudje fizt.

Mit bent Sfifigbaum leicht verwedfelt wirb wegen ber

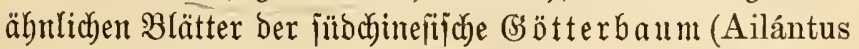

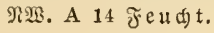




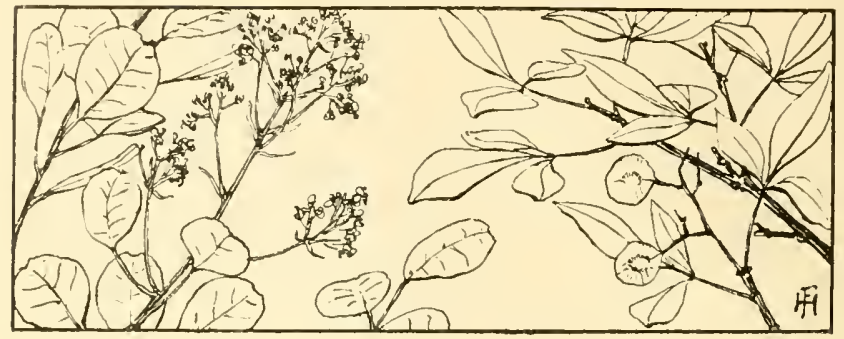

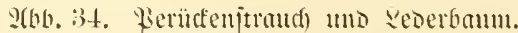

glandulósa Desf.). Die bald paarig, bald umpaar gefieder= ten Blätter erreichen biß zu eimem Meter \&änge, bie glatten

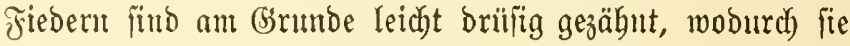
fidi) ftets von benten ber Sumadharten unterideiden. Der Ģötter= oder Şinmtelbaum, wie er wegen jeitter Şöhe in der Şeinnat genaunt wird, wäre einer injerer wertwolliten Parfbätme, wemt er nicht gar ju leidjt bå Dpfer jtrenger

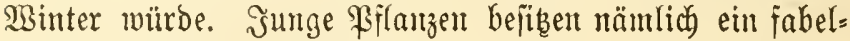

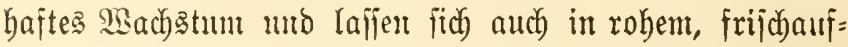

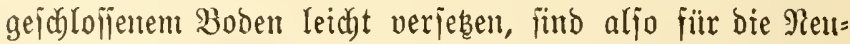

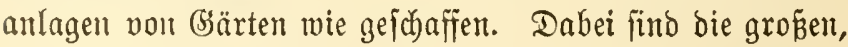
rotïberlaufenten Fructititände inl Seerbït ein prächtiger

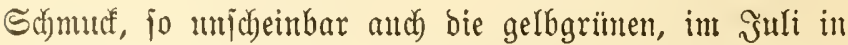

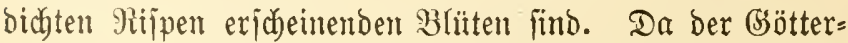
baum aber nebent den gewögnlichent żmitterigen Bäımen auch) reit mümlidye Eremplare Gervorbringt, fo fömen natïrlich nicht alle blïbenben Bäume aud Frü̈dyte tragen.

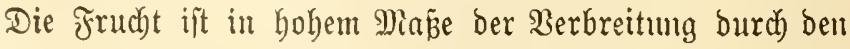
Winto angepaṕst, bemr der ölreid)e Samen fik̨t in ber Mitte eines jobraubig gebrehten, zumgenförmigen Flugblattez 


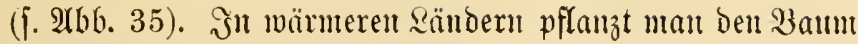

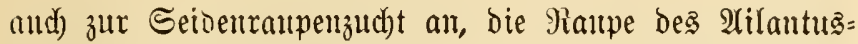
ipimuers ift jogar $a b$ und zu fdon au beutjoben Bäımten getroffert worden.

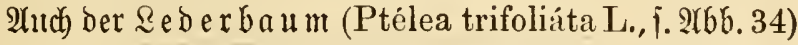
trägt eine typijche Flïgelfrucht, fie iit freișruto mo er= inuert an bie Frutb) der flatter= ulnte. Der fübamerifanijobe Straud) unit jeinen langgeptielten breizäb= ligen Blättern wird nicht jelten im Gartell gezogen.

\$Benden wir แns mu ben uns wohlvertrauten $\mathfrak{A h}$ ornarten zu, beren boppelte frlügelfrucht unt fachon in ber Sindbeit als Majen= reiter erfrest hat! Hale beimiichen

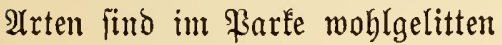
uno zühlen bäurig zu befien itatt= licbjten Bäumen. Selbit ber fleine Felbahorn (Makjholoer, Acer campéstre L.) erreidft bort viel

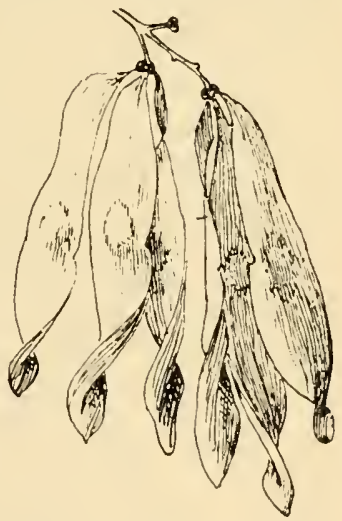

Qtb6. 35. Götterbauแ

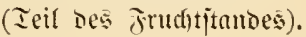
bäufiger als im Freien ganz ungewohnte, actutunggebietende Größé Som Bergahorn (A. pseudoplátanus L.) ift eine Form mit ounfelrotent Raube jebr beliebt, nidgt zu vermechjeln mit bem nordamerifanijhen Rotahorn (A. rúbrum L.), der den Ramen von ben roten, fchon vor $\mathfrak{A}$ (ङ) hat. Durd jeinen itarf zudferbaltigen Saft befannt ift ber ebenfalls norbanterifanifde 3 ud erahorn (A. sacchárinum $W$ angh.). Seime Blätter ähneln benen beş Geimijhen 
Spibahorn (A. platanoídes L.), find aber unten bläulich)grün uto leicht behaart, während bie hellgelben Blïten in locferen Irugbolben jchlaff abmärtż bängen. Der Bucferaborn zeichnet fich burch bejonbers jöbue orangerote Serbitfürbutg aus, lat aber bei ung entichiedent nicht bie ihn gebührento Berbreitumg gejunden, vielleicht meil er fdon frïbzeitig im Silberalyorn (A. dasycárpum Ehrh.,

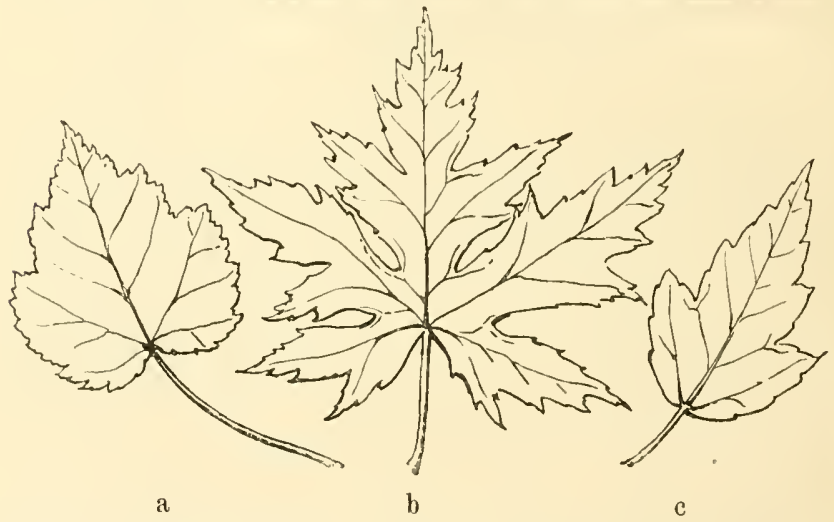

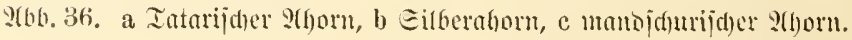

ๆ. 2(bb. 36) einen erfolgreichen Mitbewerber fand. Wabre Riejen biejes Amerifaners jteben in unteren alten Parf= anlagen, ein Beichen für die erfolgreiche (5inführung bes banf bem zierlichen, tiefeingeidynittenen saube und befien fillberhaariger lluterjeite anßzerordentlich deforativen Baumes. Sogar unjere Mifitel (Víscum álbum L.) hat johon pon

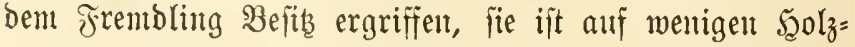
arten fo häufig wie ant bem Silkeraborn. Seider ift beffen

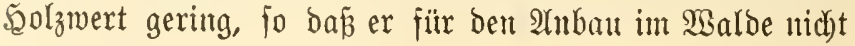


in Setradgt fommt, während ber Zudferahorn bafür viel= fach empfohlen mird.

Meben biejen Bäumen merben einige ftrauchartige Afyorn= arten leicht ïberjeben, als beren typijcher Bertreter ber tatarifabe $\mathfrak{A}$ gorn (A. tatáricum L., \{. 2(6b. 36) gelten famt. Die herzförntig=rundlichen, geiägten Blätter und bie lange nach biejen in bidjten Rijpen aufblübenden

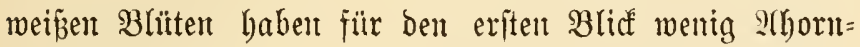
artiges an fich), bie roten Fridd) aber befumben fofort feine Bermandtichaft. Durch breiteilige Blätter mit langem Mittellappen untericheibet fich leidgt ber ähnliche man=

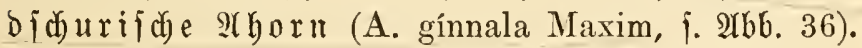
Beide 2 rten finto and in lleiteren (siärten micht jelten.

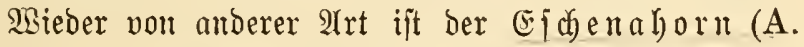

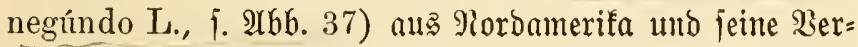
mandten. Seitu 3 lätter weichen am meiften vom $\mathfrak{A}$ horn= typus ab, fie find nämlich) gefiedert, $3-5 z$ zählig, haben aber mit bem Ejchenblatt, auf bas ber siame bimmeift, gerabe

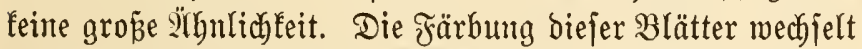
auberordentlich, weifbunte und gelbbunte Belaubung tritt

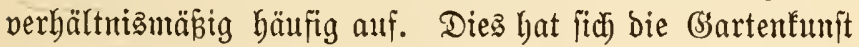
natürlich nicht entgeben laijen, jo ba pa wir Geute in unjeren Giärten fajt mehr panajchiertblättrige als normale Bäıme bes (5jchentaljorns finden. Die fronenlojen Blüten erjheinen lange vor Raubaußbruch, bie in langen, foblaffen Irauken hängendent Doppelfrüchte finto jehr flein, ihre Flügel

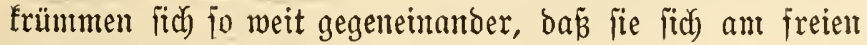
Ende nahezu berübren.

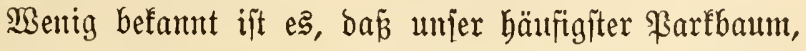

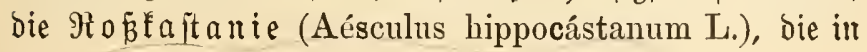




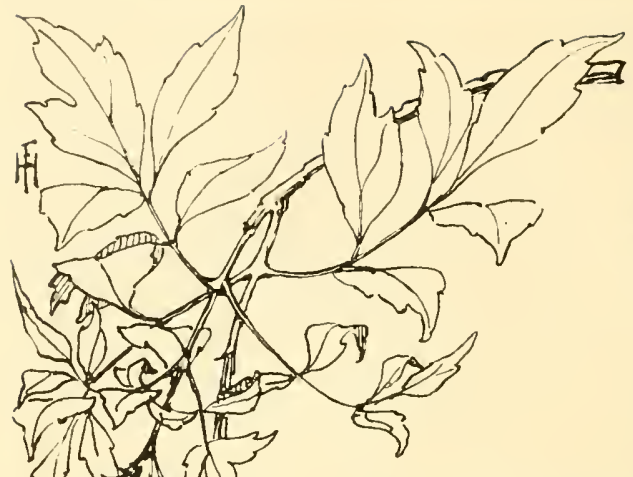

Der Syftematif bem $\mathfrak{A}$ horn nakejteht, ein Sint Europas

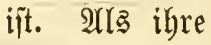
Seimtat ift mun= mehr Epirus nachgewiejen morben, von Ronftantinopel alls trat fie in ber zmeiten گ̧älfte dę̧ 16. Jahr

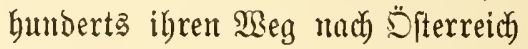
an, gewaut aher erit in Berlaufe ber Tïrfentriege größ̨eres Ssebiet, und Gente ifit fie in ganz Mittel= etropa aukerhalb des Waldes bie verbreitetite Solzart. Die idyatten= ipendenden gefingerten $\mathfrak{B}$ lätter, beren Entfaltung aus der braunen, flebrigen Snofpe fo bübich uno anziebeno zu beobachten iit, bie aufredtent weiben, leid)t rotgeflecften $\mathfrak{B l i ̈ t e n f t r a ̈ u r e ~}$ 966. 37. Eighenafform. und befonders bie itadigligen, aufipringenton Früd) mit ben gläızendbraunen Samten find jedem Rinbe wohlver=

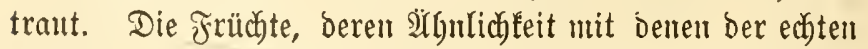
Rajtanie ( $\mathfrak{j}$. S. 84) bem 3aume ben Namen gibt, finden

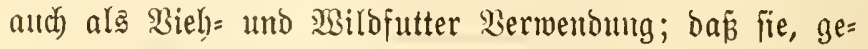
uablen bem futter zugejeb̧t, jedenfalls frïher für felgr heiljam bei Atembejchmerben ber Pferbe galten, bentet ber 


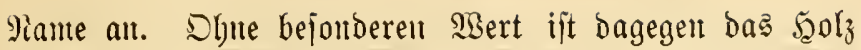

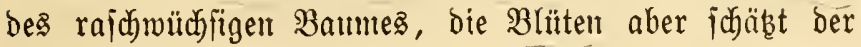
Bienenzüchter.

Trob igrer langen 3üdhtung hat die Ropfaftanie feine tentmenżwerten Epielarten ober (Sartenformen Gervorgebracht, wohl aber ift eitte Frenzung zwijchen igr mo ber nord= amerifanijden Pawie jegr verbreitet, näntich bie rot= brübelde Rof́faftanie (A. cárnea Willd.) Da fie burch Propfung auf bie gemeine 2 rt perntehrt wiro, aber weniger in bie Didfe wäd)it als biefe, jo entftebt häufig eine gauz auffallentide Sdjaftform, injofern fidj ber Stanm an ber Pfropfïtelle plöblich verichmtälert. Der 23aftard bält in jeinen Merfmalen fo zientlich bie Mitte zwijchent feiren Eltern, bie rote Blumentronte ift nicht autsgebreitet

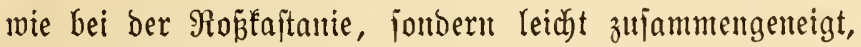

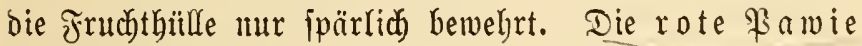
(Páwia rúbra Lam.) Felbit, die ihren Jamen zu Elyrent bes Reibener $\mathfrak{B o t a n i f e r s ~} \mathfrak{S} a 1$ erhalten Gat, trägt in röhrigem Selch eine bunfelrote, zujanmenjobließ̧ende Blumenfronte und glatte, unbemehrte Früh)te. Sie tritt an Şäufigleit febr gegenitber den eritgentamten beiden zuriicf, bildot auch) mur felten größ̄ere Bäume.

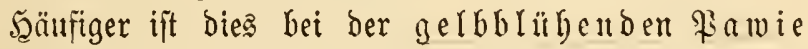
(P. lútea Poir.) der Fall. Range Bhtmenblätter ııto un= bebaarte Stanbbentel fint bas einfadjte Remnzeidjen gegent= iiber ber ftraudbigen $\mathfrak{f} \mathfrak{a} \mathfrak{h}$ en $\mathfrak{B}$ a wie (P. glábra Spach.), bie furze Blumenblätter แmb bebaarte Staubbentel trünt.

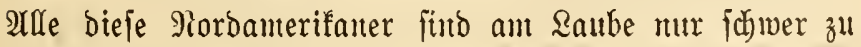
unterjobeiben, Durd ichlanfere Form ber glatten $\mathfrak{B}$ (ättchent

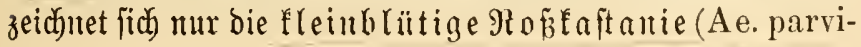


flóra Walt.) aus, bie audy in ber Blüte gröpere Bejonder= heiten zeigt, infofern bie in Sommer erfocheinenden weifen Blïtentripent des Strauthes auffallent lang und ichmal finto und bie Staubfäben weit aus ber Shäte berans= tretent.

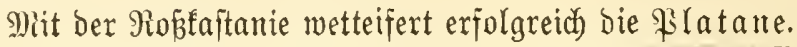

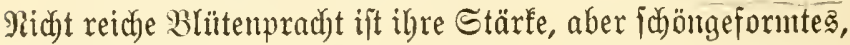

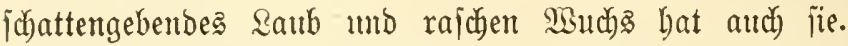

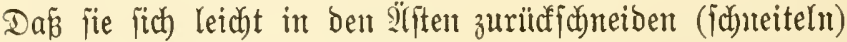
läpt, fantn febr vorteilfaft fein; wer aber nur bie übel

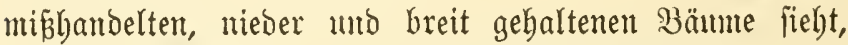

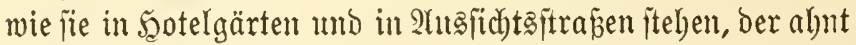
nicht, melche Schönbeit bie \$ratame ba entfaltet, wo fie in mächtigen arlleen ben jhlanten Ed)aft frei und unge= hindert emporjenbet, bie fraftwollen ïlite in meitem, vor= nebmem Bogen zur Seite breitet. Bei allem Schatten bock) zugleid) licht und freundrich), bas ift ber Fieiz der \$latame. Siicht zun menigiten trägt bazu ber Stamm jelbit bei, deflent dumfle, in rafder Ernentumg begriffene Borfe fich fortwährento in regellojen Stücfen abblättert, fo baj bie

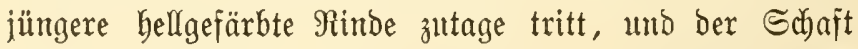
wie geffecft ericheint. Die Pilatane trägt männliche -unto. weibliche SBlüten getrennt; bie einen gelb, bie anderen tiejrot,

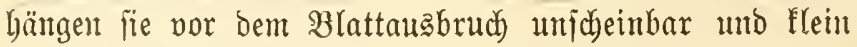
an Den 3meigen. Frö̈ß̈er find bie zu Rugeln vereintigten Früd)te, bie noch in Minter an Baume pendeln. Die Frïchtchen befizen zarte Flughaare; bieje fömmen, weut

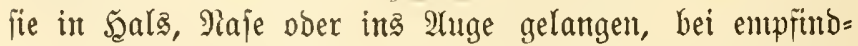
lichen Menichen Entzündungen ber Schleimbaut hervor= rufen, ebempo and bie filgigen Schubhare, bie jich bei ber 
Entfaltung der Blätter von ben jungen Trieben 〔öfen. Die Blätter jelbit leiden vielfach unter einer in ihren $\mathfrak{l l}=$

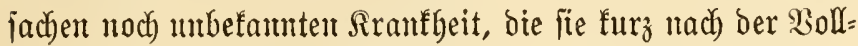

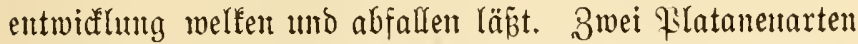
find befaunt, bie eine aus Эoroamerifa (Plátanus occidentális L.), bie andere, bei ute bie Winterfälte nur iddwer ertragende und beşhalb jeltene aus bem Drient (Pl.orien-

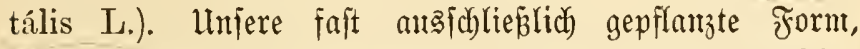
bie ahornblättrige Platane (Pl, acerifólia Willd.), fiebt ber amerifanijchen ant jebr nake, wiro aber als Sreuzungapproduft beider Arten angejehen; ihre Bermebrung erfolgt jtets ourch Stecflinge.

Die Platane wäre wohl mand $)$ mal geeignet, bei Strapaen= pflanzungen int Smtern ber Etäbte die Rinton zu ver= bräıgen, bie hier inmer in Mentge verwendet merben, ob= woll fie fich bejontors wentg bazu eignen. Machen ja bort) die Berbältnifje in engen, zugigen Sträen, der feft= gewalżte oder gar gepflafterte Boden, bie rupige, ichlechte suft einem Baum das Seben auberorbentlich jobwer; ben

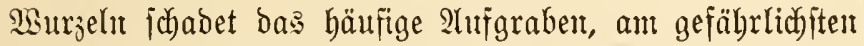

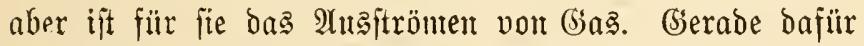
ift die Rinde bejonbers empfinolich, und bas bäufige plöb=

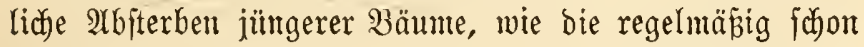

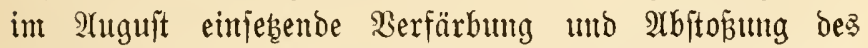
Raubes ipricht einte beutliche Sprache. Deshalb find lebens: fräftige Sintontreiken in ber Stabt jo felten, wo fie midyt von alters her jtanden und jobn ftart genug maren, ben moberment Gefahren zut troken. Arber wie wentge ber zabl= reichen alten âfeen und Rindengruppen bleiben an Reben, wenn bie wachjende Stadt fie erreicht! SBie wentge ent= 
geben dem Schicfial, ber veritünonialojen Bequemlichfeit zum Dpfer zu fallen, bie fick binter bem Schlagworte "Berfehrabedinrfuis" fo vielfad) birgt!

Dá bie Sinde heute noch viel gepflanzt mirb, ift für ben, ber bentiche Sage und Sitte fennt, mur jelbjtuer=

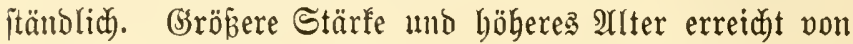
unieren heimijon arten die gropblättrige Sommer= linbe (Tília grandifólia Ehrh.), wäbrento die flein= blättrige $\mathfrak{B}$ interlinde (T. parvifólia Ehrh.) fid) ourch) größ̈eren Blïtenreidytum hervortut. Beibe Eigenfdhaften,

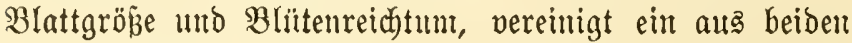
Arten gezogener $\mathfrak{B a f t a r d}$, Joch mebr aber eine andere (3artenform, bie als Sreuzung zwifjen Minterlinbe und ber bejonbers grobbeblätterten amerifanificen aiube (T. americána Du Roi) gilt. Größ̈ere Bedeutung hat vou fremben 2rrtent hauptfäcblich bie untgarifdue Silberlinde (T. argéntea Desf.). Der niebere Baum ift burch basె prächtige saub mit feimer fulberweinen haarigen Ilnterfeite fomobl als burch bie meift munberbar regelmäß̄ige eiförmige Sronte ein ganz befonderer Parffchmud, zudem blülyt er erjt anfangs Îtugujt uto verlängert fomit bie Scerrlid)feit ber Sindenblïte um eimen vollen Monat, was nidyt nur ber Freund ifres Duftes und ihrer Schönbeit, fondern auch ber Jutfer zu jüäben weif. - Die nicjt felten ge= pflanzte Sr riml inde (T. euchlóra C. K.) älntelt Der Minter= linde, trägt aber größ̈ere, nid)t rojtfarben, fonbern grau bebaarte Blätter, bie im Şerbjte länger grün bleiben. J̄m ïbrigen find unjere Parfluben laäıfig mur febr fibwer zu unteridjeiden, zumal bie Benentung und Fer= funft mandjer (Gartenform nod) feinesెnegs ficher fteht. 
Mit ben Rinden vermantof find bie Malvengenädje. Mur ein einziger bei uts gebeikender Straud) gebört ibnell

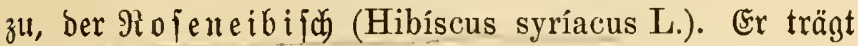
echte Malvenblütert, mattlilafarbest ober rofettrot, mit bunfeln $\mathfrak{A}$ dern, in ber Mitte Den bicfen, aus fünf șriffeln zufammengemadffenen Stempel. Die eiförmigen Blätter fitto mefrfach grobferbig gelappt. Da bie Blütent erit im Spätiommer uno ફzerbit ericheines, ift ber orientalijche Straud in biejer fonft blütenarmen Beit boppelt gefoübzt. Mit bent (Eibijch ber Şeilfunde bat aber bieje $\mathfrak{A}$ rt nict)tz zu fidaffen.

Statt ber Rinden werden in ftäbtifóden Strapen jowohl als auf Dorfpläbell vielfach ulmen gepflanzt. Werm

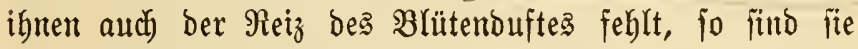

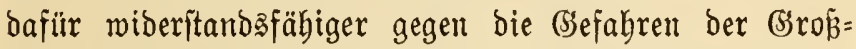
ftaot. Freilich ift ihre Berwendungsmöglich)eit nach anderer

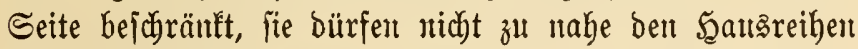

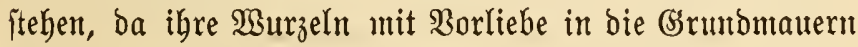
bringen und bier ifre $\mathfrak{5} e b e=$ und Sprengfraft erproben. Daß̧ bie Blütter fehr leicht von Blattläufen befiedelt und Durch Ssallen verunitaltet werden, hat ja meiter feinen Tachteil, ift aber aud nicht gerabe ichön. Bon unjeren heimijoben 2rten ift bie raubblïttrige $\mathfrak{B}$ ergulme (Ulmus móntána With.) verbreitet, aber aud bie ferbulnte (U. campéstris L.) ift nicht felten, beide bilden mandjerlei Spielarten. Bejonders die hängenden Formen find für lleite Säärten felgr geeigntet, in benten fie mit ihrem bichten, nach allen Seiten überbängenden Scyirm jebe fümptlidye Saube überflüjifig madyen. Daneben finden fich Formen

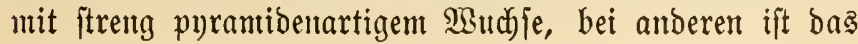


Zaub Dunfelrot ober weiß̈gefledt oder ganz eigenartig ge= rollt und gefrauft. Die fremben Irtent treten bengegen= ïber in den ફ̧intergruto. Einte japanijobe llute

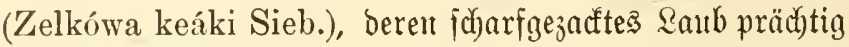
rote Szerbitfärbung annimmt, wirb ihres trefflichen $\mathfrak{g}_{0} l_{z e}$ megen für bie wärmeren Teile Deutichlantos als $\mathfrak{B a l d}=$ baum empfoblen, bod) liegen baritber noch feite aus reichenden Erjahrungen vor.

Der norbamerifanifhe Bürgelbaum (Céltis occidentális L., f. 29bb. 38) unterfibeidet fich von oen echten lllmen an meiften an ben Früd)tert. Er trägt nämliç fleine ein= janige Steimfrïchte, bie firjchenäbnlich orange= bis bram= rot färben und jäuerlid) fantecfen. Die Blätter füt un= behaart, int Lmrís ulmenälntlich, meift ungleichjeitig, aber fleiner und meijt leib)t gejägt. Die jebr ähntiche norb=

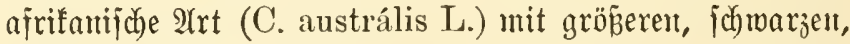
jü̈blichen Früd)ten gebeibt bei uns nut in ben wärmeren Sages, bagegen ift fie in Subtirol umb Dberitalien eine bäufige Errcheinumg, zumal ilgr fejtes Şolz auch von ber

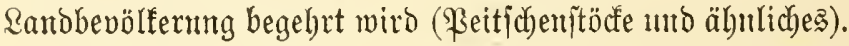

(3)leidjalls in Sildeuropa regelmäp̧ig angebaut merben

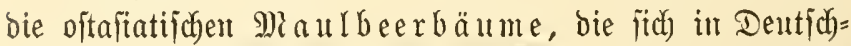

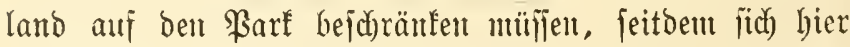
die Einfübrumg ber Seidenraupenzud al a untunlich heraits= geftellt hat. Shr saub liefert nüntlich bas Futter für bie Raupen des Seibenfpinters, uto zwar fteht basjenige des weifien Maulbeerbaunt (Mórus álba L., f. 2tbb. 38 Mitte) an erfter Stelle. Dieje Blätter erregen aber auck) anderweitig umjere 2(ufmerfiamleit: burd) ilgre Bielgeitaltig= feit. An (Şrunbe faum eingezogen, find fie breiteiförmig, 
bald ungeteilt, bald oreilappig, bald in mebreren $2 a p p e n$ einge= jonitten, mbehaart uno ungleidy= mäß̈ig gezähnt. Der $\{d \mathfrak{w} a \mathfrak{r} z e$ Mi a it b e e r b a um (M. nigra L., j. $\mathfrak{A b b} .38$ unten) bagegen trägt tiefherzförmig eingezogene ß̉ätter, die meniger abenteuerliche formen antehmen und meift ganzrandig ober nur einjeitig gelappt find. Da bie Sütllen ber in fleitut Röpfdyen znfammentgebrängten Blüten zur Fructztzeit weich und fleijchig werden und bie Piübchen untwadjjen, jo wäkfit der ganze Fruchtitand zalt einter humbeerähn= lichen Scheinbeere aus, bie, bei ber erften arrt wein, bei ber zweiten formarzpiolett, als ange= nebun jüblick $=$ jauer ichmedfendes Dbjt perwertet wirb. Das $\mathfrak{S c o l}_{\mathfrak{z}}$ des Baumes findet zu feitur Drectjilerarbeiten Bermentoung.

9)iit ben Miaulbeerbäımen teilt

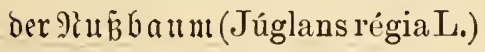
bas Schictial, juon fo frith in Sultur gefommen $3 \mathfrak{u}$ jein, $\delta a \tilde{B}$ jeine uriprïnglidge Seimat nicht mehr ficher nachgewiejen meroen fanm. Bermutlich ift fie in

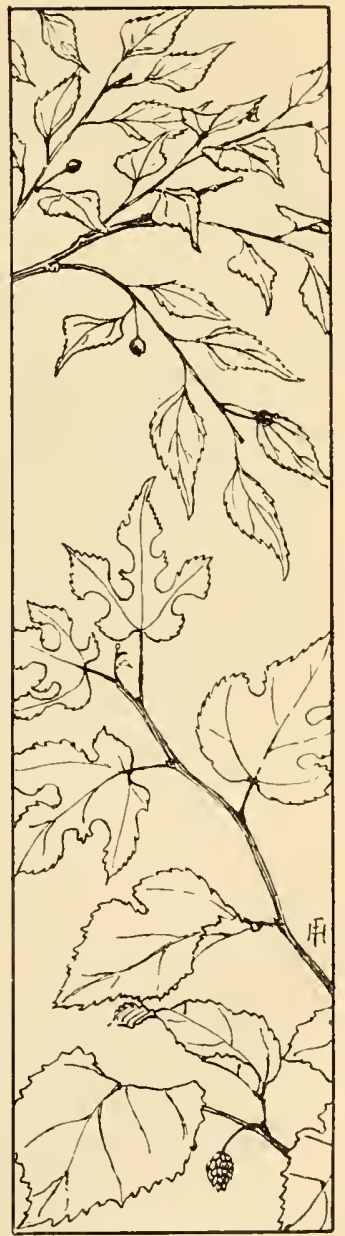

2(66, 38. 2(merifanitid)er Bürgel, weī̄er und jd)warzer Mianlbeerbaum. 
Borderafien zu jucten, jedenfalls fam der Baum von bort nad) Sildemropa. Sn unjeren Farfanlagen bilbet er

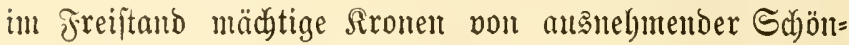
loit, boch tritt jein Zierwert gegenüber jeiner Bebeutung als Frudtbaum jegr zurüc. Dies trifft bei ben norbameri=

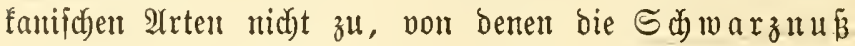
(J. nígra L.) fdenon 1629 in Europa angepflanzt murbe. Dás fie bei ung ilgr fortfommen findet, ja igres ganz herworragenden Şolzwertes (Miöbelgolz) megen unter llm= ftänden aud in șalde gebaut werben fann, ift burch bie prächtigen Stämme mujerer alten Bsärten längít er= wiefen. Ŝl ifrer Sceimat foll idjon vor einigen Sabren der lébte Beitanto alter Schmarznuß̈bäume der Scolzge= wiumung zum Dpfer gefaller jein. Dả Blatt der Sdymarz=

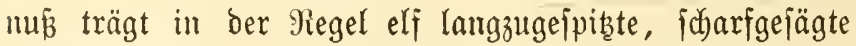
Fiederblättçen, deren Ilnterjeite ein zarter Flaum befleidet. Die jehr harten, joymarzen Siüfje itecfen in eimer fajt runden,

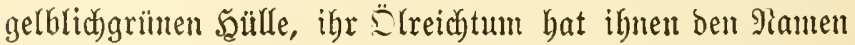
"Butterniiffe" verichafft, Dbjtwert befiken fie nicht. Etwas geringeren $\mathfrak{T}$ olzwert hat die (j) $\mathfrak{r} \mathfrak{a} \mathfrak{n} u \tilde{\beta}$ (J. cinérea L.), fie ifit bafür aber in flimatifcher Beziebung Gärter als bie anderen 2 rten. Şhre Fiederblätter find auch auf ber Dberjeite furzhaarig, bie grïnen Frïchte länglich) und flebrig behaart, bie forwarzen Siüfie jelbit ebenfalls in bie ränge gezogen.

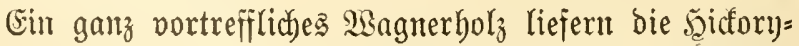
arten, insbefondere bie auch im Sald mannigfach gepflanzte

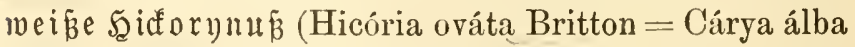
Nutt.). F̧hre fahlen Fiederblättchen ftehen nteift nur zu fünfen, bafür füto fie viel größer als bei Sdymarz= und 


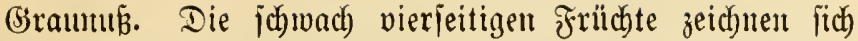
ourdy gropen Moljlgejdynad aus, gelangen bei uns aber nicht immer zur Reife. Utberhaupt bebingen die ફ̧idfory=

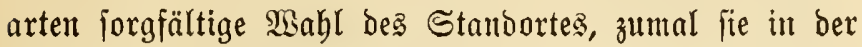
Şugend fegr froftempfindlid) find; ibre Serbreiturg in Park und Bar= ten ijt gering.

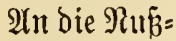
bäume ichlię̧t (iich) bie grope Berwandichajt ber fäbchenblü= tigen Bäume, denen ja bie ver= breitetiten $\Omega \mathfrak{a u b}=$ bölzer unjerer ફreimat alle ant= gebören. $\quad \mathfrak{A}[\mathfrak{s}$

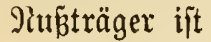
unjere $\mathfrak{H a j e l}=$

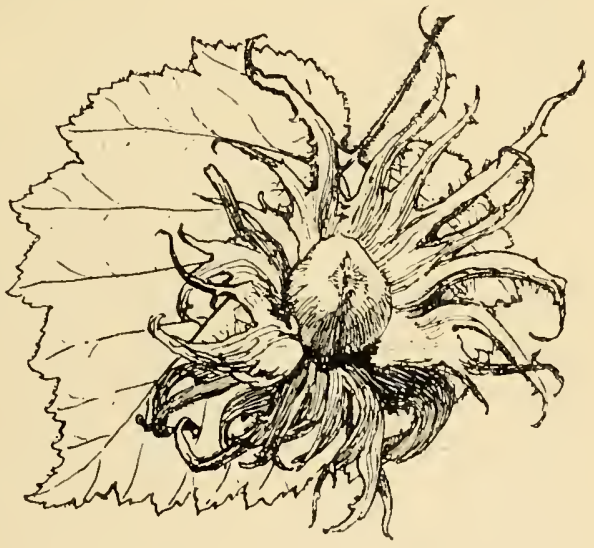

2(66. 39. Baumt)ajet.

$\mathfrak{n} \tilde{\mathfrak{\beta}}$ (Córylus avellána L.) befannt. S̄n ntehreren Sulturformen wird fie int Bufdumerf deב Dbjtgartesta

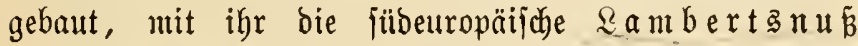
(C. tubulósa Willd.), berent Früd)te in ber röhrig= malzenförmigen Şülle völig verichmintben. Bon beiben aber itammen veridjiedene Bierformen im Sarten, bald

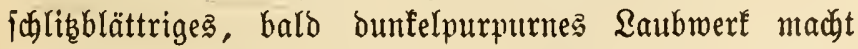
die Şajel zum Schmudfítrauth, dem zudem der grope Borzug zufommt, autch im Schatten anderer $\mathfrak{B a ̈ u m e ~ a l s ~}$ Unterbolz prächtig zu gedeihen. 
Ein Somentinto dagegen ift bie ftattliche $B$ aumbajel (C. colúrna L., j. $\mathfrak{A b b}$. 39) aus Sïbofteuropa, burch) ihren meift ebenmäpig jpitzovalen 1 Gudbs eine ganz bejondere Zierbe als Einzelbaum. Das geferbt gejägte $R a u b$ zeigt bie $\mathfrak{A} b=$

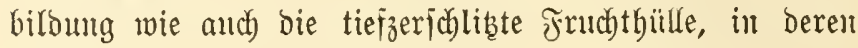

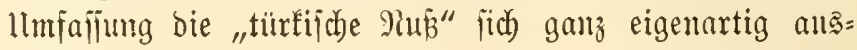
nimmt.

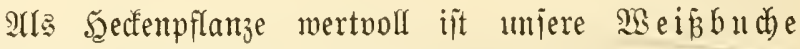
(5̧agbuct)e, 5̧ornbaum, Carpínus bétulus L.), demt fie gebeiht gut auf idhled)tem Boben und im Schatten und

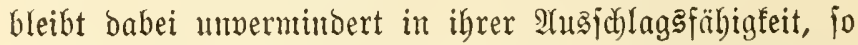

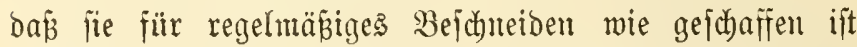
(j. Tajel IV). Daj jie beşhalh audf zeitweije in ber Garten= funit eine fübrende Salle ipielte, ijt in ber Einleitumg jchon erwähnt. Da ifhr bürres Raub jum gropent Teil erjt im Frïhjabr abfälnt, fo liefern ibre Sectert auch eimen nicht zu verachtenden Echub gegen Winto uno Schnee. Daj

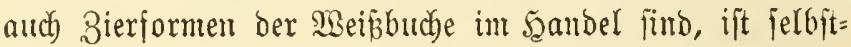

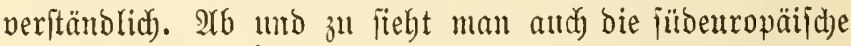
Şopfenbudie (Óstrya carpinifólia Scop.), die ilyr jefr

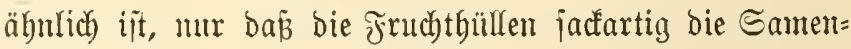

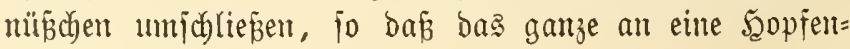
fructit erimtert.

Bon ber Rotbud de (Fágus silvática L.) ift am be=

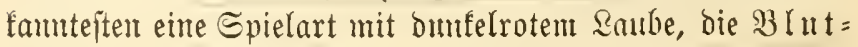

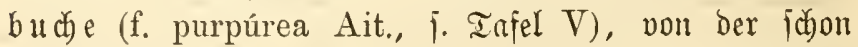

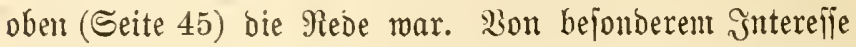
ift ber bei ber Bhutbuctje gelungene Nachweis, baj einte jolche Bildungababeidung (Bariation), mie bas rote Saub, eine jantenbejtänbige, vererbliche Eigenjchajt jein 


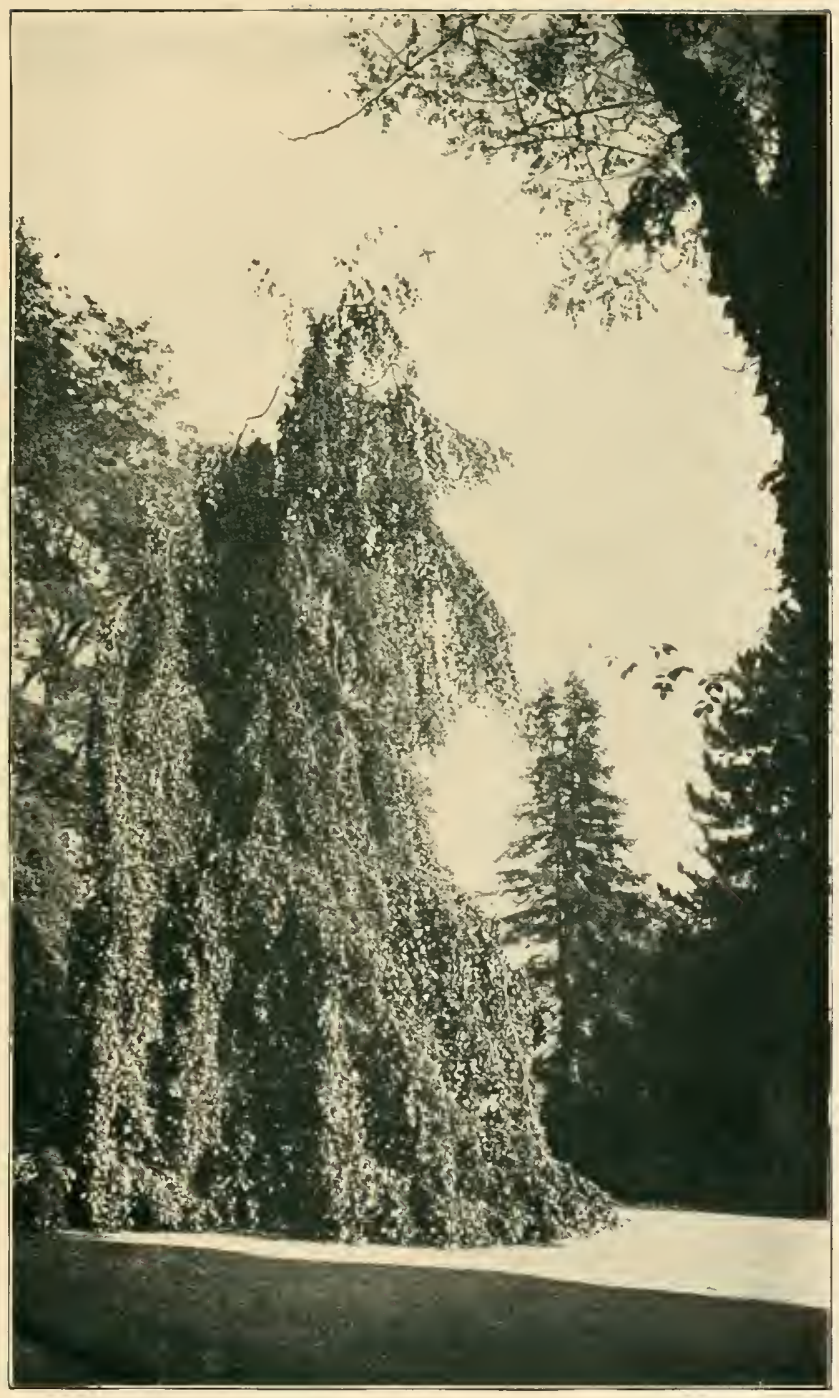

Safel VI. jängebuche (obere (Ecte (jteditjd)ie). 

fautu. SBarımt, $\mathfrak{b} z \mathfrak{w}$. tutter weldyent Beotingungen foldje Sariationen überbaupt anftre= ten, ift beute nod) eine offente Frage; daf bie Buctue, äbu= (ich) wie bie Fichte, bejonbers reiches Seobachtungsmaterial liejert, bätgt natïrlich mit ibrer gropent Berbreitung in פBalde zujamnten. भIbweidjende Blattformten finto in $\mathfrak{2} b \mathfrak{b} .2$ bargeftellt, währent Tafel VI ein anjchaulicbes Silto ber Trauter= oder ફ̧ängebucthe giht, Deren 3weige im 3 ogen fteil abrörts wad)jen; ba infolge= befien Stamm mo S̈fte feime ourchgelyenden Reittriebe be= fiben, fondern ibre פBeiter= fiibrumg ftets von einer nentent Seitenfnofperibernommen mer: Den mus, jo ift es erflärlich),

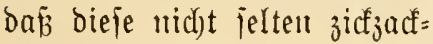
artig verrentft fint. Sine Steigerung biejer Erjobeinung birbcn bießnenf= ober $\Xi d$ langen= buthen, wie fie 3. Э. vom Eïutelgebirge hefannt jüb.

भtud) Stielcidbe mo Iraubeneide (Quércus รูis. A 14 geudt.

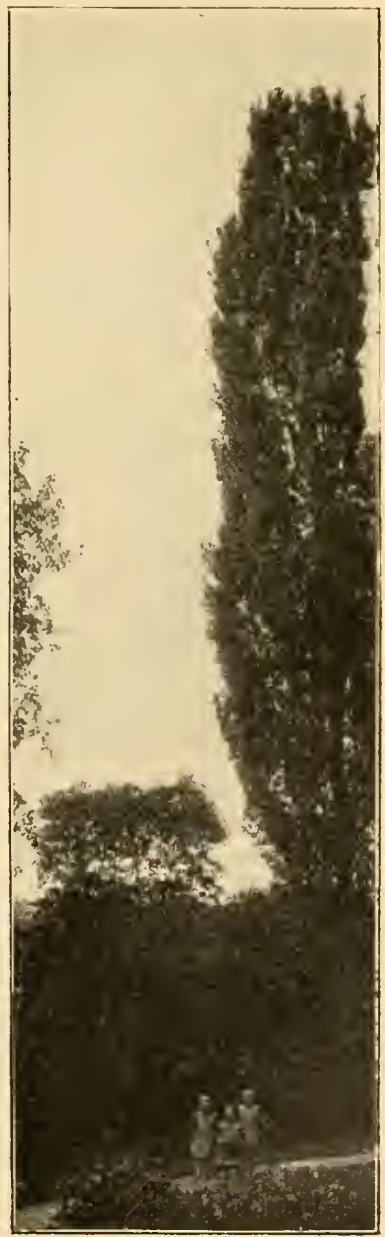

266. 40. Eüulentidhe. 
pedunculáta Ehrh. umb sessiliflóra Ehrh.) variieren in manterer Richtung, bie Etieleid)e bejonders zeigt auf=

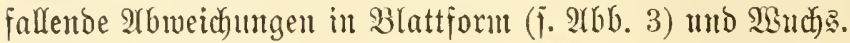
Biel gepflanzt wird bie Säuleneid)e (flufastigiáta D. C., ¡. A(b6, 40), eine Form mit iteil anjwärts wachjenden 3weigen, bie oft von ber befamten Pryramidenpappel aus

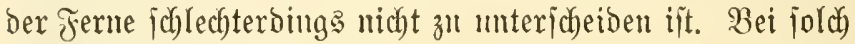
abmeichenden Formen bört natürlich jebe Beftimunumg =

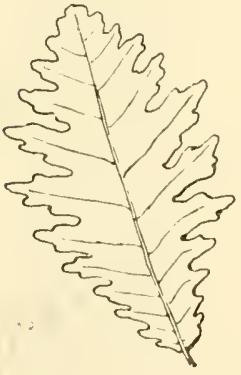

a

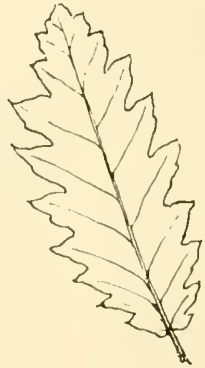

b

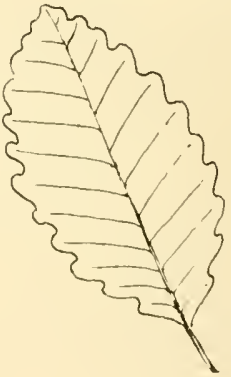

c

2666. 41. a Intuarifge Eiche, b 3erreidte, c Gerfereiche.

möglicheteit, ob Stiel= ober Traubeneidhe vorliegt, auf,

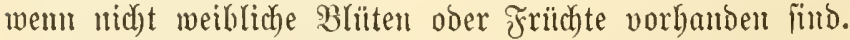
Schon bei ben normalen Bflanzen ift ja bie lntericheidumg nad) Blattform uno Sironenbildung allein oft höbjt tritgerifdy.

Der Irmuleneiche fteht bie weidhanarige (Eid)e (Qu. pubẻscens Willd.) nabe, bie von Sübeuropa her an einzelnen Fumften auch auf bentjech Soben übertritt, aber, ba fie meift mur itraudyartig bleibt, leime weitere Bebeutung befibt. SBie der Mame andeutet, fund ibre 
Blätter auf ber lutterjeite mit eitten bleibenden weichen

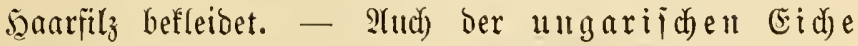
(Qu. hungárica Hub. = conférta Kit., f. 2lbb. 41) fommt eine größere Bebentung uidjt zu, boch ift fie ihres großenen, ichöngeformten 2aubes megen nidyt jelten im Parfe zn treffert.

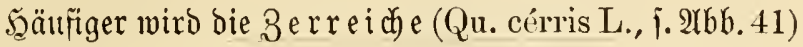
autgepflamgt, ein Bamm, ber ebenfalls Sulbemropa und

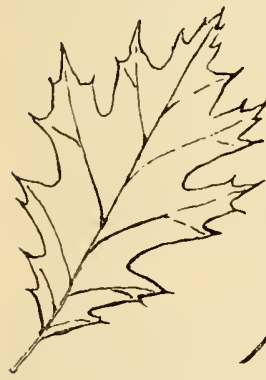

a

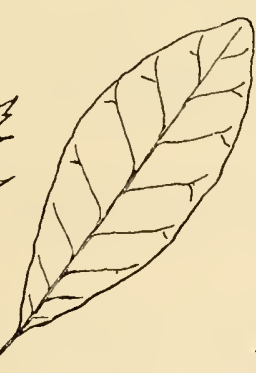

b

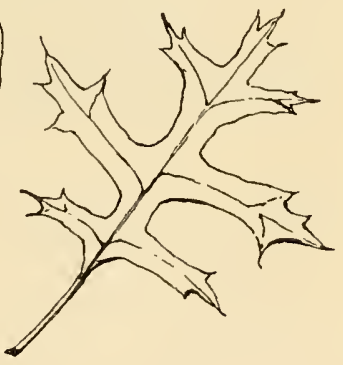

C

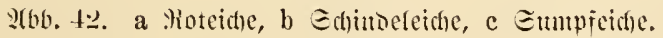

Inngarn bewohnt Imo fich burch fein ipiblappiges, im itbrigen aber fehr mamuigfad) geformte Blatt auszeichnet. Anf ein ipanifiches Bolf, bie Cerretaner, wiro der römijhe Taure zurïcfgefïgrt. Ein ficheres Erfemten ber $\mathfrak{A r t}$ ge= itatten bie fadenförmigen Bipfel, in meldye bie Snoppen= fouppen auzlaufer, und bie den ganzen Sonmer über micht abfallen. Die Blattoberfläche erimert durch ihrent

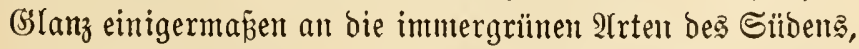
als beren Sertreter ums bie Steineidje (Qu. ilex L.) aus ber flajiijoben siteratur gelöufig ift. 
Durch igre prïchtig rote Šerbitfärbung madyen fich nemerbings inmer mebr beliebt mehrere mordanterifanijde

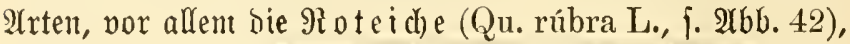
bie aud) in bentichen saldoe vielfach gepflanzt wirs. jhrem 3 latte nad wiurde ihre Zugehörigfeit zu ben Eichen manchen 3 weifel erregen, entfernen fich bod) bie meiften fremben atrten ganz erherlich von bent ung Dentf(t)en ge= läufigen Segriffe bes Eichenblattę̧. Šierfür find bie auf 2(b). 42 bargeftellten Blattformen ber amterifantichent Suntpfeiche unb Schiubeleiche (Qu. palústris Dur. und imbricária Mich.) bereste Beifpiele. Eimer anberen

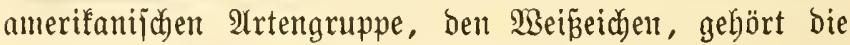
berbereiche (Qu. prínos L., i. 2Akh. 41) an, beren ginde ben allen (5idben eigenen Bserbjtoff in bejonders Gobem Grabe entbält.

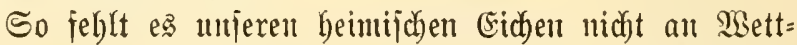
bewerbern, bie bereit find, fie aus unjeren Partanlagen

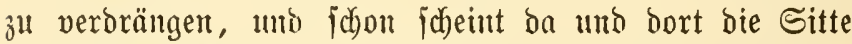
einzureifer, wemn alz bsebenffbaum zur Erimerumg an eine madytoolle Beriönlichleit eine Eidbe gepflanzt werbent

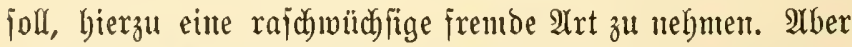

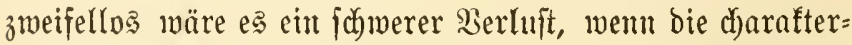
volle Schöntheit ber im Freiftande erwachjenten (siche ben ipäteren (siejc)lect)tern genontment würbe; verntag ja bod)

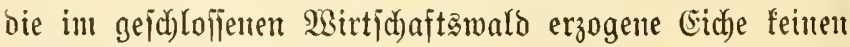
Erjat Gierfür zul bieter.

Sn ben meiften Teilen Deutfhlands mur ein Part = baum ift bie Edelfaftanie (Castánea vésca Gaertn.),

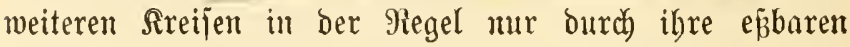
Frïdyte befunnt, bie and) mnter bem italienijotyen giamen 
Maroni verfauft werben. Miördlich ber Alpen fonmen bieịe freilich) felten zur vollen Sieife, aber bie bichtbewebrten, einem gelbgrüneı Seeigel vergleichbaren Fruchtbüllen, beren büm, Stachelfortiätbe nach allen Seiten ftarren, find eine Gäufige Ericheimung. Dieift fällt im Şerbite ber ganze Frudhtfnäuel zumal vom 3weige, zwijhyen den Stachel= Eugeln ragen modh bie vertrodfueten Säbchen Der Staub: blïtent. Das grofe, eiförmig längliche Blatt ift burch jeine

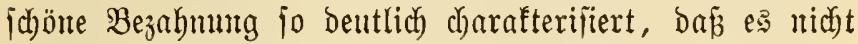
leidyt verkannt werden Lann. S̈m Rheintal, insbejondere am Fube der \$ogejen ulo des Schmarzwaldes, bildet bie Sinftanie ausgebebnte Sieberwaldungen, in benen in furzen Ilmtrieb jullante, zu Rebifteden verwertbare Stämmatyen gezilichtet werdell.

Don weiteren Rätchenblïtern find die Erlen und Birfen zu nemun. Den eriteren fommt, abgejeben vou einigent Bierformen ber $\Re_{0} \mathrm{t}=$ oder $S_{\text {dy }}$ arzerle (Alnus glutinósa Gaertn.) für Parf umo (Sarten mur untergeoronete Bebeutung zu. Die Birfent bagegen, vor allem bie ourd) ihre jabwanf herabhängenden 3 weige ansagezeichnete $\mathfrak{B}$ e $i \tilde{B}=$ birfe (Bétula verrucósa Ehrh.), fino mit ihrem frijchen

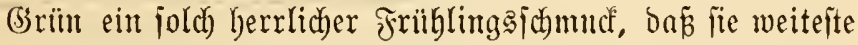
Berbreitung veroienth. Ilno bas un fo mebr, als fie banf

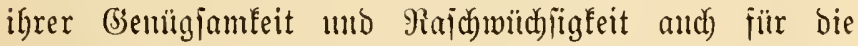
fleinjten 5ausgärten geeignet fint. Son bejonderem Pieij

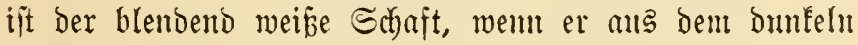
(Giriut einer Mabelfoljgruppe bervorlestchtet. Sine idhlib=

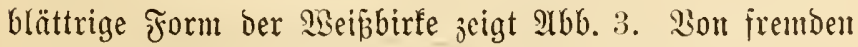

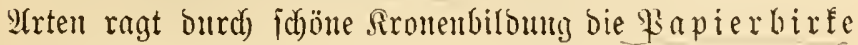
(B. papyrácea Ait.) hervor, anb Deren leicht ablöbarer 
Borkenlbaut in igrer Szeimat, Morbanterifa, eine 2 rt Fiapier hergeftellft wiro.

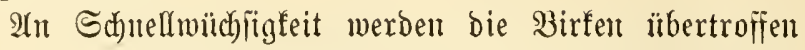
von saeiden und Bappeln, bie benn and) bas wertwollite Materinl für bie Rengrïnoung von Bartenanlagen bildest. Die 1 seißzweide (Sálix álba L.), bie vielen mur als itänbig zurïcfgeichuittenes Sopibol vom llfer ber Bäche befaunt iijt, erreicht bier eine Şöhe und Stärfe, bie Staunen

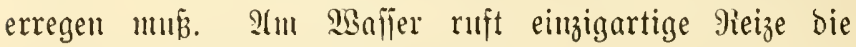
Tranerweide (S. babylónica L.) hervor, die aus Borberafien fonmut uno mit ibren in fanftem Bogen ïber= bängenden Eeitentiften autd) auf unjeren Frieblyöfen eit regelunäpiger Bajat geworben ift. Diejen beiben gegenüber tritt bie Mienge ber übrigen SEeidenarten ganz zurüd,

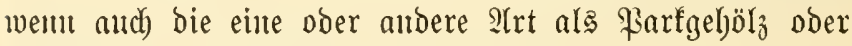
als Straßenbaum Bermentumg findet.

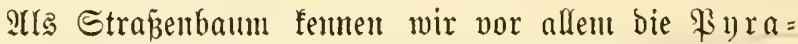
mibenpappel (Pópulus pyramidális Rozier), die vor 170 Jalyren eritmals aus Sübeuropa zu uns fom mo

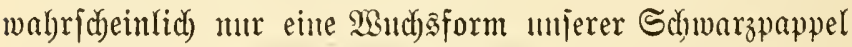
(P. nigra L.) ift. Эn ïberwiegend ntännlichen Erentularen burch) Stedflitge vermelyrt, hatte bie \$ruramidestpappel in furzen ganz Deutichlauto erobert; wo es der Boben irgento

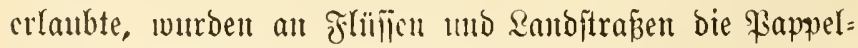

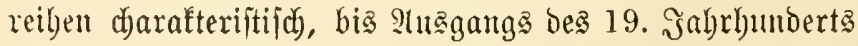
ber sisechjel ber Miode ibre Şerridyaft (brad). Freilid)

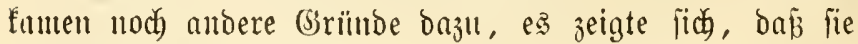
feill hohes alter erreichte, joubern bald wipfeloürr wurbe mo allerband Inngeziefer Duartier bot, Dinge, bie viel= Yeicht zujammenbängen mit ber S(bwäd)แn ber \$fflanzen 


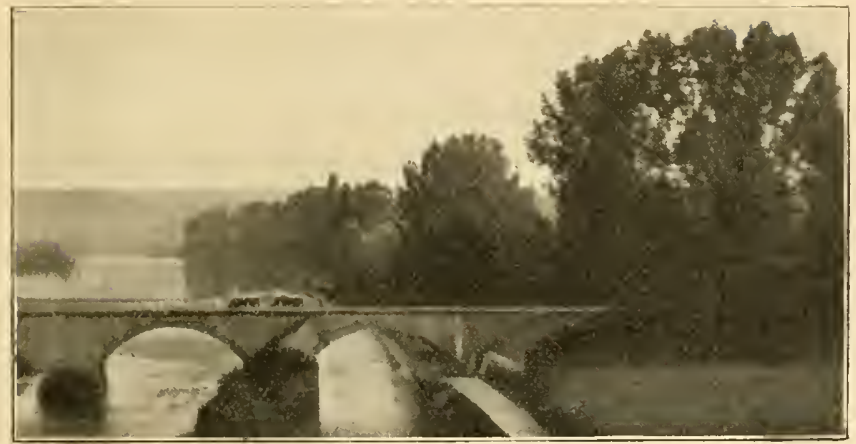

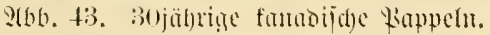

burd) bie fortwährento vegetative Sernebrumg, der mast

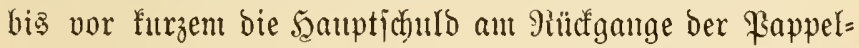

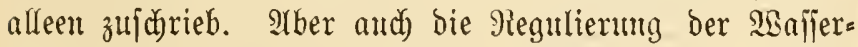
länfe und die bamit verbundene ïntorung ber Grumb= mafjerverbältuifje brachte vielen Sflanzutgen bas Ende, uno beute, wo ber äjthetijobe gieiz ber fteilaufitrebenton Fappel wieder böher gewertet wiro, fäll ein anderer \$iş= ftand viel megr als frither in bie sgagichale: die \$appelst

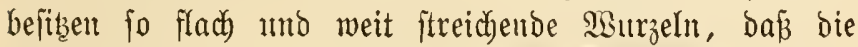
angrenzenden Felber ftarf auşgejogen, nid)t jelten autch die Schotterbecfen der Strajen in Ilnoronming gebracht werben.

Durch \$3udse, Selaubung und Stanmfärbung eiu ganz herworragenter Parfbaum ijt die Silberpappel (P. álba L.), nicht ohne (Sinund hat fie beute itberall weitab von igren natürlichen Standorten Serbreitung ge=

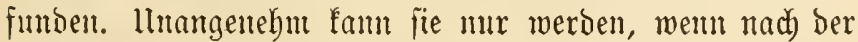
Frudbtreife bie in meißje Flugwolle gehüllten Santen wie 
Schneeflocfen fid) itber bie llmtgebung verbreiten. Wo dię läptig empfunden wirb, fantu es burch Pflanzung mur

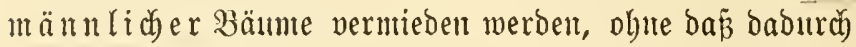
bie Sdjönkeit einer joldjen Srruppe irgenomie beeinträc) tigt wirb.

Son ben mancherlei fremben 2 rten verbient die in

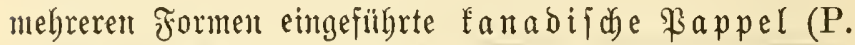

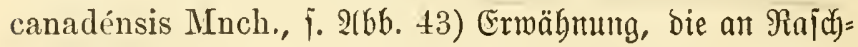

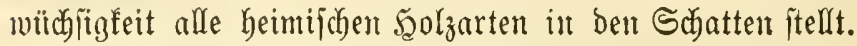
Sie ähnelt außzerorbentlich der Schwarzpappel, boch find ibre 3 lätter mebr breiedfig, am Grambe gerabe abgeidnitten und an Enorpeligen Ranbe häuftg leidgt behant, während bie sangtriebe burch Sortrippen etwas gefantet find und bie

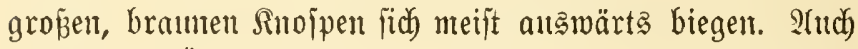
fitreben bie 2ifte megr in bie Sabhe als bie ber Sdymarz= pappel, oody ift bie llnterid)eidung häufig nidft leidht. Da bie

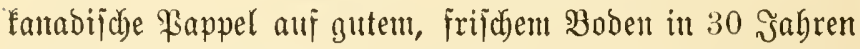
eine F̧öbe vost $30 \mathrm{~m}$ mit gerabem, $80-100 \mathrm{~cm}$ ftarfem Schaft erreichen faum, jo ift aud ilyr f̧olzertrag ganz bedentento.

$\mathfrak{A}$ die SBeiden erimtern in ibrer Blattform zmei Sträucher, D̈lweide und Sandoorn, ohne aber tiefer=

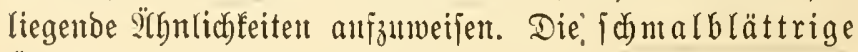
D̈lweibe (Elaeágnus angustifólia L.) aus dent Drient

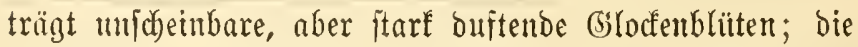
lanzettlichen, unterjeitz filberweinen Blätter zeichnen fich gleich bent jungen Trieben burdy füülferige Sdyuppen aus,

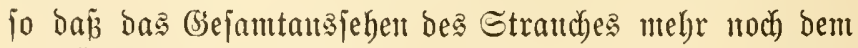
bes D̈rbaumes nabefommt als bem einer sieide. Diejes icjülfrige Silberkleio ift nod) viel ftürfer anşgebifdet bei 
der norbamerifanifore Sil= berölmei de (E.argéntea Pursh), bie fich ourd breitere, mehr ei= förnige Blätter uno braute Iriebe von ber exfteren unteridjeidet uno bei ifrem hoben beforativen $\mathfrak{B}$ ert intmer mehr in 2 nnlagen und $\mathfrak{B} o r=$ gärten gepflanzt wirb.

Schmälere, unten ebemp fillbrige Blätter trägt der ভand boru (Hippóphaë rhamnoídes L., 1. 2(6b. 44), ein bentid)er Strautch), Den aber bejonders bie gelbrotent beerenähnliḑen Früchte, untit benen er fich im Spätfonmter fadmütfft, zum beliebten Gartenjommud ge= macht haken. Jebent Bejutcher ber Deutichen Rüjten ift er vertraut, bock trifft mant ibn ebenio auf ben Flügejchieben bes भlpen= vorlanoes an, beren d)aratteri= fiticher Begleiter, zujammen mit der Tamarizle (Myricária germánica L.) er ijt.

2uch bieje hat den $\mathfrak{B e g}$ in den Sarten gefunden, allerbing vormiegend in ber jübeuropäijchen Yrt, ber fog. frauzäjifd en Iamariałe (Támarix gállica L., 广. \$6b. 44), berent feimzerteilte,

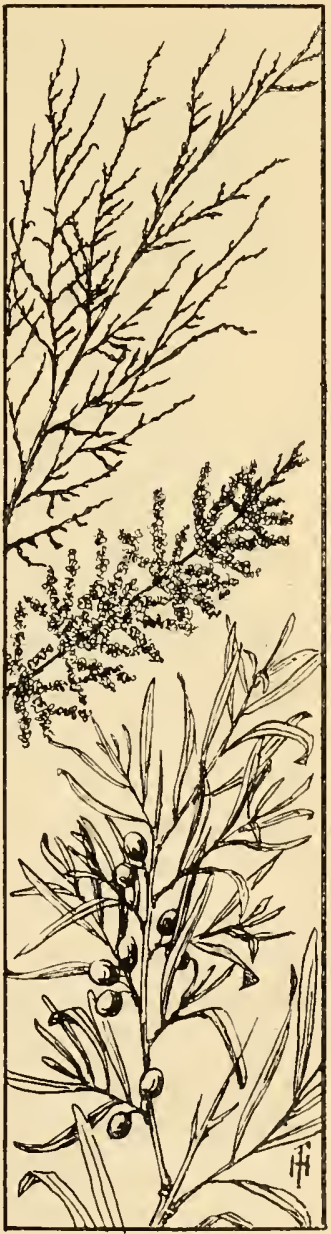

9(66. 44. Iamariste mis Embontr. 


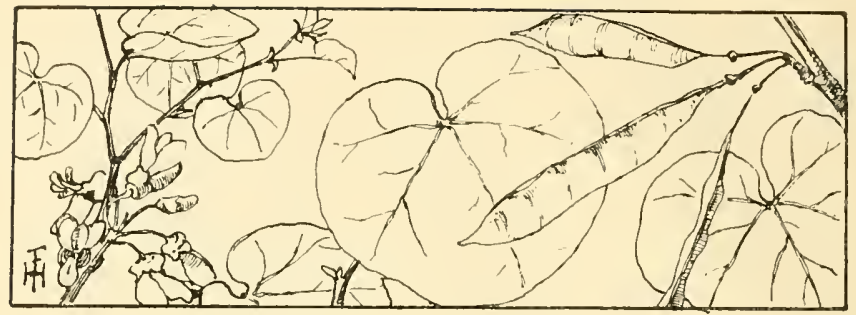

$9(66 .+5$.$) )$

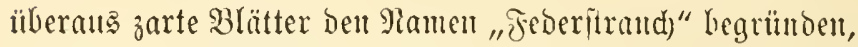
unter bem fie vielfach gezogen wird. Die flemen bla $\bar{b}=$ violetten 3 lïtchen häufen fich in auperoroentlich bicht= ftebenten ïlgren zwifden ben 3lättern oft fo maflenthaft

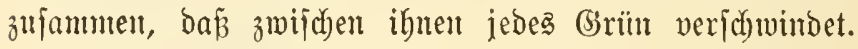

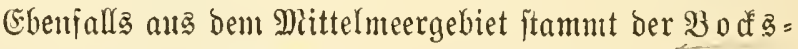
born (Lýcium europáeum L.), ein Straud mit über= l)ängenden 3weigen umo Yanzettlicb=eiförmigen Blättern,

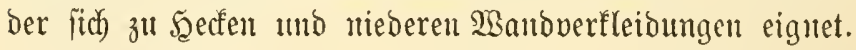
Seine Şanptriebe laufen, ähnlich wie beim Sandobrn, in Dornen aus, ans ben rotvioletten, nachtfdettenartigen Blüten hängen die Stanbfäben nidht hervor, woburch

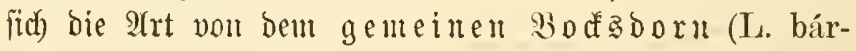
barum L.) unterid)eidet, ber in vielen Teilen Deutfolanos

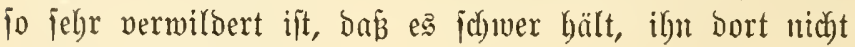
fïr beimifich zat halten.

Moch ein Sïbeuropüer, ber jochon in Tirol ïberall willo

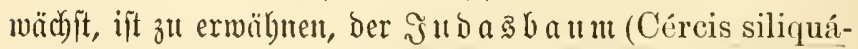

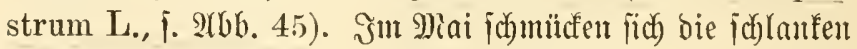
3weige mit biticheligen rojarotent 3̧lïten, beren Form fie in bie Serwandida)aft ber Sd)metterlinggblüten weijt mo 
die Den Blättern um einige Iage voran find an Grumb hergförmig eingejdutten, in itbrigen aber ganzrandig und fajt freişrund, wilhrend bie tief in ben Sisinter hinein am 3weige bleibenden braunen Frïchte bie befaunte Şüljenform der Reguminojeu jeigen und wohl autd) als "jaliches కొo= hamuisbrot" bezeichnet twerden. Den Piamen Subasbaum jelbit ver= bautt ber Baum der Regentoe, nad) ber fich) S̆แoas an ihm erhängt Gabest foll. Da er in Faläftiua bäuf̈ig ift, jo wäre bieş inmterbin nicht unnüglich.

Inders liegt der fall bei ber ifm vermanden (3) lebitidie (Gleditschia triacínthos L., j. 2 bb. 46 und IajelVI), aus beren fduarfbewelyr=

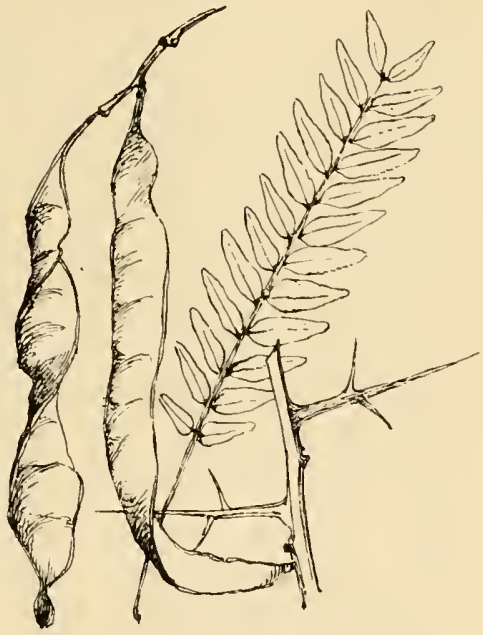

2(6). 46. (bladitidic. ten 3meigen bie Dornenfrone Chrifti bejtanten haben joll. Sie wird beshalb aud chriftusoorn genamt, bod) ift ber nach) dent Berliner (Sartendireftor (Sleoitjd) benamte Baum in Pordamerifa ju Şauje แmb exjt in 18. Jahrhmoert in bie Arlte פaelt gefommen. Die Dornemwehr ber (3)le= bitichie ijt alferbings ganz hervorragend, indem oberhalb

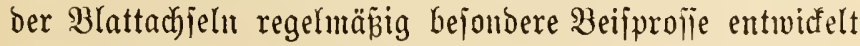
merben, bie in eine jcharfe Spibe endigen mo meift jelbit 
wieber zmei furze Seitenoornen außjendent. Bei einzeluen Bäunten lyäufent fich derartige Dormiprofle auch am Stamme

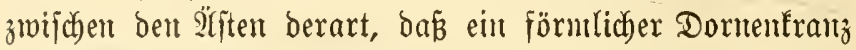
den Sdyaft ungibt. Dauteben fintot jidh aber auth eiute Form ohne alle Dornbilloung, die für den Ssarten vielfach vorgezogen wird. Die paarig gefiederten, an den Rangtrieber zum Teil Doppelt gefiederten Blätter tragent eine groß̉e Zahl jommaler

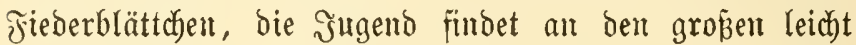
georehten Şülfen Gefallen, in beren flacher, braumer Şülle eit jü̈liches Mark die flactent Samen umidhlieft. Die (S)leditjaje findet menerbing vielfach als Strapenbaum

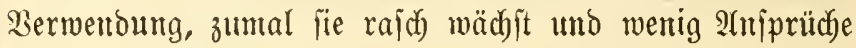
an bie Bodengüte itellt.

Seltener trifift man den ebenfalls nordamerifanijden Śd ufjer $\mathfrak{b}$ a um (Gymnócladus canadénsis Lam.), deijen Sament fo fugelrmto futo, da $\tilde{B}$ fie mit den Schuffern (Schnellern) der Sinder verwechjelt werden töntu. Er blülyt in weizen Irauben, jeine Blätter find itets boppelt= gefiedert, mit breiteiförmig zugeipibten Fieberteilen.

Eimfache Fiederblätter trägt mieder ber japanifabe

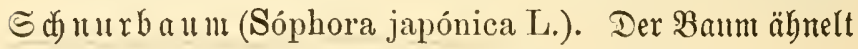

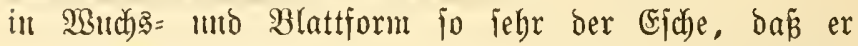
meift ein verfanntes Dajein friftet, bis er plößlich (Ende 2hugut, werm alle anderen ausgeblüht baben, fid) mit einem lid)tgelbgrünen Schleier jodymürcft, den vielveräjtelten 3lütenitänden, an benten zeritreut Eleine, wohlaugagbildete Srhmetterlingablüten fïken. Den perlichnurartigen Şitlien verdantt bie Sophore ihren deutichen Mament.

3on unjeren jometterliugablütigen Bäumen ijt

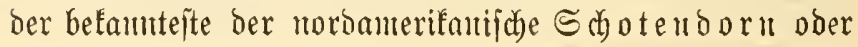


die giobiute (Robinia psendacacia T.), der, erftutals vor bald 300 sabren in \$aris burd) Robin augepflamzt, hente

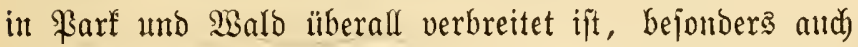
anf Sdutthalben uno Böjdungen, bie er mit feinem aus=

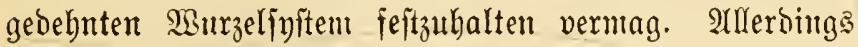
lat fich ber faljche Siante "Âtajie" für ben \$aum jo jelgr

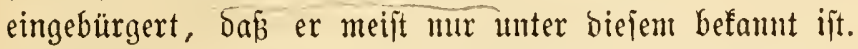

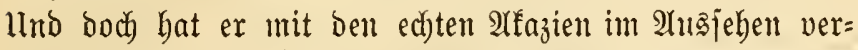
jumintond menig silgnlichteit. Dieje fommen bei uns im Freien nicht fort, merben aber im (şemächshaus und als Bimmerpflanze in manchen $\mathfrak{A}$ rten gezogen, auch werben im Borfrüling bie goldogelb blithenden 3meige verichiedenter allftralijcher Srrten in Mienge von ber Piviera bei uns eingefülyrt, aber - um den SBirrwarr noch größ̄er zu machen - von ben $\mathfrak{B}$ lumenthändlerı als "Mimojen" vers fauft. Die richtige Mimoje (Mimósa pudíca L.) ift ihrer iprichwörtlichen Empfindjamfeit wegen eine ftündige Erjobeinung ber (sewäc)shäujer, bei bem geringiten Pieize nämlich) (Erichütterung, ß̧erïbrung) falten fich bie Fieber= blättchen zujammen und jenfen fid bie Blattitiele abwärte, um fich erit nach völliger Bernbigung wieber aufauridyten.

Eime entfernte 2lnbeutung jolcher gieizbewegungen finden wir auch beim Echotendorn: Eeine Fieberblättchen, bie in ber Regel flach ausgebreitet fimb, um bas \&idht mög= lichjt autinitben zul fömen, ftellen fich bei zul ftarfer $\mathfrak{B} e=$ lend)tung jenfred)t, mit ber Sante gegen bas Richt, fo bais die Serbunftung herabgejeţt wird, bei fübler sBitterung unt abentos jenfen fie fict nad) unten mo legen fid), ge= wiffermaß̧en fid) gegenjeitig erwörment, leid)t gegenein= anber. Steigt bei antontermber Scike ber sgafjerverbrand) 
in beoroblicher 2Geife, jo hilft fid) ber Sdyotendorn, wie

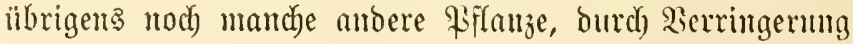
jeiter Iranjpirationsfläb)e, $\delta$. h. er mirft einfach eitrent Ieil jeiner Blätter ab.

Die fdarfen, die Blattadjeln jobirntenden Dormpare

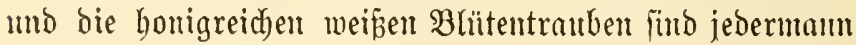
vertrant. Fm Siarten wird eine Form mit fugligem

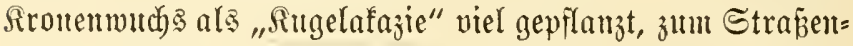
barm eiguen fith bie Formen mit wideritandsfähig(m (weniger wimbbritdrigem) Şolze ganz auggezeid)net. Die borfige Robinie (R. híspida L.) trägt größere, roja= rote $\mathfrak{B l u ̈ t}$, während igre 3weige mit braumen Stachel= boriten bicht bejebt fint, an deren Stelle bei ber bellröt= lichen flebrigen Robinie (R. viscrisa Vent.) flebrige Drüjenthaare treten.

Widbtiger nod) ale ber Schotentorn ijt für ben (Sarten ber (Goldregen oder Bohnenbanm (Cýtisus labúrnum L.), unitreitig einer unjerer joböniten Blütenitrüucher und beshalb allgemrin verbreitet, trok dem jucharjen (Sifte, bas er in fait allen Teilen, am meijten in bell fugligen Samen entbält. Diejes (sifit ift allerbings micht fïr alle Tiere gefägrliç, fo werden die grimen Stämmuden mit

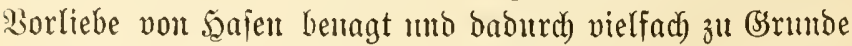
gerichtet. Die goldgelben, hängenden Blütentranben gleichen in ber Form benen bes Echotendorns, bagegen find bie Blätter nicht gefiedert, fondern fleeartig oreigeteilt.

Bon ganj bejonderem Sntereffe ift ber (Jioloregen burch) eine jeiner Gartenformen geworben. ơn Witry bei Rariz erzog der \$flanzenzuichter stoam an einem jeimer gepfropften Strüncher eimen 3weig, ber in feimen Dierfmalen eime 
Sereinigutg ber Eigenjectaften des Edelreijes (purpurner (5oloregen) uno feiner lluterlage (gemeiner (5iplbregent)

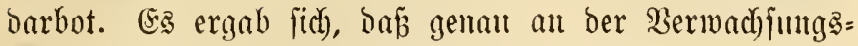
itelle beiber 2(rten ein Trieb jid) gebildet batte, ber von beiben Eltern bejtinute (Eigenid)aften ge= erbt batte, aljo eilt ridftiger $\mathfrak{B a}=$ itard war. Baitardierutg ver= wandter 2 rtell ift ja il ber Runft= gürtnerei einte gemöhnliche Erichei= unt, wir futb ifgr bei eitter Dienge von Bierfträıchern ıno =bäแmen begegutet, und zmei ber einfadyften, auch) in ber freien Ratur vor= fommender Fälle, in benen das Sirentutgaprobuft in feiuen Mierf= malent die Mitte bält zwifchent denert feiner Eltern, find auf Seite 46 abgebildet. Int allelt diejent Fällen handelt es fich aber ım gejchlechtliche Bermijechung in= jolge frember Befrudd)turg, mähreno iur $\mathfrak{A}$ b a mis $=$ (S) oldregeu etwa gantz lieues anftrat, eine reit vegetative Baftaroierumg burch Ber= idfmelzung zmeier Sinofpentantagent

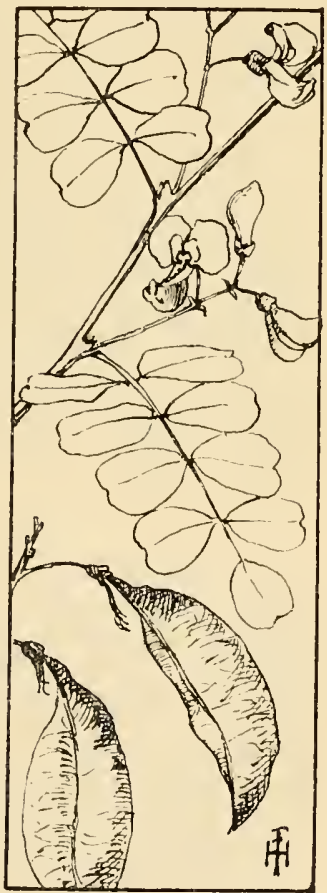

2(66. 47. Blajenjtraudf.

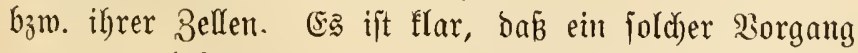
mur unter befonders günitigen lluitänden eintreten farm, ood) ift es eifriger Bühtustg in lebter 3eit mebrfach ge= lutgen, nod) bei eirigen anberent Fiflanzent berartige, in 


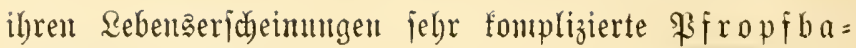
it arbe zu bildent.

Der gemeine (Soldregen fommt auf ber Sildjeite ber Allpen willo vor, umb gleich ihm find zahlreiche jeiner Berwanton,

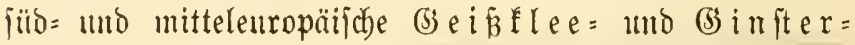
arten, in ben Garten geholt worbest. Son ihnen erwectt ber vereinzelt ichon in Eindontichlanto wild wadjento $3 \mathfrak{I} a$ fenftraud) (Colútea arboréscens I., i. $\mathfrak{A b b} .47$ ) befondere 2ufmerfjamteit, nicht burd) bie unpaar gefiederten Blätter und bie menig zablreich)en braungellent Blüten, jondern burd) bie Frucht. Die Sgülje, an beren Sumenwand bie fleiten Samen lyäıgen, wirb nämlich burch bie vou ber Pflanze ausgeidjebente faneritofireidye Ruft zu einer großen Blaje prall anfgetrieben, bie nach ber Reife vout \$sind entiülyrt miro, bis fie, alfmählich zerreibent, die Samen entlübt uno jo ihre anereitung fidjeritellt.

Unß Sibirien fommt ber Grbjenbaum (Caragána arboréscens Lam.), ein anfpruç) slojer viel gepflanzter Strantch, Defien gelbe Blüten, jede für fich geftielt, ju fleinen Büfdeln vereinigt find, im Begenfatz zu dem nie= drigeren (Erbjenftraud) (C. frutéscens D. C.), bei bem fie einzeln zmijhen ben parig gefiederten Blättchen ftehen. Die Blätter bes eriteren tragen mehrere, die bes lebteren mur zwei Fiederpare. Die erbjenartigen Camen beiber 2trten fömuen als Beflügelfutter Bermendung f̈nbest.

$2 \mathfrak{6}$ und z̆ swiro man in Biergärten nod) mantd) an= beren id)metterlingsblitigen Etraud) antreffen, boch bat feinter mebr eine joldy allgenteme Beliebtheit errmgen. Siur eiu Schlingitrand barf nidyt unerwälunt bleiben, ber

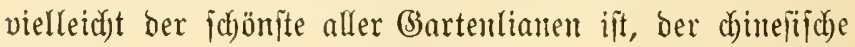




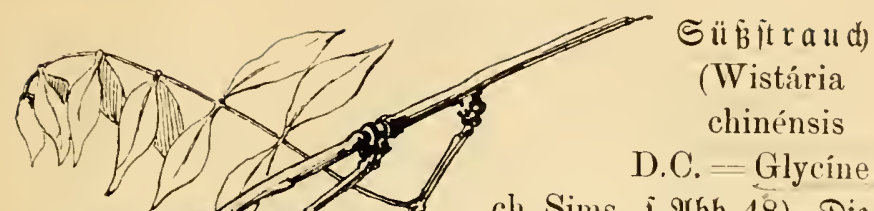

ch. Sims, i. 2(bb.48). Die ïizen Sinollest, auf bie der Siante hinmeift, gebören eiuter anberen $\mathfrak{A} r \mathrm{rt}$ an, für Ints ift bauptjäcblich bie genamnte "Sllyciue" von Bebentung, die in ber blaźnioletten, ouftenden Pradyt ber bicht geicharten itber= hängenden Bliitentrauben alsखand = und Raubenbefleioung unerreicht bajteht.

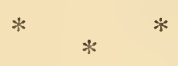

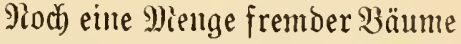
uno Sträudber fömnte aufgeiübrt werben. So manche भrt wirb ber Sejer vermiffen, die er, fei's ver= einzelt, jei's als Miodepflanze oder auts flimatijcken (Sründen in be: fimmten Begentoen allgemeinter ver= breitet antrifft. Şat er erft einen liberblicf über die \$flanzenmelt ber (Särtent gemontuen, fo wirb er fich) iut ben Bejtinmungabüthern obue groв́ Mï̈he zurechtrinden.

2(6ь, 48. Gilycite.

शำ. A 14 je 


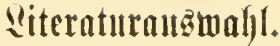

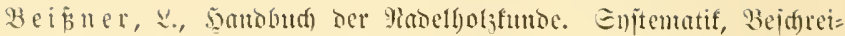
bung, Serwendma und Sultur der Freilants=dioniferen. 2. 94fl. Berlin 1909.

Dentrologijde Gejellidat, Dentiche, Mitteilutgen Der I. D. G. Jägrlich ein Banto.

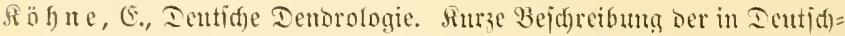

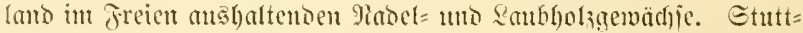
gart 1893.

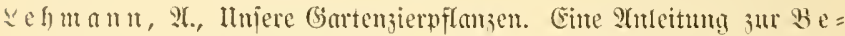

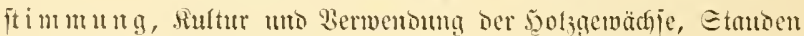

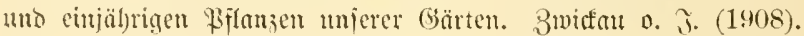

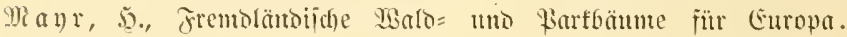
Berlin 1906.

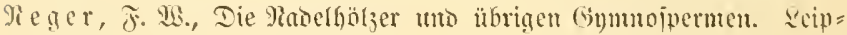
jig 1907 .

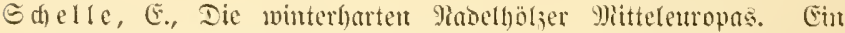
janthud) für Gärtmer umb Gartenfreunbe. Stutgart 1908.

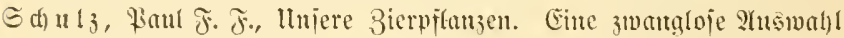
Giologiidger Betradytutgen von Garten= uns Bimmerpflanzen, jomie vou Kartgel)ölzen. Reipzig 1909.

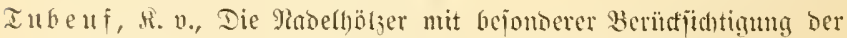
in Mitteleuropa winterlyarten 9frten. Enttugart 1847. 


\section{Snd)regifter.}

(* bedeltet mit slbbiloung.)

Abies 13

Acer $67^{\text {* }}$

Aesculus 69

Mhormatten 67 if.*

Ailantus 6j*

2tusie 93

Alnus 85

Ampelopsis $56^{*}$ *

Amygdalus 44

Iprifoje 43

Aranearia 24

Aristolochia 54*

A ronia 47

9roe $1722 *$

21 temourjeln 25

วิ)

B̆ananten 8

Baîtarbe 695

Baumfarme 8

Beintuetbe 58

Berberis 62

Betula 85 *

Biota $25^{*}$

-şirfen 85 ii. *

Blafenftraud) 96 *

Blattoariationen 6 \%*

Bleiftiftce oer 32

shlittertapfel 46

Bod5oorn 90

Bolnenbaum 94

srombeeren 50

Buthen 80 if. *

sूuttermú 78

Buxus, Bur 564

C'aragana 96

Carpinus $80^{*}$

Carya 78

Castanea 84

Ceber, virginifue 32

Cedrus, Ceder 23*

Celtis $76^{*}$

Eentifolie 49

Cephalotaxus 33

Cercis $90^{*}$

Chaenomeles 43 *

Cbamaecyparis 25 *

(c)riftusborn 91 *

Clematis 53 *

Colutea 96 *

Cornus 36

Corylas 79 *

Cotoneaster 47

Crataegus 47 *

Cryptomeria 23 *
Cuplessus 26

Encadeen 8

Cyprefien 25 ff.

Cytisus 94

Dentzia. Deusie 61*

Touglajie, Touglastanne 16 *

Dïrlişe 36

Eoilfaitanie 81

Eิеน 55

Eibe 32 *

(Eibijd) 75

Eidjen 81 ii.*

Elaeagnus 88

Cleiantenobrbaum 35 *

Elsbeere 47*

Erbienbaum 96

Erbjenjtraud) 96

Erlen 85

Eident 39 fi.*

Eifighaum 65

Eutalinte 25

Evonymus 61

Fagus $80^{*}$

F̌eberitrand) $90 *$

Jelfenbirne 47

Freutedorn 48

芹iditell 9 fif. *

Tieberipiere 52

fitieber 37 if.

त्रrúceser 29 *

Tïhre, ford) 17 *

Forsythia 36 *

Fraxiuus 39 *

Tiudsebe 57

रินี山urg ber Blinte 44

(5) зigblatt 57

(Sicipflee 96

(isiftefen 65

Ginfgobaum, Ginkyo s 31 *

(B)infter 96

Gleditschia 91 *

Glycine 97 *

Goldregen 94

Götterbaum 65*

Gyunocladns 92

sogabude $80^{*}$

jagebutten 49

galbcuprefien 25 ii.*
Diervillea 58 *
ฐุดิ๋ไกนธี $79 *$

Dedenfiridell $\mathbf{5} 8$

lledera $5 j$

Semlodstaunen 15 *

Б口yberie 29 *

Siba 30 *

Hibiseus 75

5idory, Hicoria 78

5imbere, Łanadifite 50*

5immelbaum 66 *

Hippophaë $89^{*}$

5irid) tolbenitraus 61

50 lunber 59

5onigorüjen 60

5onigroie 53 *

5opfenbude 80

5ornbaum 80

Sortenfie 60

sitlle 64

Hydrangea 60

3asิmin, Jasminum 3760

- falfder 60

¿̀längerjelieber 57

Jeridgorole 57

llex 64

iohanniśbeeren 61 *

Johannisbrot, falfdies 91 *

ๆนdaรbaum $90^{*}$

जugendiormen $27^{*}$

Juglans 77

iungfermrebe 56 *

Juniperus 31 *

Staftarie 81

- (Rośtaftanie) 69

Seafi $76^{\circ}$

Siernobft 4346

Kerria, Rerrit 53*

Riefern $17 \mathrm{ff}$. *

Sirfder 44 ii.

Mirfdjpflaume 45

flimaprovin:en 6

Ropfeiben 33

Siornelfiride 36

sirnptomerip 23 *

sambertรณฑ 79

Уär(h)e, Larix 522 ff.

Raubbölier 35 if.

Sebensbäume 28 if.*

¿ebenbbaumcupreffen $25 \mathrm{ji}^{*}$ *

Eederbaum 67 *

Libocedrus 29 *

¿igufter, Lignstrum 39

sinden 73 ii. 
Liriodendron 12 *

Lonicera 58

Lycium 9u

Magnolia, Magıtolien 42 * Matinue 62 *

Malus 46

Mammuthaum 24 *

Wiandel 44

Ihandelapritoje 44 *

yianta 41

Diaromen 85

Dá̧bolber 67

Maulbeetbasm $; 6$ *

Mreblbeere $47^{*}$

Mimoje 93

Wijtel 68

Morus 76 \%

Myriearia 89

atabel böLer \&

jiaturbentmält *

9ในธ̄bauแ 77

YuB, tïrtifule 80 *

(9)ulieren 48

Dimeiben 85

Oetrya 80

\section{Zalmen 8}

Liappela 86 it.

Happeraol, amerifan. 42

fiartualo 2

Pawia, Harvie 71

Terüdenfirata) 65 *

Heterḡftraud) $59 *$

ظfaffenbütden 6.1

Bieifertujei 54 *

uffeifenitraud) 60

Hfeifemvinse 54 *

Rfirfit) 13

Biropinaitcroe 96

Philadelubus 60

Picea $10^{*}$

qimpermu范 64

Pinus 17 *

Pirus 43

PLatane, P]atanus 72

'Heumatonboten 25

Popalus 86 *

Prinus $43^{*}$

Prendotsuga 16;
Ptelea 67 *

Pyracantba $4 \mathrm{~s}$

Quercus 81 *

Cuinaria = Ampelopsis

Eritte ( Ddeinquitte) $43^{*}$

\section{Etaintoeide 39}

Hanunfelftrand) 53 *

Yaud)vergiftum 13

Heizbewegungen 93

Retinisııra 27*

Rbus $64^{*}$

Ribes 61 *

Robinia, Hobinic 93

Rosa, Kojen 48 î.

Höscenmaniol 44 *

Roṕfaftanien 6 )

Yintbuthen 6 so*

Motborn 17

Pinttanue 10 *

Rnbus 50*

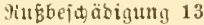

Sabebaum 32

Sabeitrautd 31

Salisburia 34 *

Salix 86

Sambuens 59

Eatroblu 89*

巨auinouติträneแ 11

Sauerborn 62

S()einquitte 43 *

Edierlugstanne $14 \mathrm{f}$. *

Sdincehall 59

Edneebeer" 5 *

5d)

Edotendrrn 92

ङ(t)uijerbaum 9:2

Sequoia $24^{*}$

Eeventaum 31

Sophora 12

Soibaria 52

Sorbus $47 *$

Sviclarten 7

Spierītüuđex 50 if.

Epinbelbaum 64

Spiraea 50

Enortzweice 7

Staphylea 64

Etedyalme 56.1

Etcimmifpel 47
Stein obit 43

Etcinmeidjel 46

巨trā́enbäume 73

Etrober 19 if.*

Silgi $23 *$

Eımad 64

ङampjcnurejie 25

ङüb̂́trand $97 *$

symphoricarpus $5 \mathrm{~S}$ *

Syringa 37

Qabatspietien 54 *

Tamatiste, Tamarix $89^{*}$

Iannen 913 if. *

'laxodinm 25

'I'axus 32 *

Thuja $29 *$

Tbujopsis 30 *

Tilia 74

Tinteubeeren 39

Tsuga 15*

Iulvenbaun 42 *

खlluen, Ulıns 75

7̧ariation 7

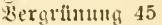

Viburnum 59

Visenm 68

Vitis 56

ㅇogelbeere $17 \%$

\$adnolver 30 iा. *

Walbrebe 53 *

BBafieritraud) 6 n

Meiben 86

Meigelie $58 *$

meiureben 57

Bein, twilber $56^{*}$

geiffude $80^{*}$

Met5oorn $47 *$

अeif́tame 5 13 ï.*

खुellingtonie 24 *

Wirtidnaftiowalo "

Wistaria $97 *$

Yelkowa if

Birbelut 22

Sirme $22 *$

3̈̈rgeไbattm $75 \%$ 


\section{Tremdländiscbe und seltene

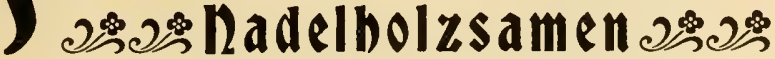

direkt von den Uríprungsländern bezogen.

Eigenes Erzeugnis der Tiroler Waldiamen-Klenganitalten

\section{Wallpach-5chwanenfeld, Innsbruck.}

Zur Aufforitung, Artveredlung und Beitandesgründung eignet fich vorzüglich das Saatgut aus der angeítammten uriprünglichen Alpenheimat der europäiichen foritbäume.

Dieles aus günitigiten Standarten in Naturwäldern mittlerer Höhenlagen Tirols und der Offalpen gewonnene Saatgut bietet die größjte Sicherheit kräftigen Gedeihens und der Vallentwicklung aller Arteigenichaften.

\section{Exotilche Holziamen :: Waldpflanzenzucht}

Lieferant $\mathrm{kgl}$. preufificher, $\mathrm{kgl}$. bayrifcher, $\mathrm{kgl}$. württembergifcher und auswärtiger Regierungen.

3oll- und frachtfreier Veriand. Man verlange Preisblatt.

\section{Werlag von Etreffer \& Garöber in Gtuttgart}

\section{Deutiche Movje und Farne}

Son Profefinor Dr. $\mathfrak{B}$. Migula

Mit 50 Sextabbiloungen. Oftav. 141 Geiten

Gebeftet $\mathfrak{X} 1 .-$, gebunden $\mathfrak{X} 1.40$

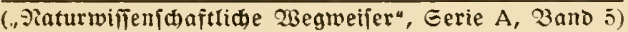

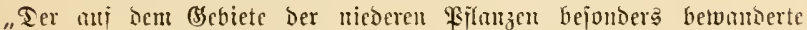
Berfafier bietet in bem anprecbend, เven! aud einfach atsgeftutteten

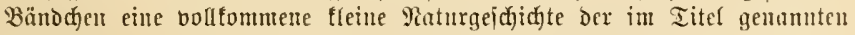

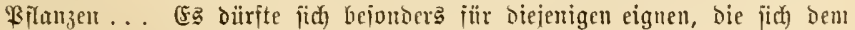
Etudium ser jo reijuollen Miopic wiomen wollen. Fïr joldhe ijt es eime bortreffliche erîte Drientiernng."

$(\mathfrak{x} \mathfrak{a} u \mathfrak{r}$.)

3u bezieben Dur(h) jede 3 udbandung oder Diref́ vom Berlage Etrecter \& Echröber, Etuttgart 


\section{Rultux $\mathfrak{u n d}$ Patux}

\section{$\mathfrak{i n}$ Der Gartentumit}

Son $\mathfrak{B a} a$ ter Frbr. v, Engelgardt

100 Geiten. EETeg. Eartoniert $\mathfrak{M} 1.60$

Q)as Snterefle an Der Gartonfunit ift im Qaufe Der lezten Sabrzelnte zufebendz in Deutjdano ge= wachfen. Slber neben ber gefteigerten allgemeinen Inteilnabme und bem grop̧en Liebbabereifer in Der Betätigung nuf Diefem Gebiete macht fich einte be= Denfliche Slnflarbeit in Der fïmftlerifdyen bewertung von Part = und Gartenanlagen bemertbar, bie Darauf

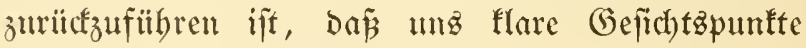
felylen, die die Silbung eimes gefunden Slrteilz in Diejen Dingen crmöglicben. Sm vorliegenden Surbe fiilbrt Der alz Gireftor Dez Gtäbt. Gartenbauantez in Diiffelourf wirkende Serfaffer Dem Lejer in Elarer, gemeinverfïmblicher Darfitlung die Entftebung, Den Einn und bie Zebeutung Der verfhiedenften 2lrten

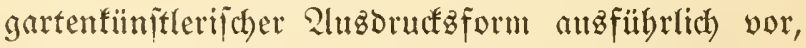
prifft ifre Qumenoungas= แnD Sombinationsmöglict)= feiten und bemint gleichzeitig ibre fümflerifche $\mathcal{Z} e=$ rechtigung an ber ant ber 3 weckbefimmung.

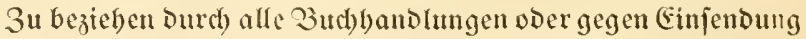
Des̃ Betrages bireft vom Serlag Gtrecter \& Gduröber in Gtutgart 


\section{Berlag von Etrecfer \& Echröber in Etuttgart}

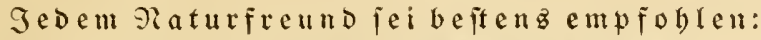

\section{Die Paturdenfmalpflege}

Die Bejtrebutgen zur Erbaltung oer Paturdenfmäler und igre Durch fḯnrung

Bon Profeijor $\mathfrak{B}$. Bodf

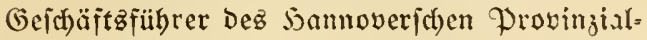
und Bezirfztomiteez für 9iaturdentmalpflege

Mit 8 Safeln und 17 2bbiloungen im Sert. Oftav. 117 Seiter. Gebeftet $\mathfrak{X} 1 .-$ gebunden $\mathfrak{X} 1.40$

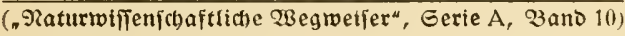

Der G(h) ber Ratur ift Die vornebmite Slufgabe jedeş wahren Raturfreundez. Nä̌thtig hat in den lerzten Gabren

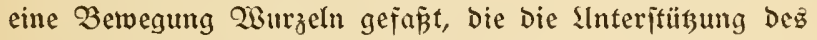
ganzen Bolfez verbient. Sie will bie zum Seil ichon im Berif)winden uno SIus̄jterben begriffenen G(bönheiten Der heimatlichen Patur, "Die Piaturdentmäler", erbalten

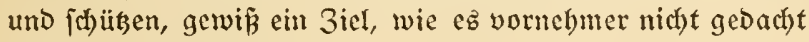
werben tann.

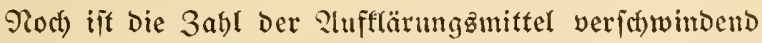
gering, und ez werfen fich Deăhalb bei Der Teubeit Der Servegung täglich Die Fragen añ:

$\mathfrak{Z a z}$ find $\mathfrak{R}$ aturbentmäler?

TBarm jolfell jie gejthit\}t werben?

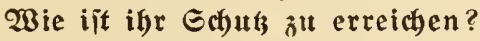

In fact)tumbiger Weife gibt Daz vorliegende 3ändrhen

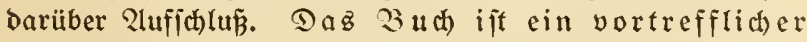
Berater für jeden, Dem Die Erbaltung Der natür=

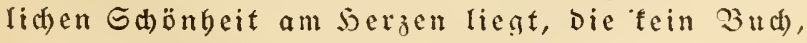
tein Bito und fein Mrodell eriersen tann.

3u bezieben Durd) jede 3uchbandung oder bireft vom Berlage Gtreffer \& Eathöber in Etuttgart 


\section{Berlag von Etrecter \& Echröber in Etuttgart}

\section{Wertvoll für jeden $\mathfrak{B a n d e r e r}$}

= แno Platurfreund!

\section{Die Zäumt u. Gträıcher

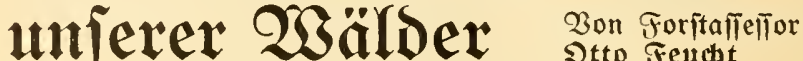

Mit 6 Safeln und 47 Sertabbiloungen

$=$ Oftav. 125 Geiten $=$

Gcbeftet $\mathfrak{P 2} 1 .-$, gebunden $\mathfrak{D} 1.40$

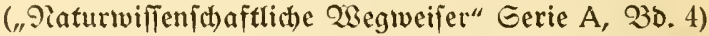

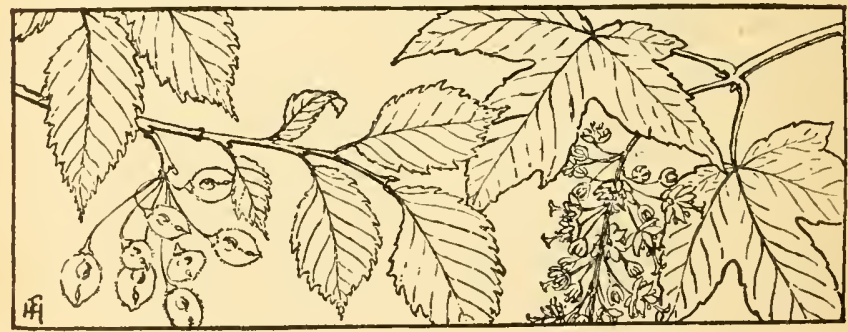

Flatterulme

Bergaborn

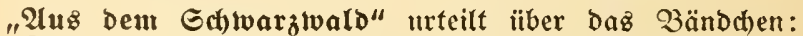

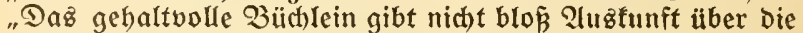
Solzgerwäct) fe, wie fie firth in $\mathscr{B}$ ald und $(5$ arten, im Part und Buf(c) fowie an Der Etraßje finden, fonbern öfnet aud) Den Blidf für Das Beritänonis jo mand)er Zorgänge im Leben

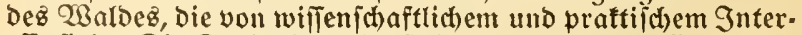
efle fino. Die Daritellung ift frifh und fellelno. Ein bejon= Derer Edhmud find neben fed) 2 Baldbildern nad photogra. phifd)en Slufnabmen Des 3 erfallers weitere 47 reizende Feder. zei(d)mungen nach) Der Siatur bon Der funjtoeritänbigen (Battin

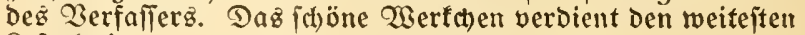
Seferfreiz."

3u beriehen Durd jede 3 udhandung oder bireft vom Serlage Etrecfer \& Erhröber, Gtuttgart 
-

$-$ 



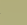


